\title{
PRODUTIVIDADE DE GRÃOS E VARIAÇÃO TEMPORAL DE FITOMASSA SECA DA CULTURA DE FEIJÃO EM FUNÇÃO DE DOSES DE NITROGÊNIO
}

DANIELA ARNOLD TISOT

\author{
Dissertação apresentada à Escola Superior de \\ Agricultura "Luiz de Queiroz", Universidade de São \\ Paulo, para a obtenção do título de Mestre em \\ Agronomia, Área de Concentração: Fitotecnia.
}

P I R A C I C A B A

Estado de São Paulo - Brasil

Outubro - 2002 


\title{
PRODUTIVIDADE DE GRÃOS E VARIAÇÃO TEMPORAL DE FITOMASSA SECA DA CULTURA DE FEIJÃO EM FUNÇÃO DE DOSES DE NITROGÊNIO
}

\author{
DANIELA ARNOLD TISOT
}

Engenheiro Agrônomo

Orientador: Prof. Dr. DURVAL DOURADO NETO

\author{
Dissertação apresentada à Escola Superior de \\ Agricultura "Luiz de Queiroz", Universidade de São \\ Paulo, para a obtenção do título de Mestre em \\ Agronomia, Área de Concentração: Fitotecnia.
}

P I R A C I C A B A

Estado de São Paulo - Brasil

Outubro - 2002 


\title{
Dados Internacionais de Catalogação na Publicação (CIP)
} DIVISÃO DE BIBLIOTECA E DOCUMENTAÇÃO - ESALQ/USP

\author{
Tisot, Daniela Amold \\ Produtivida de de grãose variação temporal de fitomassa seca da \\ cultura de feijão em função de doses de nitrogênio / Daniela Amold Tisot. \\ - - Piracic aba, 2002. \\ $71 \mathrm{p}$. \\ Dissertação (mestrado) - - Escola Superior de Agricultura Luiz de \\ Queiroz, 2002. \\ Bibliografia. \\ 1. Adubação 2. Feijão 3. Fertilizantes nitrogenados 4. Grão 5. Matéria \\ seca 6. Rendimento 7. Va riação I. Título
}

CDD 635.652

\section{'Permitida a cópia total ou parcial deste documento, desde que citada a fonte - $O$ autor'}




\section{"É muito melhor lançar-se à busca do}

triunfo, mesmo expondo-se ao insucesso, do que permanecer na fila com os pobres de espirito, que não sofrem muito, nem gozam muito, porque vivem numa penumbra cinzenta e não conhecem o gosto da derrota, nem da vitória".

Franklin Delano Roosevelt 
Aos meus pais, Orley e Maria Inês, pelo constante exemplo de vida e por me ensinarem o valor do trabalho, da persistência, da honestidade e do caminho da vitória.

Ao meu irmão Rodrigo, pelo incentivo e amizade.

Aos meus avós, Danilo e Anita, e Edy (In Memorian), pelo carinho e apoio.

\section{OFEREÇO}

Ao Rogério, que em meu coração é algo de inseparável ... 


\section{AGRADECIMENTOS}

Aos meus pais, Orley Fauth Tisot e Maria Inês Arnold Tisot, pela confiança, incentivo, dedicação e oportunidade;

Ao Rogério Costa Campos, pelo companheirismo nos momentos mais difíceis;

Ao professor Dr. Elmar Luiz Floss, da Universidade de Passo Fundo - RS, pelos ensinamentos de fundamental contribuição para minha formação profissional, e pelo constante apoio, apesar da distância;

Ao professor Dr. Durval Dourado Neto, pela orientação, amizade e sinceridade que caracterizou nosso trabalho, e pelo admirável exemplo de caráter, humanidade e bom humor constante;

Ao professor Dr. José Dias Costa, pela amizade e convivência enriquecedora;

Aos professores Ricardo Ferraz de Oliveira (Departamento de Fisiologia Vegetal, ESALQ/USP), Dr. Eduardo Caruso Machado (IAC), Dr. Antônio Enedi Boaretto (CENA/USP) e Dr. Décio Barbin (Departamento de Matemática e Estatística, ESALQ/USP) que, indiretamente, contribuíram para realização deste trabalho;

Aos professores Dr a . Maria Lúcia Carneiro Vieira, Drª Beatriz Appezzato da Glória, Dr. Durval Dourado Neto e Dr. Antônio Luiz Fancelli pela compreensão, confiança e oportunidade oferecida;

Aos professores Dr. Pedro Jacob Christoffoleti, Dr. Marcos Silveira Bernardes, Dr. José Laércio Favarin, Dr. Edgar Gomes Ferreira de Beauclair, Dr. Ederaldo José Chiavegato, Dr. Gil Miguel de Sousa Câmara, Dr. Antônio Luiz Fancelli, pela constante solicitude e atenção; 
Ao colega Eng. Agr. Márcio Augusto Soares, pelo exemplo de dedicação profissional e amizade;

Ao colega Dr. Axel Garcia y Garcia e aos estagiários do Departamento de Produção Vegetal, Alexandre Garcia Machado (Motosserra), Edison Gaion Rojais (Geográfico), Luciana Verardino (Bruák), Luiz Fernando Trevisan Buso (Metal), Marcelo Augusto Ewert (Cebolinha), Rafael Arisawa Capelari (Arisko), Rodrigo de Sousa Magalhães (Rosk), Ithamar Prada Neto (Tupete) e Marcio Akira Ito (Lulú), pelo empenho e dedicação durante a etapa experimental deste trabalho, meu mais profundo agradecimento;

À colega e Pesquisadora Eng ${ }^{\mathrm{a}}$. Agr ${ }^{\mathrm{a}}$. Aline de Holanda Nunes Maia (EMBRAPA - Meio Ambiente), pela valiosa colaboração na análise estatística, e pelo sincero apoio e amizade desenvolvida no decorrer desta etapa;

Aos meus colegas, Engenheiros Agrônomos, Fiorella Fernanda Mazine, Bianca Moschetta de Moraes Sarmento, Norma Virginia Migone Segovia, María Del Valle Basanta, Lília Sichmann Heiffig, Mônica Cagnin Martins, Silvia Elisandra Pasqua Paulino, Graciela Decian Zanon, Eros Artur Bohac Francisco e Cláudio Roberto Segatelli, pela amizade e pelos bons momentos proporcionados;

Às secretárias, Silvia Borghesi e Maria Aparecida Soledade, e aos funcionários do Departamento de Produção Vegetal, Celestino Alves Ferreira, Claudinei Martins Valério, Adilson de Jesus Teixeira, Ananias Ferreira Sousa, César Renato Galvão Desiderio, Wilson Góes da Silva, Cláudio do Espírito Santo Ferraz, Osvaldo de Jesus Pelissari, José Soares de Almeida, José dos Reis Lopes, João Rodrigues, Edson Ademir de Moraes, Edson Roberto Teramoto, Adilson Aparecido Dias, Antonio Pereira de Andrade, Daniel Luiz Theodoro, Laerte Tiberio, Rodrigo Camargo Campos, Osmair Neves, Jair Victorio Arthur e Marcelo Valente Batista, pelo agradável convívio e constante solicitude;

Às bibliotecárias Eliana Maria Garcia e Silvia Maria Zinsly, pela revisão das normas e editoração; 
À Escola Superior de Agricultura "Luiz de Queiroz", Universidade de São Paulo e à Coordenação do Departamento de Produção Vegetal, pela realização do Curso de Mestrado;

À Coordenação de Aperfeiçoamento de Pessoal de Nível Superior (CAPES), pela bolsa de estudos concedida;

A todos aqueles que de alguma forma contribuíram para a realização deste trabalho, meu sincero agradecimento. 


\section{SUMÁRIO}

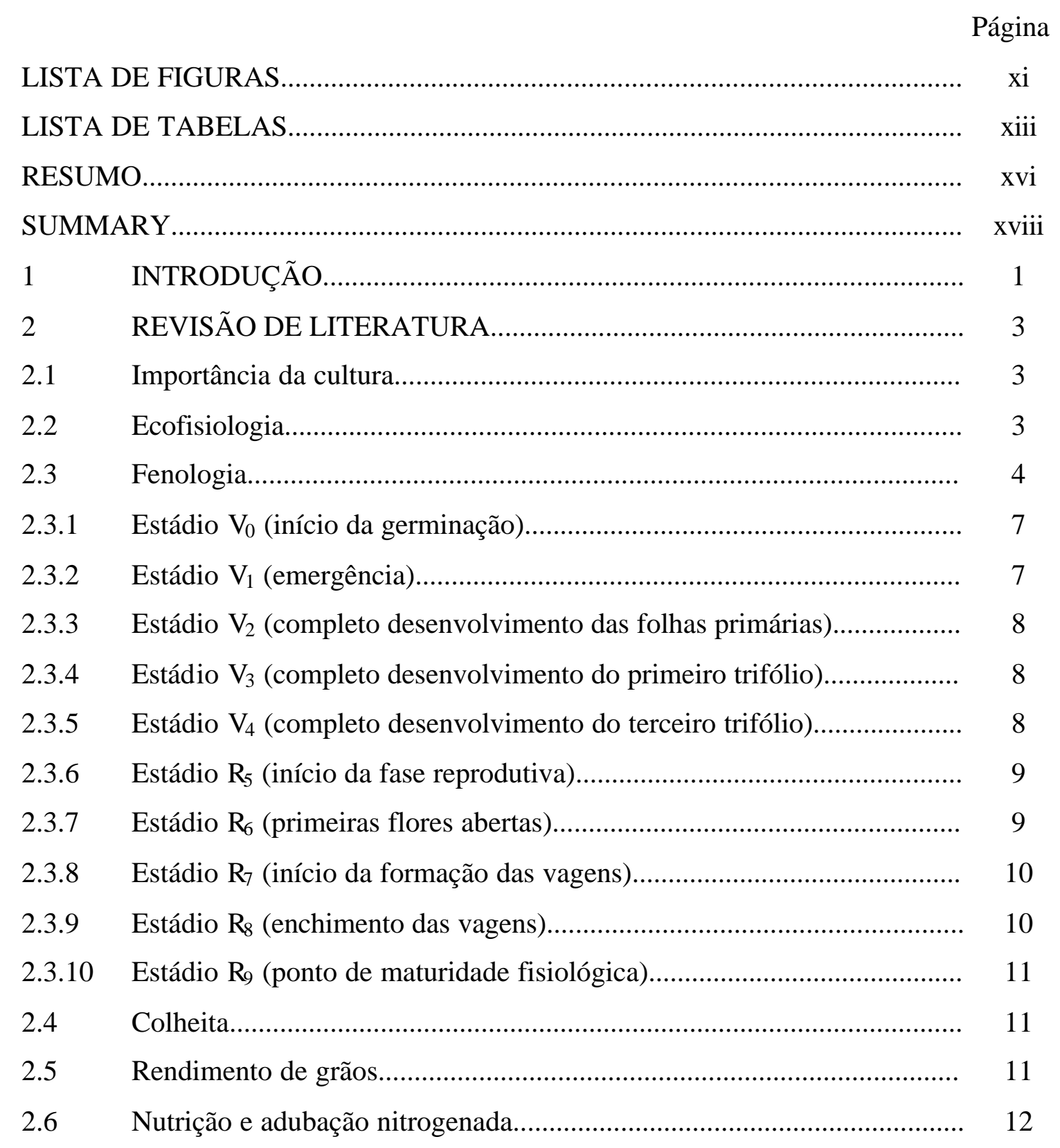


2.7 Modelagem em agricultura............................................................... 18

3 MATERIAL E MÉTODOS...................................................... 22

3.1 Local do experimento.................................................................... 22

$3.2 \quad$ Clima

$3.3 \quad$ Genótipo

$3.4 \quad$ Condução da cultura........................................................................... 27

$3.5 \quad$ Delineamento experimental............................................................. 28

3.6 Atributos avaliados.................................................................. 28

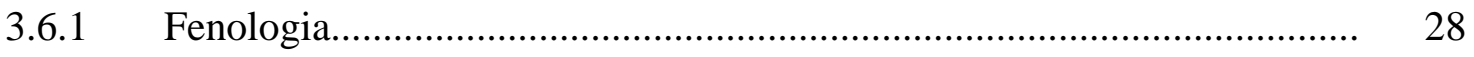

3.6.2 Fitomassa seca....................................................................... 28

3.6.3 Rendimento de grãos e seus componentes................................................... 29

$3.7 \quad$ Análise estatística................................................................................ 29

3.7.1 Modelos propostos para descrever a variação de fitomassa seca em função do desenvolvimento relativo da cultura de feijão............................. 29

3.7.1.1 Fistomassa seca de raízes, hastes e folhas.................................................... 29

3.7.1.2 Fitomassa seca de órgãos reprodutivos..................................................... 31

3.7.1.3 Fitomassa seca total........................................................................ 33

3.7.2 Modelo quadrático para descrever o efeito de nitrogênio sobre fitomassa seca, rendimento de grãos e seus componentes.......................... 35

$4 \quad$ RESULTADOS E DISCUSSÃO........................................................ 37

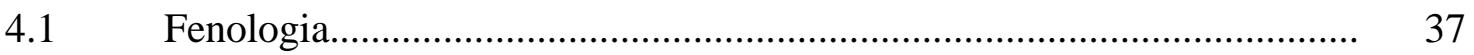

4.2 Modelos ajustados para descrever a variação de fitomassa seca em função de desenvolvimento relativo........................................................... 41

4.2.1 Fitomassa seca de raízes..................................................................... 41

4.2.2 Fitomassa seca de hastes................................................................... 45

4.2.3 Fitomassa seca de folhas................................................................. 48

4.2.4 Fitomassa seca de órgãos reprodutivos.................................................... 51

4.2.5 Fitomassa seca total..................................................................... 54

4.3 Análise do efeito da adubação nitrogenada na produção de fitomassa seca. 
4.4 Análise do efeito da adubação nitrogenada no rendimento de grãos e seus componentes....................................................................... 60

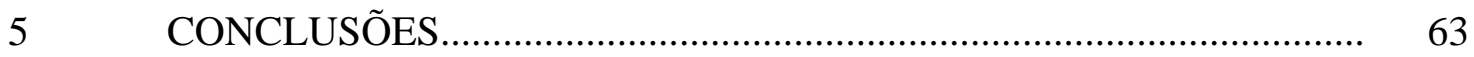

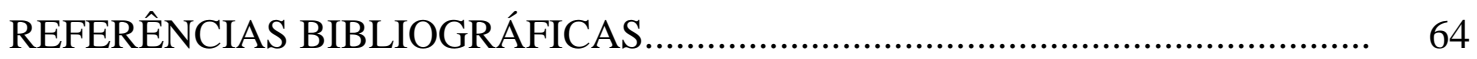




\section{LISTA DE FIGURAS}

Página

1 Produção de fitomassa verde $\left(F V\right.$, g.planta $\left.{ }^{-1}\right)$ e seca $\left(F S\right.$, g.planta $\left.{ }^{-1}\right)$ em função dos dias após a emergência (DAE) (adaptado de Haag et al., 1967)

2 Disposição do conjunto experimental sob pivô central da área experimental do Departamento de Produção Vegetal da ESALQ, Universidade de São Paulo. Piracicaba, SP.

3 Variação da fitomassa seca relativa de raízes ( $\left.F S R r, \mathrm{~kg} \cdot \mathrm{ha}^{-1}\right)$ em função do desenvolvimento relativo da cultura de feijão para diferentes doses de

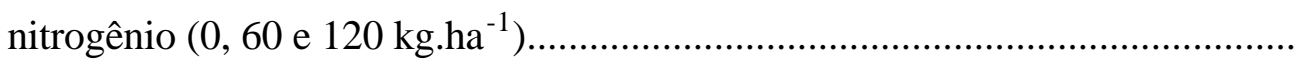

4 Variação da fitomassa seca de raízes $\left(F S r, \mathrm{~kg} \mathrm{ha}^{-1}\right)$ em função do desenvolvimento relativo da cultura de feijão para diferentes doses de

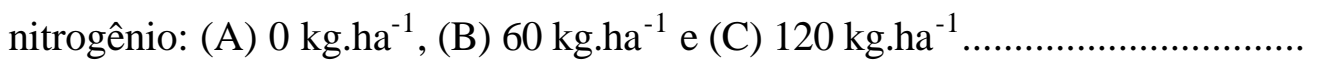

5 Variação da fitomassa seca relativa de hastes $\left(F S R h, \mathrm{~kg}^{-h a^{-1}}\right)$ em função do desenvolvimento relativo da cultura de feijão para diferentes doses de

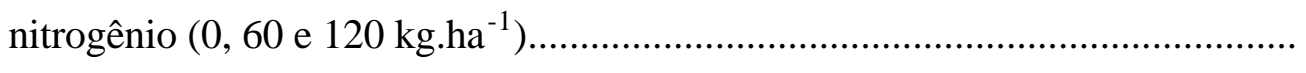

6 Variação da fitomassa seca de hastes $\left(F S h, \mathrm{~kg} \mathrm{ha}^{-1}\right)$ em função do desenvolvimento relativo da cultura de feijão para diferentes doses de nitrogênio: (A) 0 kg.ha ${ }^{-1}$, (B) $60 \mathrm{~kg} \cdot \mathrm{ha}^{-1} \mathrm{e}$ (C) $120 \mathrm{~kg} \cdot \mathrm{ha}^{-1}$....

7 Variação da fitomassa seca relativa de folhas ( $F S R f, \mathrm{~kg}^{-h a^{-1}}$ ) em função do desenvolvimento relativo da cultura de feijão para diferentes doses de nitrogênio $\left(0,60\right.$ e $\left.120 \mathrm{~kg} \cdot \mathrm{ha}^{-1}\right)$ 
8 Variação da fitomassa seca de folhas ( FSf, $\mathrm{kg}^{-h a^{-1}}$ ) em função do desenvolvimento relativo da cultura de feijão para diferentes doses de nitrogênio: (A) 0 kg.ha ${ }^{-1}$, (B) $60 \mathrm{~kg} \cdot \mathrm{ha}^{-1} \mathrm{e}$ (C) $120 \mathrm{~kg} \cdot \mathrm{ha}^{-1}$

9 Variação da fitomassa seca relativa de órgãos reprodutivos (FSRor, kg.ha ${ }^{-1}$ ) em função do desenvolvimento relativo da cultura de feijão para diferentes doses de nitrogênio $\left(0,60\right.$ e $\left.120 \mathrm{~kg} \cdot \mathrm{ha}^{-1}\right)$

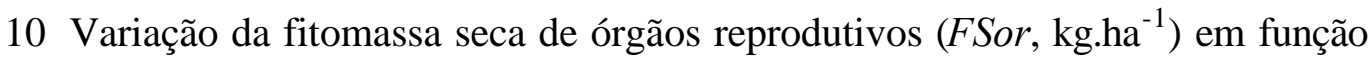
do desenvolvimento relativo da cultura de feijão para diferentes doses de nitrogênio: (A) $0 \mathrm{~kg} \cdot \mathrm{ha}^{-1}$, (B) $60 \mathrm{~kg} \cdot \mathrm{ha}^{-1} \mathrm{e}$ (C) $120 \mathrm{~kg} \cdot \mathrm{ha}^{-1}$....

11 Variação da fitomassa seca relativa total (FSRT, ${\left.\mathrm{kg} . h a^{-1}\right)}$ em função do desenvolvimento relativo da cultura de feijão para diferentes doses de nitrogênio $\left(0,60\right.$ e $\left.120 \mathrm{~kg} \cdot \mathrm{ha}^{-1}\right)$

12 Variação da fitomassa seca total $\left(F S T, \mathrm{~kg}_{\text {.ha }}{ }^{-1}\right)$ em função do desenvolvimento relativo da cultura de feijão para diferentes doses de nitrogênio: (A) $0 \mathrm{~kg} \cdot \mathrm{ha}^{-1}$, (B) $60 \mathrm{~kg} \cdot \mathrm{ha}^{-1} \mathrm{e}$ (C) $120 \mathrm{~kg} \cdot \mathrm{ha}^{-1}$

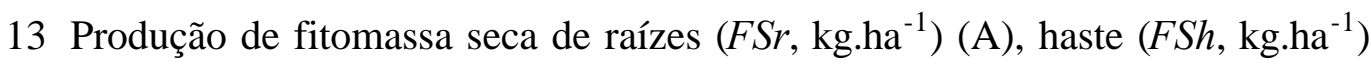
(B) e folha $\left(F S f, \mathrm{~kg} \mathrm{ha}^{-1}\right)(\mathrm{C})$ em função de três doses de nitrogênio $(0,60 \mathrm{e}$ $\left.120 \mathrm{~kg} \cdot \mathrm{ha}^{-1}\right)$......

14 Figura 12. Produção de fitomassa seca de órgãos reprodutivos (FSor, kg.ha ${ }^{-1}$ ) (A) e fitomassa seca total $\left(F S T, \mathrm{~kg} \cdot \mathrm{ha}^{-1}\right)(\mathrm{B})$ em função de três doses de nitrogênio $\left(0,60\right.$ e $\left.120 \mathrm{~kg} \cdot \mathrm{ha}^{-1}\right)$

15 Produção de fitomassa seca de grão $\left(F S g, \mathrm{~kg} \mathrm{ha}^{-1}\right)(\mathrm{A})$, número de vagens por planta $\left(N V p l\right.$, vagens.planta $\left.{ }^{-1}\right)(B)$ e número de grãos por vagem $(N G v$, grãos.vagem $\left.{ }^{-1}\right)(C)$ em função de três doses de nitrogênio $\left(0,60\right.$ e $\left.120 \mathrm{~kg}^{\circ} \mathrm{ha}^{-1}\right)$ 


\section{LISTA DE TABELAS}

Página

1 Descrição sucinta dos estádios fenológicos da cultura de feijão comum............ 6

2 Concentrações de nutrientes minerais presentes na matéria seca, suficientes para o crescimento adequado das plantas.................................................... 13

3 Valores diários de temperaturas máxima $\left(\operatorname{Tmax},{ }^{\circ} \mathrm{C}\right)$, mínima $\left(\operatorname{Tmin},{ }^{\circ} \mathrm{C}\right) \mathrm{e}$

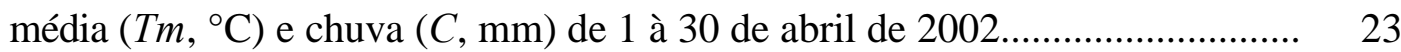

4 Valores diários de temperaturas máxima $\left(\operatorname{Tmax},{ }^{\circ} \mathrm{C}\right)$, mínima $\left(\operatorname{Tmin},{ }^{\circ} \mathrm{C}\right) \mathrm{e}$

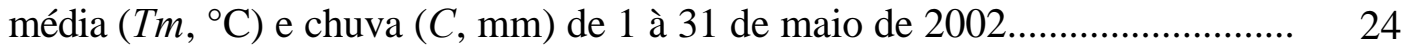

5 Valores diários de temperaturas máxima $\left(\operatorname{Tmax},{ }^{\circ} \mathrm{C}\right)$, mínima $\left(\operatorname{Tmin},{ }^{\circ} \mathrm{C}\right) \mathrm{e}$

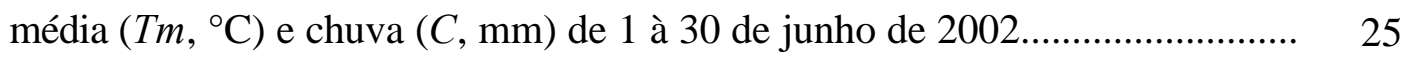

6 Valores diários de temperaturas máxima $\left(\operatorname{Tmax},{ }^{\circ} \mathrm{C}\right)$, mínima $\left(\operatorname{Tmin},{ }^{\circ} \mathrm{C}\right) \mathrm{e}$

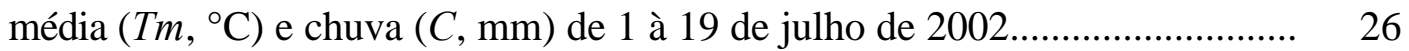

7 Caracterização geral do modelo referente à fitomassa seca de raízes, folhas e hastes (modelo 1)

8 Caracterização geral do modelo referente à fitomassa seca dos órgãos reprodutivos (modelo 2$)$........................................................................... 33

9 Caracterização geral do modelo referente à fitomassa seca total (modelo 3)..... 35

10 Esquema da análise de variância do modelo quadrático (florescimento e colheita)

11 Número de dias após a semeadura $(D A S)$, data, diferença diária entre a temperatura média $\left(T m,{ }^{\circ} \mathrm{C}\right)$ e a temperatura base inferior $\left(T b=10^{\circ} \mathrm{C}\right)$, grausdia acumulados (GDac, ${ }^{\circ} \mathrm{C}$.dia) e desenvolvimento relativo da cultura no período de 1 a 30 de abril de 2002. 
12 Número de dias após a semeadura $(D A S)$, data, diferença diária entre a temperatura média $\left(\mathrm{Tm},{ }^{\circ} \mathrm{C}\right)$ e a temperatura base inferior $\left(\mathrm{Tb}=10^{\circ} \mathrm{C}\right)$, grausdia acumulados $\left(G D a c,{ }^{\circ} \mathrm{C}\right.$.dia) e desenvolvimento relativo da cultura no período de 1 a 31 de maio de 2002 .

13 Número de dias após a semeadura $(D A S)$, data, diferença diária entre a temperatura média $\left(\mathrm{Tm},{ }^{\circ} \mathrm{C}\right)$ e a temperatura base inferior $\left(\mathrm{Tb}=10^{\circ} \mathrm{C}\right)$, grausdia acumulados ( $G D a c,{ }^{\circ} \mathrm{C}$.dia) e desenvolvimento relativo da cultura no período de 1 de junho a 19 de julho de 2002

14 Estimativas dos parâmetros dos modelos que descrevem a variação temporal da fitomassa seca acumulada de raízes da cultura de feijão para as doses 0,60 e $120 \mathrm{~kg} \cdot \mathrm{ha}^{-1}$ de nitrogênio

15 Estimativas dos parâmetros dos modelos que descrevem a variação temporal da fitomassa seca acumulada de hastes da cultura de feijão para as doses 0, 60 e $120 \mathrm{~kg} \cdot \mathrm{ha}^{-1}$ de nitrogênio.

16 Estimativas dos parâmetros dos modelos que descrevem a variação temporal da fitomassa seca acumulada de folhas da cultura de feijão para as doses 0,60 e $120 \mathrm{~kg} \cdot \mathrm{ha}^{-1}$ de nitrogênio.

17 Estimativas dos parâmetros dos modelos que descrevem a variação temporal da fitomassa seca acumulada de órgãos reprodutivos da cultura de feijão para as doses 0,60 e $120 \mathrm{~kg} \cdot \mathrm{ha}^{-1}$ de nitrogênio.

18 Estimativas dos parâmetros dos modelos que descrevem a variação temporal da fitomassa seca total acumulada da cultura de feijão para as doses 0,60 e $120 \mathrm{~kg} \cdot \mathrm{ha}^{-1}$ de nitrogênio.

19 Estimativas dos parâmetros referentes ao modelo quadrático que descreve o efeito da adubação nitrogenada na fitomassa seca de raízes $\left(F S r, \mathrm{~kg} \cdot \mathrm{ha}^{-1}\right)$, hastes $\left(F S h, \mathrm{~kg} \cdot \mathrm{ha}^{-1}\right)$, folhas $\left(F S f, \mathrm{~kg} \cdot \mathrm{ha}^{-1}\right)$, órgãos reprodutivos $\left(F S o r, \mathrm{~kg} \cdot \mathrm{ha}^{-1}\right)$ e total $\left(F S T,{\left.\mathrm{~kg} . h a^{-1}\right)}\right.$ no florescimento. 
20 Estimativas dos parâmetros referentes ao modelo quadrático que descreve o efeito da adubação nitrogenada na fitomassa seca de grãos ( $F S g$, kg.ha $\left.{ }^{-1}\right)$, número de vagens por planta ( $N V p l$, vagens.planta $\left.{ }^{-1}\right)$ e número de grãos por

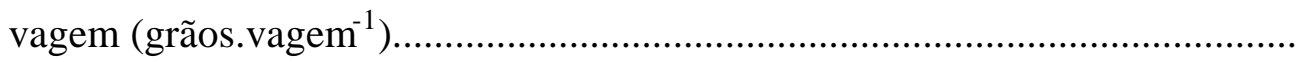




\section{PRODUTIVIDADE DE GRÃOS E VARIAÇÃO TEMPORAL DE FITOMASSA SECA DA CULTURA DE FEIJÃO EM FUNÇÃO DE DOSES DE NITROGÊNIO Autor: DANIELA ARNOLD TISOT \\ Orientador: Prof. Dr. DURVAL DOURADO NETO}

\section{RESUMO}

Com o objetivo de caracterizar a variação temporal de fitomassa seca de raízes, hastes, folhas e órgãos reprodutivos, e de verificar o efeito da adubação nitrogenada no rendimento de grãos e na produção de fitomassa seca dos diferentes órgãos da cultura de feijão (Phaseolus vulgaris L.) no florescimento, conduziu- se um experimento na área do Departamento de Produção Vegetal, Esalq, Universidade de São Paulo, Piracicaba-SP. O solo foi classificado como NITOSSOLO VERMELHO Eutroférrico; a variedade cultivada foi IAC-Carioca Tybatã (hábito de crescimento indeterminado), e o delineamento estatístico foi o inteiramente casualizado. Os tratamentos foram constituídos de combinações dos fatores doses de nitrogênio $\left(0,60\right.$ e 120 kg.ha $\left.{ }^{-1}\right)$ e épocas de avaliação (nove estádios fenológicos). Os seguintes parâmetros foram avaliados: fenologia da cultura, a fitomassa seca de raízes, hastes, folhas e órgãos reprodutivos, em cada estádio fenológico, e o rendimento de grãos e seus componentes. Para descrever o padrão de variação da fitomassa seca de raízes, hastes, folhas, órgãos reprodutivos e fitomassa seca total, foram ajustados modelos não lineares utilizando o procedimento NLIN (Non LINear regression) do SAS ${ }^{\circledR}$ System (SAS Institute, 1998). De acordo com o que foi discutido, os resultados permitem concluir que: (i) os modelos propostos são adequados para caracterizar a variação de fitomassa seca de raízes, hastes, folhas e órgãos reprodutivos durante o ciclo da cultura de feijão (Phaseolus vulgaris L.), (ii) no florescimento e na colheita, a fitomassa seca dos diferentes órgãos da cultura de feijão e o rendimento de grãos, respectivamente, variam com a adubação nitrogenada 
segundo uma função quadrática, (iii) o máximo rendimento de grãos é obtido com a dose de $60 \mathrm{~kg} \cdot \mathrm{ha}^{-1}$ de nitrogênio, e (iv) a variação da fitomassa seca relativa em função do desenvolvimento relativo da cultura de feijão apresenta o mesmo padrão de comportamento independentemente da dose de nitrogênio, o que possibilita extrapolar e comparar resultados de experimentos cond uzidos em diferentes locais e épocas. 


\section{GRAIN YIELD AND TEMPORAL VARIATION OF DRY MASS OF THE COMMON BEAN CROP AS FUNCTION OF NITROGEN DOSES}

Author: DANIELA ARNOLD TISOT

Adviser: Prof. Dr. DURVAL DOURADO NETO

\section{SUMMARY}

With the purpose of characterizing the temporal variation of the roots, stems, leaves and reproductive organs dry mass of the common bean (Phaseolus vulgaris L.), and of verifying the effect of nitrogen fertilization on its grain yield and dry mass accumulated into the different plant organs at flowering, an field experiment was carried out at Crop Science Department, Esalq, University of São Paulo, Piracicaba, Brazil. The soil was classified as Rhodic kandiustalfs; the cultivar was IAC-Carioca Tybatã (indeterminate genotype) and the statistical experimental design was completely randomized. The treatments were nitrogen doses $\left(0,60\right.$ and $\left.120 \mathrm{~kg} \cdot \mathrm{ha}^{-1}\right)$ associated with nine crop phenological stages. The following parameters were evaluated: crop phenology; roots, stems, leaves and reproductive organs dry mass for each phenological stage; and the grain yield and its components. Non linear models were used to describe the standard variation of roots, stems, leaves, reproductive organs and total dry mass using the NLIN procedure (Non LINear regression) of the SAS ${ }^{\circledR}$ System (SAS Institute, 1998). According to the discussion, the results allowed to conclude that: (i) the proposed models are appropriate to characterize the roots, stems, leaves and reproductive organs dry mass variation during the common bean (Phaseolus vulgaris L.) crop cycle, (ii) the dry mass of all organs and grain yield of common bean, in response to nitrogen fertilization at flowering and harvest, respectively, follow a quadratic function, (iii) the maximum grain yield is obtained with $60 \mathrm{~kg} \cdot \mathrm{ha}^{-1}$ of nitrogen, and (iv) the relative dry mass as function of the common bean development stage presents the same performance 
independently of the nitrogen dose, therefore, the results can be extrapolated and compared with data obtained in different situations. 


\section{INTRODUÇÃO}

Embora o rendimento de grãos de feijão tenha crescido acentuadamente nas últimas décadas, problemas como excesso ou falta de fertilização (especialmente adubação nitrogenada) ainda são freqüentes (Portes, 1996).

Os parâmetros químicos comumente obtidos pela análise de solo não têm sido eficazes como critério de recomendação de adubação nitrogenada. O histórico de uso da área, bem como o conhecimento do manejo de outros fatores de produção, é comumente adotado como guia na determinação da dose de nitrogênio a ser aplicada (Empresa Brasileira de Agropecuária - EMBRAPA, 1993).

A importância da técnica de modelagem é dependente da natureza do problema, do objetivo do investigador, e do tipo de modelo matemático escolhido (Thornley, 1976).

Por outro lado, os seguintes aspectos relevantes podem ser enumerados: (i) a modelagem em agricultura pode ser útil para melhor entender as interações que ocorrem no sistema (Dourado Neto et al., 1998), onde uma hipótese com base matemática possibilita o melhor entendimento da interação da planta com o ambiente em termos quantitativos (Thornley, 1976), (ii) a concepção de um modelo matemático ajuda a definir as prioridades de pesquisa (Dourado Neto et al., 1998), principalmente onde há limitação de conhecimento, (iii) a modelagem pode estimular a elaboração de novas idéias, bem como auxiliar no planejamento de experimentos, (iv) o modelo pode minimizar a redução da quantidade de experimentos, possibilitando planejá-los de forma a permitir obter respostas para problemas específicos de forma extrapolável, (v) comparado com procedimentos tradicionais, os modelos freqüentemente permitem utilizar melhor os dados com menor custo, (vi) informações referentes ao crescimento da planta permitem uma visão global do sistema agrícola evidenciando a necessidade de 
criação de grupos de trabalho de caráter interdisciplinar, (vii) modelo possibilita uma maior organização da informação e dos dados, (viii) utilizando modelos, pode-se estabelecer métodos de interpolação, extrapolação, predição e previsão, e (ix) modelo pode ser utilizado para sugerir prioridades para aplicação de recursos financeiros utilizados em pesquisa (ciência e tecnologia), bem como auxiliar no manejo do sistema agrícola (Thornley, 1976).

O presente trabalho apresenta os seguintes objetivos: (i) caracterizar a variação temporal de fitomassa seca de raízes, hastes, folhas e órgãos reprodutivos, e (ii) verificar o efeito da adubação nitrogenada no rendimento de grãos e na produção de fitomassa seca dos diferentes órgãos da cultura de feijão (Phaseolus vulgaris L.). 


\section{REVISÃO DE LITERATURA}

\subsection{Importância da cultura}

O feijão é um dos alimentos básicos do povo brasileiro e de grande parte da América Latina. Tal produto apresenta não somente importante fonte de proteína, como também elevado valor energético (345 calorias por 100g), quando comparado a outros alimentos. Seu teor de proteína varia de 15 a 33\%, sendo que a maioria das variedades cultivadas nacionais apresenta teores desses compostos entre 20 e 25\% (Vieira, 1983 e Fancelli, 1987a, 1990a, b, 1992, 1994).

Apesar do feijão ser um alimento de consumo mundial, comercializado in natura e de culinária regional, o mesmo possui características que dificultam o aumento do consumo em outros países (Menezes, 2001). Porém, o Brasil é um grande produtor e consumidor de vários tipos de feijão, o qual varia conforme a região (Menezes, 2001).

Na safra de 2000/2001, foram produzidas 2.575.100 t de feijão em 3.742.500 ha colhidos. Nesse mesmo período, foram importadas $90.000 \mathrm{t}$ e consumidas $2.900 .000 \mathrm{t}$ $\left(16,81 \mathrm{~kg} \cdot\right.$ habitante $^{-1} \cdot$ ano $\left.^{-1}\right)$ (FNP, 2002).

\subsection{Ecofisiologia}

Devido ao grande número de fatores e a complexibilidade das interações envolvidas em qualquer estudo planta-clima, a maioria dos estudos fenológicos tem sido conduzido pela comparação do desenvolvimento do vegetal com um simples elemento ambiental, e na maioria das vezes usando-se a temperatura média do ar (Centro Integrado de Informações Agrometeorológicas - CIIAGRO, 2002).

A temperatura na qual, a maioria dos processos fisiológicos ocorre, varia de aproximadamente 0 a $40^{\circ} \mathrm{C}$ (Wang, 1960). Os efeitos da temperatura sobre a vida individual e sobre os processos de desenvolvimento de um vegetal, devem ser muito 
bem estudados e analisados para que o efeito da temperatura sobre os vegetais possam ser interpretados. Os métodos que se baseiam somente na temperatura do ar para análise do desenvolvimento vegetal, pressupões uma linearidade entre temperatura e desenvolvimento; porém, isto não é totalmente correto, pois sabe-se que limites existem, além dos quais o desenvolvimento da planta é prejudicado devido a temperaturas muito elevadas ou muito baixas (CIIAGRO, 2002).

A definição de unidades térmicas ou de graus-dia $(G D)$, assume a existência de uma temperatura (temperatura base, $T b$ ) abaixo da qual a planta não se desenvolve, e se o fizer é em quantidade muito reduzida; além disso pressupõe uma relação completamente linear entre acréscimo de temperatura e desenvolvimento vegetal. Cada genótipo possui uma temperatura base, e esse valor pode variar em função da idade da planta. Várias equações têm sido sugeridas para o cálculo das unidades térmicas ou graus-dia, necessárias para que um vegetal atinja um certo estádio do seu ciclo vital de desenvolvimento e crescimento (Arnold, 1959; Lana \& Haber, 1951; Lindsey \& Newman, 1956 e Thom, 1954).

\subsection{Fenologia}

A necessidade da utilização de uma escala fenológica 'fundamental em pesquisas agrícolas com fertilizantes, onde os estádios de desenvolvimento das culturas devem ser determinados no momento das aplicações e das avaliações (Bleiholder et al., 1991). Por outro lado, há produtores e técnicos que têm insistido em utilizar recomendações de manejo baseadas em simples escala de tempo, representada pelo número de dias transcorridos após a semeadura ou emergência (Dourado Neto \& Fancelli, 2000a). Para esse fim, o recomendável é utilizar chaves fenológicas descritivas (Bleiholder et al., 1991 e Dourado Neto \& Fancelli, 2000a) baseadas nas mudanças morfológicas da planta e nos eventos fisiológicos que se sucedem durante o ciclo de vida da cultura, no intuito

de aumentar a eficiência do uso de insumos, defensivos e água, e de favorecer o estabelecimento de estratégias de manejo e de tomada de decisão, objetivando a obtenção de rendimentos satisfatórios e lucrativos (Dourado Neto \& Fancelli, 2000a). 
Com a intenção de padronizar os sistemas de pesquisa na agricultura, o código $\mathrm{BBCH}^{1}$, por meio de uma escala decimal dividida em macro e micro estádios baseados na escala para cereais de Zadoks et al. (1974), permite a codificação uniforme dos estádios de desenvolvimento abrangendo as mais variadas espécies cultivadas e silvestres. Porém, esse tipo de escala não permite a reprodução detalhada de todos os estádios específicos de cada tipo de planta (Bleiholder et al., 1991).

O desenvolvimento do feijoeiro compreende, basicamente, duas fases distintas e sucessivas, denominadas de fases vegetativa e reprodutiva, diferenciadas entre si pela manifestação de diferentes eventos bioquímicos, morfológicos e fisiológicos. A fase vegetativa tem seu início caracterizado pelo completo desdobramento das folhas primárias prosseguindo até o aparecimento dos primeiros botões florais (Dourado Neto \& Fancelli, 2000a e Fancelli, 1990a, b, 1992, 1994). O período vegetativo é favorecido pela ocorrência de temperaturas moderadamente elevadas (superior a $21,0^{\circ} \mathrm{C}$ e inferior a $29,5^{\circ} \mathrm{C}$ ), adequada disponibilidade hídrica e abundante luminosidade. A fase reprodutiva se transcorre desde a emissão dos primeiros botões florais até o ponto de maturidade fisiológica. A mencionada fase evidencia sensibilidade a deficiência e excesso de água no solo.

O ciclo da cultura pode ser dividido em quatro fases: desenvolvimento e crescimento vegetativo (fase 1), podendo incluir também o tempo desde a semeadura até a emergência da cultura (fase 0) e finda com o aparecimento do terceiro trifólio desdobrado em $50 \%$ das plantas; fase reprodutiva (fase 2), cujo início coincide com o aparecimento dos primeiros botões florais até o surgimento das primeiras vagens cheias; o terceiro período (fase 3), que inicia com o aparecimento das primeiras vagens cheias em $50 \%$ das plantas e finaliza com a modificação da cor das vagens, e a última fase, que

\footnotetext{
1 A abreviação da escala BBCH deriva de instituições que juntas desenvolveram essa escala: BBA, Biologische Bundesanstalt für Land - und Forstwirtschaft (German Fereral Biological Research Centre for Agriculture and Forestry); BSA, Bundessortenamt (German Federal Variety Authority); Chemical Industry, Industrieverband Agrar, IVA(German Association of Manufactures of Agrochemical Products).
} 
inicia com a modificação da cor das vagens em 50\% das plantas (do verde ao amarelo ou pigmentado) e termina com a colheita da cultura (fase 4) (Saad \& Libardi, 1997).

O desenvolvimento do feijoeiro é, inicialmente, muito lento, e só a partir do vigésimo dia é que a taxa de crescimento torna-se mais intensa, atingindo o máximo desenvolvimento aos 55-70 dias. Após, começam a prevalecer os fenômenos de translocação, em substituição ao de crescimento (Oliveira \& Thung, 1988).

Tabela 1. Descrição sucinta dos estádios fenológicos da cultura de feijão comum.

\begin{tabular}{|c|c|c|}
\hline Fase & Estádio & Descrição do início de cada estádio \\
\hline \multirow[t]{5}{*}{ Vegetativa } & $\mathrm{V}_{0}$ & Instante em que a germinação for iniciada em $50 \%$ das sementes \\
\hline & $\mathrm{V}_{1}$ & $\begin{array}{l}\text { Instante em que os cotilédones de } 50 \% \text { das plantas estiver ao } \\
\text { nível do solo }\end{array}$ \\
\hline & $\mathrm{V}_{2}$ & $\begin{array}{l}\text { Instante em que as folhas primárias de } 50 \% \text { das plantas estiver } \\
\text { completamente desenvolvida }\end{array}$ \\
\hline & $\mathrm{V}_{3}$ & $\begin{array}{l}\text { Instante em que o primeiro trifólio de } 50 \% \text { das plantas estiver } \\
\text { completamente desenvolvido }\end{array}$ \\
\hline & $\mathrm{V}_{4}$ & $\begin{array}{l}\text { Instante em que o terceiro trifólio de } 50 \% \text { das plantas estiver } \\
\text { completamente desenvolvido }\end{array}$ \\
\hline \multirow[t]{5}{*}{ Reprodutiva } & $\mathrm{R}_{5}$ & $\begin{array}{l}\text { Instante em que os primeiros botões florais são observados em } \\
50 \% \text { das plantas }\end{array}$ \\
\hline & $\mathrm{R}_{6}$ & Instante em que abrir a primeira flor em $50 \%$ das plantas \\
\hline & $\mathrm{R}_{7}$ & $\begin{array}{l}\text { Instante em que são observadas as primeiras vagens em } 50 \% \text { das } \\
\text { plantas }\end{array}$ \\
\hline & $\mathrm{R}_{8}$ & $\begin{array}{l}\text { Instante em que é observada a primeira vagem cheia em } 50 \% \text { das } \\
\text { plantas }\end{array}$ \\
\hline & $\mathrm{R}_{9}$ & $\begin{array}{l}\text { Instante em que houver modificação da cor das vagens em } 50 \% \\
\text { das plantas (do verde ao amarelo ou pigmentado) }\end{array}$ \\
\hline
\end{tabular}

Fonte: adaptado de Fancelli (1987b e 1994). 
Na cultura de feijão, as fases de desenvolvimento não apresentam nítida separação, principalmente quando se tratar de plantas de hábito de crescimento indeterminado, constatando-se sobreposições representadas pelas possibilidades de emissões simultâneas de folhas, flores e vagens (Fancelli, 1994 e Saad \& Libardi, 1997). Assim, para maior segurança na definição das ações de manejo na cultura de feijão, fazse uso da escala fenológica proposta por Gepts \& Fernández (1982), a mais utilizada para essa cultura, cujo ciclo biológico do feijoeiro é constituído de 10 estádios de desenvolvimento (Dourado Neto \& Fancelli, 2000a). Para a avaliação e a determinação do referido estádio, utiliza-se área mínima de $1 \mathrm{~m}^{2}$, devendo $50 \%$ das plantas presentes evidenciar a diferenciação estipulada (Fancelli, 1990a, b, 1992, 1994).

A duração do período entre os estádios de desenvolvimento da cultura de feijão pode ser afetada por alguns fatores, dentre os quais merece especial destaque o genótipo, o clima e as condições de fertilidade do solo (Dourado Neto \& Fancelli, 2000a).

\subsubsection{Estádio $\mathrm{V}_{0}$ (início da germinação)}

Após a absorção de água pela semente, inicia-se a germinação, caracterizada pelo aparecimento da radícula (geralmente pelo lado do hilo). O feijoeiro possui grande sensibilidade à falta de água após a semeadura. Valores de potencial total da água no solo (em módulo) superiores a 3,5 atm podem reduzir drasticamente a germinação (Magalhães \& Carelli, 1972). Ainda, o feijoeiro não apresenta satisfatória tolerância à semeadura profunda. Tal procedimento poderá contribuir para o aumento dos efeitos negativos da presença de camadas (crostas) na superfície do solo, em decorrência da natureza epígea de sua emergência. Depois do aparecimento da radícula, o hipocótilo também se alonga e os cotilédones aparecem na superfície do solo (Fancelli, 1990a, b, 1992, 1994).

\subsubsection{Estádio $V_{1}$ (emergência)}

A emergência é caracterizada pela presença dos cotilédones acima da superfície do solo em processo de desdobramento da "alça" do hipocótilo. A seguir, o epicótilo se alonga e as folhas primárias, que já se encontravam diferenciadas no embrião da semente, expandem-se (Fancelli, 1990a, b, 1992, 1994). 


\subsubsection{Estádio $V_{2}$ (completo desenvolvimento das folhas primárias)}

As primeiras folhas do feijoeiro são denominadas de folhas primárias e são simples (um folíolo), opostas e encontram-se inseridas no segundo nó da haste principal.

O desdobramento, conformação e tamanho das folhas primárias são extremamente importantes para o estabelecimento da cultura no campo por representar a estrutura inicial de conversão de energia (Fancelli, 1990a, b, 1992, 1994).

\subsubsection{Estádio $V_{3}$ (completo desenvolvimento do primeiro trifólio)}

$\mathrm{O}$ estádio $\mathrm{V}_{3}$ inicia quando o primeiro trifólio se encontra plenamente desenvolvido, o que pode ser caracterizado pela constatação dos folíolos em posição horizontal. A partir desse momento, evidencia-se o rápido desenvolvimento vegetativo da planta, o qual assume ritmo máximo no estádio $\mathrm{V}_{4}$. Nesse estádio, os cotilédones foram exauridos e, freqüentemente, já sofreram o processo de abscisão (queda). Dessa maneira, a planta passa a depender diretamente dos nutrientes presentes no solo. $\mathrm{O}$ período compreendido entre os estádios $V_{1}$ e $V_{3}$ confere à planta de feijão maior tolerância a estresses hídricos e baixas temperaturas, em níveis não muito acentuados (Fancelli, 1990a, b, 1992, 1994).

\subsubsection{Estádio $\mathrm{V}_{4}$ (completo desenvolvimento do terceiro trifólio)}

Nesse período, o terceiro trifólio está completamente desenvolvido e tem início a ramificação da planta. O tipo de ramificação (número e tamanho dos ramos, principalmente) depende de inúmeros fatores, tais como genótipo (características da variedade cultivada), condições ambientais, sistemas de produção adotados e população de plantas, principalmente (Fancelli, 1990a, b, 1992, 1994).

Deficiências hídricas nesse período poderão restringir significativamente o porte e o índice de área foliar do feijoeiro. Ressalta-se que os efeitos relacionados a disponibilidade de água e nutrientes estão diretamente ligados à população de plantas utilizada. A altura das plantas de feijão atinge valor máximo aos 40 dias após a emergência nas maiores densidades, e aos 50 dias nas menores densidades populacionais empregadas (Brandes et al., 1973). Da mesma forma, espaçamentos menores ocasionam 
a diminuição do número de ramos laterais, contribuindo para a redução da área foliar de cada planta, sobretudo nas variedades cultivadas de hábito de crescimento indeterminado (Fancelli, 1990a, b, 1992, 1994).

Nesse estádio, temperatura baixa (inferior a $15^{\circ} \mathrm{C}$ ) e/ou baixa luminosidade ocasionam a diminuição da formação de ramos laterais ou axilares no feijoeiro, contribuindo para a redução da área foliar (Crookston et al., 1975).

A produção excessiva de folhas, estimulada pelo clima, condições edáficas, irrigação ou insumos, poderá comprometer o desempenho da planta em função do aumento da taxa respiratória e transpiratória, bem como da redução da eficiência fotossintética. $\mathrm{O}$ índice de área foliar deverá ser condizente com o sistema de produção adotado (Dourado Neto \& Fancelli, 2000a).

\subsubsection{Estádio $R_{5}$ (início da fase reprodutiva)}

Nesse estádio ocorre o aparecimento dos primeiros botões florais. Nas variedades cultivadas de hábito de crescimento indeterminado (tipos II, III e IV), o desenvolvimento vegetativo prossegue mediante a emissão de novos nós, ramos e folhas (Fancelli, 1994).

Genótipo, temperatura, restrições hídricas e fotoperíodo constituem os principais elementos determinantes do momento do aparecimento dos botões florais (Fancelli, 1992, 1994).

Essa etapa de desenvolvimento pode ser considerada como uma das mais críticas quando há falta de água (Dubetz \& Mahalle, 1969; Hostalácio \& Válio, 1984 e Magalhães et al., 1979).

Ao término da pré-floração, os pedúnculos se alongam, a corola se sobressai por

entre as bractéolas e as pétalas adquirem a pigmentação característica da variedade cultivada (Fancelli, 1994).

\subsubsection{Estádio $\mathbf{R}_{\mathbf{6}}$ (primeiras flores abertas)}

A abertura das primeiras flores definem o estádio $R_{6}$. Nas plantas de hábito de crescimento determinado (tipo I), a abertura das flores tem início no último nó da haste principal e prossegue em sentido descendente. Nas plantas de hábito de crescimento 
indeterminado (tipos II, III e IV), a abertura das flores apresenta sentido ascendente (Dourado Neto \& Fancelli, 2000a).

As flores do feijoeiro são extremamente sensíveis a danos mecânicos e ao efeito abortivo de produtos químicos de natureza diversa (alguns fertilizantes e defensivos), principalmente aqueles a base de K, S, N, Cu e Sn (Fancelli, 1992 e Dourado Neto \& Fancelli, 2000a).

A primeira flor apresenta normalmente maior probabilidade e capacidade de originar vagem. Flor jovem apresenta maior probabilidade de ser abortada (Fancelli, 1994).

\subsubsection{Estádio $\mathbf{R}_{7}$ (início da formação das vagens)}

Nesse estádio, começa a aparecer as primeiras vagens, após a murcha da corola, apesar da planta continuar emitindo novas flores, por tempo relacionado aos tipos de habito de crescimento. A presente etapa é também extremamente influenciada pelas condições climáticas reinantes, além de ser considerada como uma das etapas críticas quanto à falta de água. Deficiência hídrica nesse estádio proporciona a redução da produtividade pela queda de vagens (abortamento) e pela diminuição do tamanho das vagens (Fancelli, 1990a, b, 1992, 1994).

\subsubsection{Estádio $R_{8}$ (enchimento das vagens)}

$\mathrm{O}$ estádio $\mathrm{R}_{8}$ inicia com o enchimento da primeira vagem. Nesse estádio o tamanho da vagem já se encontra definido e a ocorrência de condições climáticas desfavoráveis, principalmente falta de água e de nutrientes, poderão concorrer para a diminuição da produtividade, devido a redução do número e massa média de grão. Após esse estádio, evidencia-se o começo do processo de pigmentação das sementes e em seguida das vagens. O desenvolvimento e crescimento vegetativo das variedades cultivadas com hábito de crescimento indeterminado termina no estádio R (tipos III e IV, principalmente), além de se evidenciar o início do amarelecimento e queda das folhas inferiores da planta (Fancelli, 1990a, b, 1992, 1994).

A aplicação tardia de nitrogênio (entre $R_{5}$ e $R_{7}$ ), via foliar, poderá contribuir para a redução da taxa de produção de vagens chochas, para o aumento da retenção e da 
duração da área foliar, com conseqüente favorecimento do enchimento de vagens, bem como para o prolongamento do ciclo da cultura. Contudo, a utilização indiscriminada dessa estratégia poderá resultar na elevação da taxa respiratória, devido ao estímulo desnecessário de produção de folhas novas, além de tornar a planta mais susceptível a doenças e pragas (Dourado Neto \& Fancelli, 2000a).

\subsubsection{Estádio R9 (ponto de maturidade fisiológica)}

O referido estádio é caracterizado pela mudança de cor das vagens (amarela ou pigmentada de acordo com a variedade cultivada), onde as sementes adquirem sua cor e brilho final. O processo de senescência da planta (amarelecimento e queda das folhas) é acelerado. A evolução normal dessa etapa exige a ausência ou baixa disponibilidade de água na área (Fancelli, 1990a, b, 1992, 1994).

\subsection{Colheita}

O momento da colheita é determinado pela taxa de desfolha apresentada pela cultura, para variedades de hábito de crescimento determinado, corresponde a 85-90\%, enquanto que para genótipos de hábito de crescimento indeterminado varia entre 70 e $80 \%$. Entretanto, as plantas de feijão necessitam ser arrancadas antes de atingirem as taxas de desfolha comumente recomendadas em função da variedade cultivada, das condições climáticas no momento da colheita e à necessidade da obtenção de um produto com tegumento claro, evitando iniciar a foto-oxidação (Dourado Neto \& Fancelli, 2000a).

\subsection{Rendimento de grãos}

O rendimento de grãos da cultura de feijão depende do índice de área foliar (área foliar da cultura de feijão por unidade de área de solo explorado) no florescimento $\left(\mathrm{R}_{6}\right)$ (Jones, 1971), sendo marcadamente afetado pela falta de água, principalmente, a partir desse estádio (Dourado Neto \& Fancelli, 2000a e Jones, 1971). Em virtude do crescimento da haste principal e dos ramos laterais, quanto maior o crescimento dos ramos maior a área foliar, maior interceptação de luz e, conseqüentemente, maior produtividade de fitomassa seca e de grãos (Jones, 1971); porém, dependendo das 
condições climáticas na fase de formação das vagens, a correlação entre área foliar e rendimento pode ser negativa ou positiva (Davis, 1945). O índice de área foliar, dentro de certos limites, pode aumentar com a população, esperando-se, portanto, maior produtividade em densidades maiores (Brandes et al., 1971; Portes \& Carvalho, 1983 e Tanaka \& Fujita, 1979).

A produção de folhas pelas plantas e a duração da área foliar, em geral, tende a aumentar com o aumento da densidade de semeadura sendo mais pronunciado nas variedades cultivadas do tipo IV do que nas do tipo I, sendo que os genótipos de hábito de crescimento do tipo IV chega a alcançar até $100 \%$ a mais de duração de área foliar em comparação com as variedades arbustivas (tipo I) (Portes \& Carvalho, 1983). Apesar da duração de área foliar aumentar do tipo I para o tipo IV (Laing et al., 1983), as produtividades de grãos, quando aumentam, não o fazem na mesma proporção (Laing et al., 1984). Essa relação é dada pela eficiência da área foliar, que relaciona a produtividade de grãos com a duração da área foliar. $\mathrm{O}$ que condiciona essa diminuição de eficiência, do tipo I para o tipo IV, é a aparente produção excessiva de folhas (Portes \& Carvalho, 1983).

Ainda, o controle de pragas, plantas daninhas e doenças se faz necessário para que não haja redução do rendimento almejado (Dourado Neto \& Fancelli, 2000a ).

\subsection{Nutrição e adubação nitrogenada}

O feijoeiro é considerado uma planta exigente em nutrientes, em função do sistema radicular pequeno e superficial e do ciclo curto, sendo portanto, fundamental que o nutriente seja colocado à disposição da planta em tempo e local adequados (Moraes, 1988 e Rosolem \& Marubayashi, 1994).

Embora haja variação no ciclo da cultura em relação ao hábito de crescimento, as variedades cultivadas de feijão mais comuns apresentam um ciclo com duração ao redor de 90 dias (Almeida \& Bulisani, 1980), iniciando o período de florescimento, normalmente, a partir dos 40-45 DAE, para depois entrarem nas fases de granação e de maturação. 
O feijoeiro requer quantidades relativamente altas de nitrogênio e potássio, e quantidades relativamente baixas de fósforo, cálcio, magnésio e enxofre. Esses nutrientes são obtidos do solo e dos fertilizantes aplicados, com exceção do nitrogênio que, além dessas duas fontes, pode ser obtido pela fixação biológica, processo simbiótico das bactérias do gênero Rhizobium (Oliveira \& Thung, 1988). Porém, a fixação biológica do nitrogênio pode mascarar a resposta do feijoeiro ao nutriente (Rosolem, 1996).

Os teores de macro e micronutrientes podem variar consideravelmente dependendo da espécie de planta, da idade, e da concentração do outros elementos minerais (Tabela 2) (Marschner, 1986).

Tabela 2. Ordem de grandeza dos teores de nutrientes minerais presentes na matéria seca, suficientes para o crescimento adequado das plantas.

\begin{tabular}{lccccc}
\hline Elemento & Símbolo & $\mu$ mol.g & $\mathrm{mg}^{-1} \mathrm{~kg}^{-1}(\mathrm{ppm})$ & $\%$ & $\begin{array}{c}\text { Número relativo } \\
\text { de átomos }\end{array}$ \\
\hline Molibdênio & $\mathrm{Mo}$ & 0,001 & 0,1 & - & 1 \\
Cobre & $\mathrm{Cu}$ & 0,10 & 6 & - & 100 \\
Zinco & $\mathrm{Zn}$ & 0,30 & 20 & - & 300 \\
Manganês & $\mathrm{Mn}$ & 1,0 & 50 & - & 1.000 \\
Ferro & $\mathrm{Fe}$ & 2,0 & 100 & - & 2.000 \\
Boro & $\mathrm{B}$ & 2,0 & 20 & - & 2.000 \\
Cloro & $\mathrm{Cl}$ & 3,0 & 100 & - & 3.000 \\
Enxofre & $\mathrm{S}$ & 30 & - & 0,1 & 30.000 \\
Fósforo & $\mathrm{P}$ & 60 & - & 0,2 & 60.000 \\
Magnésio & $\mathrm{Mg}$ & 80 & - & 0,2 & 80.000 \\
Cálcio & $\mathrm{Ca}$ & 125 & - & 0,5 & 125.000 \\
Potássio & $\mathrm{K}$ & 250 & - & 1,0 & 250.000 \\
Nitrogênio & $\mathrm{N}$ & 1.000 & - & 1,5 & 1.000 .000 \\
\hline Fonte: Massch & & & &
\end{tabular}

Fonte: Marschner (1986). 
A absorção dos macronutrientes fósforo, potássio, cálcio, magnésio e, sobretudo, nitrogênio, seguem aproximadamente, a mesma tendência da produção de fitomassa seca (Caballero et al., 1985; Cobra Netto, 1967; Haag et al., 1967 e Mafra et al., 1974), atingindo o máximo aos 60-70 DAE (Cobra Netto, 1967; Haag et al., 1967 e Mafra et al., 1974), apresentando algumas variações para a variedade cultivada Roxinho (Cobra Netto, 1967). A absorção diária de nutrientes é pequena no início do desenvolvimento, aumentando a partir do vigésimo dia, independente do ciclo do material usado (Mafra et al., 1974 e Moraes, 1988), e mais intensa no intervalo de 20 a 30 dias, isto é, imediatamente antes do florescimento (Mafra et al., 1974), podendo sugerir que a disponibilidade dos nutrientes no solo nos primeiros 15 dias de crescimento da cultura tem pouca significância (Moraes, 1988).

Para a variedade cultivada Rico 23, na semeadura das águas, as raízes apresentam massa máxima no intervalo de 40 a $50 \mathrm{DAE}$, as hastes dos 40 aos 60 dias e as vagens entre 50 e 70 dias. As folhas atingem esse máximo dos 30 aos 50 dias, e aos 70 dias senescem completamente. Considerando a planta toda, a massa máxima é atingida aos 60 dias, quando as vagens apresentam a massa máxima e as folhas apenas começam a ser abortadas. Na seca, as raízes também atingem a massa máxima entre 40 e $50 D A E$, mas as hastes alcançam esse ponto aos $50 D A E$ e as vagens aos $70 D A E$. O ponto de máxima massa de folhas ocorre aos $40 D A E$ e o máximo de fitomassa seca de toda a planta ocorre dos 50 aos 70 dias, desconsiderando-se as folhas caídas (Mafra et al., 1974).

Para se obter a curva referente ao acúmulo de nitrogênio ao longo do ciclo da cultura, basta multiplicar a curva referente ao acúmulo de fitomassa seca no tempo pelo teor médio de nitrogênio na planta. $\mathrm{O}$ mesmo procedimento pode ser efetuado para os demais nutrientes (Dourado Neto \& Fancelli, 2000b).

O nitrogênio é o nutriente absorvido em maior quantidade pelo feijoeiro, que extrai cerca de $200 \mathrm{~kg} \cdot \mathrm{ha}^{-1}$ (Haag et al., 1967). Uma população de 250.000 plantas retém aproximadamente $101 \mathrm{~kg} \cdot \mathrm{ha}^{-1}$ de nitrogênio para a produção de $1.100 \mathrm{~kg}$ de grãos (Cobra Netto, 1967). Para a produção de $4.000 \mathrm{~kg} \cdot \mathrm{ha}^{-1}$ de fitomassa seca total, a cultura de feijão absorve $138 \mathrm{~kg} \cdot \mathrm{ha}^{-1}$ de nitrogênio (Caballero et al., 1985). 
A partir da emergência, o processo de absorção de nitrogênio é crescente até 50 dias para as variedades cultivadas Carioca (Almeida \& Bulisani, 1980) e Rico 23 (Mafra et al., 1974), atingindo o máximo entre 50 e $60 \mathrm{DAE}$, iniciando uma fase decrescente a partir desse estádio.

Para que a curva de produção de fitomassa seca do feijoeiro apresente o mesmo padrão da curva referente à absorção de nitrogênio (Caballero et al., 1985), o suprimento desse nutriente deve ser adequado. Se o solo é pobre em nitrogênio, ou se a taxa de liberação (decomposição da matéria orgânica) não é suficiente para atender a necessidade das plantas, o nitrogênio deverá ser complementado na forma de fertilizante. Em se tratando de uma leguminosa, o nitrogênio também será adquirido através da fixação simbiótica (Moraes, 1988).

A fixação simbiótica de nitrogênio, resultante da inoculação das sementes, como única fonte de nitrogênio deve ser recomendada para níveis de produtividade de até $1.500 \mathrm{~kg} \cdot \mathrm{ha}^{-1}$ (Franco, 1995), por ser insuficiente para suprir toda a necessidade da planta durante o seu ciclo (EMBRAPA, 1993), podendo contribuir com 20 a $40 \mathrm{~kg} \cdot \mathrm{ha}^{-1}$ de nitrogênio (Dourado Neto \& Fancelli, 2000b). Para produtividades superiores, devese recomendar adubação com nitrogênio mineral em cobertura no início do florescimento, dando tempo suficiente ao estabelecimento da simbiose, visto que a inoculação pode proporcionar bons resultados quando comparada a não aplicação de nitrogênio e não inoculação da semente. Porém, quando é feita a adubação nitrogenada, a produtividade é maior (Peres et al., 1994).

Em todas as recomendações de nitrogênio para a cultura de feijão, parte do nitrogênio deve ser aplicada no sulco de semeadura, e parte em cobertura no início do florescimento, para assegurar o suprimento de nitrogênio no período de máximo crescimento (Moraes, 1988). A adubação nitrogenada por ocasião da semeadura é estipulada de acordo com a época (das águas e da seca); já a adubação em cobertura, é recomendada com base no rendimento almejado, definido basicamente pelo mercado (preço de venda), condições climáticas e material genético, devendo ser parcelada quando a cultura for instalada em solo com teor de argila inferior a $30 \%$ e a quantidade de nitrogênio a ser utilizada for superior a $60 \mathrm{~kg} \cdot \mathrm{ha}^{-1}$ (Dourado Neto \& Fancelli, 2000b). 
A aplicação de até $40 \mathrm{~kg} \cdot \mathrm{ha}^{-1}$ de nitrogênio na semeadura, pode resultar no crescimento vigoroso da planta no início do ciclo (Diniz et al., 1995), no entanto recomenda-se que 2/3 do adubo nitrogenado seja aplicado 30 a $45 D A E$ (Meirelles et al., 1980). Recomenda-se que a adubação de cobertura não exceda $40 \%$ da primeira, devendo ser efetuada, para melhor aproveitamento do fertilizante, aos 15-22 DAE (Fancelli, 1994 e Miyasaka et al., 1963), podendo se exceder até 36 DAE (Rosolem, 1987). A adubação de cobertura pode ser parcelada em até duas vezes, sendo a primeira entre os 15 e $20 D A E$ e a segunda até os $35 D A E$ das plantas (Rosolem \& Marubayashi, 1994).

Parcelando-se a adubação nitrogenada em pulverizações foliares, nas variedades cultivadas Carioca e Aporé, de hábito de crescimento indeterminado, dos $25 D A E$ até o final da floração, pode-se constatar aumento no índice de área foliar máximo, na fitomassa seca, na taxa de crescimento, na duração da área foliar e no rendimento de grãos (Portes, 1996).

Considerando que cerca de $60 \%$ do nitrogênio mineral total do feijoeiro é absorvido nos 15 dias entre o florescimento $(35 D A E)$ e o período médio de enchimento dos grãos (50 DAE) (Meirelles et al., 1980 e Hungria et al., 1985), a adubação em cobertura deve ser feita antes do período de maior requerimento (Moraes, 1988), sendo que, nesse período, a planta absorve de 2,0 a 2,5 kg.ha ${ }^{-1} \cdot$ dia $^{-1}$. A partir desse momento, a participação do fertilizante diminui e aumenta a proporção de nitrogênio do solo no conteúdo total desse nutriente na planta (Meirelles et al., 1980).

O nitrogênio é muito importante especialmente na fase de floração e de enchimento de grãos. Como há muitas vagens e muitos grãos crescendo quase ao mesmo tempo, a demanda por esse nutriente é considerável. Como o nitrogênio nas folhas é translocado para os grãos, as folhas inferiores caem e a taxa fotossintética das folhas remanescentes decresce quase simultaneamente devido à escassez de nitrogênio (Oliker et al., 1978 e Tanaka \& Fujita, 1979).

Quando algum outro fator que não a falta de nitrogênio limita o crescimento das plantas, o feijoeiro pode acumular mais de 5\% de nitrogênio na parte aérea (Muzilli \& Godoy, 1977). 
A freqüência e a amplitude de resposta ao nitrogênio variam em função do clima e das condições fitossanitárias da cultura (Rosolem, 1987). Uma das condicionantes da resposta do feijoeiro ao nitrogênio aplicado é a disponibilidade de água, pois o nitrato entra em contato com as raízes, principalmente por fluxo de massa. Na época seca, ou seja, com menor disponibilidade de água, a probabilidade de resposta ao nitrogênio tem sido menor (Rosolem, 1996).

O componente de produção do feijoeiro mais afetado pela adubação nitrogenada é o número de vagens por planta (Vale, 1994; Calvache, 1995 e Diniz et al, 1995). Dessa forma, a adubação deve ser realizada de modo a propiciar uma boa nutrição da planta na época em que ainda é possível aumentar o número de vagens por planta, isto é, até o início do florescimento (Rosolem, 1996).

A cultura, no final do ciclo, possui sementes e palhas. Na palhada incluem-se vagens, hastes, restos de raízes e folhas. As sementes constituem $60 \%$ desse material (Almeida \& Bulisani, 1980).

Inicialmente, o crescimento do feijoeiro é lento, produzindo nos primeiros 20 $D A E$ apenas $5 \%$ da matéria seca total. Dos 30 aos 50 DAE, as plantas crescem rapidamente, mas a partir desse momento o crescimento diminui (Figura 1). A diminuição brusca na fitomassa verde após $50 \mathrm{DAE}$ é devido ao secamento das plantas (Haag et al., 1967). A taxa assimilatória líquida segue a mesma curva, e o enchimento dos grãos deve ocorrer principalmente às expensas dos fotossintatos transferidos das folhas para as vagens e os grãos (Lopes et al., 1982). 


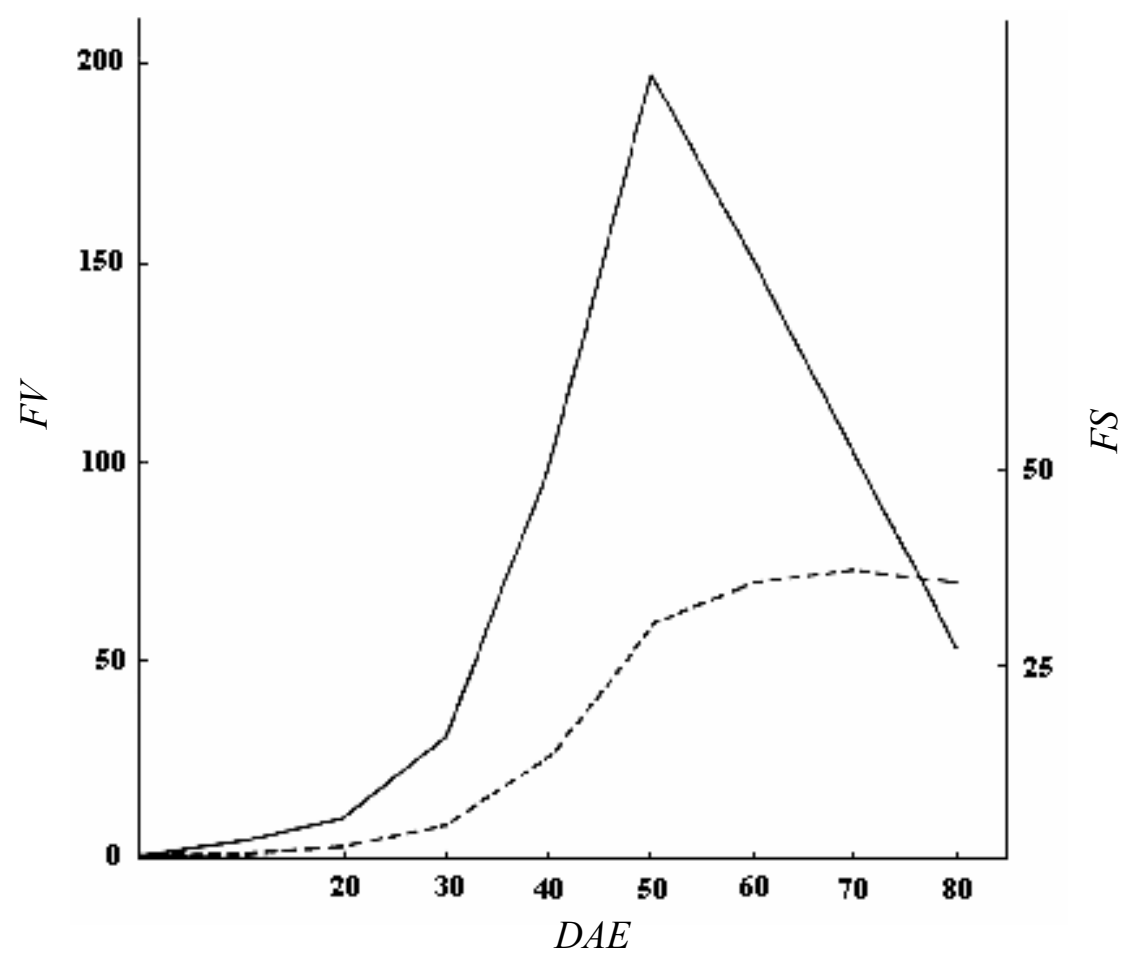

Figura 1 - Produção de fitomassa verde $\left(F V\right.$, g.planta $\left.{ }^{-1}\right)$ e seca $\left(F S\right.$, g.planta $\left.{ }^{-1}\right)$ em função do número de dias após a emergência $(D A E)$ (adaptado de Haag et al., 1967).

\subsection{Modelagem em agricultura}

De modo geral, um modelo é uma representação de um sistema em determinada forma de linguagem, não necessariamente a linguagem matemática (Pessoa et al., 1997).

Os modelos matemáticos são descrições construídas em linguagem matemática, mediante simplificações do sistema (De Wit, 1978 e Engel, 1984), enquanto que a modelagem é o processo de desenvolvimento dessa representação. A simulação inclui os processos necessários para a operacionalização ou solução do modelo, visando simular o que acontece no sistema (De Wit, 1978), muitas vezes ainda não testado em cenário real (Pessoa et al., 1997).

Entende-se por sistema um conjunto de elementos que descrevem as principais características de uma situação real a estudar, sendo que a seleção desses elementos 
depende dos objetivos do estudo (De Wit, 1978; Jones et al., 1987 e Pessoa et al., 1997). Quanto melhor a interpretação dada aos fenômenos envolvidos no sistema, maior exatidão será alcançada na sua descrição (Pessoa et al., 1997).

Partindo-se do princípio que determinada área agrícola pode ser vista como um sistema, integrando processos ecológicos, econômicos e sociais, o uso de modelos matemáticos e simuladores, que representem a integração entre as variáveis envolvidas nos processos de sustentabilidade, aparecem como importante ferramenta na pesquisa agrícola. Tais modelos permitem evoluir para um estágio de desenvolvimento metodológico mais avançado, integrando, de forma organizada, o conhecimento gerado e prevendo o desempenho de um ou de vários fenômenos, pelo acompanhamento da dinâmica espaço-temporal do problema (Pessoa et al., 1997).

Os modelos matemáticos são representados por: elementos, parâmetros, variáveis e relações funcionais (Naylor et al., 1977).

Os elementos são componentes que definem os sistemas; já os parâmetros são atributos específicos ao elemento (Pessoa et al., 1997), de valores previamente estabelecidos para o funcionamento do sistema (Pessoa, 1994) e geralmente constantes (Jones et al., 1987 e Pessoa, 1994) ou dependentes do estado do sistema, mas não necessariamente do tempo. Os parâmetros podem definir, por exemplo, a resposta funcional da fotossíntese à luz, a resistência do solo à densidade de fluxo de água, a resposta funcional da variação temporal do índice de área foliar e a perda de água pela planta através do processo evapotranspiratório (Jones et al., 1987).

As variáveis de estado são atributos que descrevem as interações entre os componentes no sistema (De Wit, 1978; Jones et al., 1987 e Pessoa et al., 1997). A interação entre componentes e sistema, e algumas vezes entre variáveis de estado no sistema, ocorrem como resultado de vários processos. O conteúdo de água no solo e a biomassa da cultura, por exemplo, são duas variáveis de estado que mudam com o tempo na maioria dos modelos de cultivo, em função da chuva, evapotranspiração, e processos de fotossíntese e respiração, respectivamente. Dessa forma, pode-se dizer que um modelo de cultivo é um conjunto de relações matemáticas que descrevem as 
mudanças nas variáveis de estado como resultado dos diferentes processos que ocorrem nesse sistema (De Wit, 1978 e Jones et al., 1987).

As relações funcionais descrevem a forma como ocorrem as interações entre os elementos do sistema. Tais relações se apresentam como identidades ou como características operacionais. As identidades são definições e, as características operacionais, são hipóteses, geralmente apresentadas em forma de equação matemática (Pessoa et al., 1997).

Usando um modelo para estimar a importância e o efeito de certos parâmetros, um pesquisador pode observar quais fatores podem ser melhor estudados numa pesquisa futura, aumentado assim o entendimento das interações no sistema solo-planta-atmosfera (Dourado Neto et al., 1998).

Em agricultura a simulação é importante para prever os resultados de um determinado sistema de manejo ou de determinadas condições ambientais (Wu et al., 1996).

Os modelos matemáticos e simuladores buscam avaliar o desempenho de processos que possam induzir o aparecimento de impactos negativos, além de ser grande ferramenta na compreensão das particularidades envolvidas nos próprios processos. Muitas vezes, também permite visualizar, probabilisticamente, o desempenho futuro do sistema, ante a criação de diferentes cenários de aplicação ainda não explorados em experimentos reais, alertando o pesquisador para novas alternativas de pesquisas futuras ou a testes mais direcio nados, reduzindo gastos e esforços (Pessoa et al., 1997).

Existem dois tipos de modelo: (i) modelo mecanístico, e (ii) modelo empírico. O modelo mecanístico permite entender a resposta de um sistema biológico a uma ação de um agente externo (interação sistema-meio). O sistema é subdividido em compartimentos que interagem entre si. O entendimento da interação entre esses compartimentos possibilita compreender o mecanismo de funcionamento do sistema (Thornley, 1976).

No meio agronômico, os modelos matemáticos mais difundidos são os empíricos; são essencialmente descritivos e identificados por equações matemáticas capazes de representar os dados experimentais de forma aceitável (Prosser, 1993) apenas 
descrevendo o fato observado, sem possibilitar a compreensão do mecanismo de funcionamento do sistema (Thornley, 1976). Por ser resultante única e exclusivamente de dados experimentais, geralmente esse tipo de modelo é apresentado em gráficos onde são plotados os valores reais, os valores por ele estimados e os desvios. Qualquer tipo de extrapolação para condições diferentes daquelas em que os dados originais foram obtidos é extremamente limitada. Em consequiência, a experimentação é feita de forma repetitiva no espaço e no tempo, até que se consiga acumular um volume considerável de informações que permitam parametrizar os resultados e fazer inferências e previsões calibradas. Exemplos de suas aplicações: as curvas de análise de crescimento, as curvas de resposta de taxas de fotossíntese à radiação solar, à água e à temperatura; as respostas na produção das culturas à adição de fertilizantes (Pessoa et al., 1997).

Cabe salientar que os dois tipos de modelos são úteis e amplamente utilizados pelos pesquisadores. Porém, o modelo mecanístico, sempre que possível, é preferível (Thornley, 1976).

A aplicação de modelos matemáticos empíricos é freqüentemente encontrada na área da ciência conhecida como Logística, que estuda a alocação de recursos naturais escassos (Engel, 1984). Por esse motivo, alguns modelos que descrevem a disponibilidade de recursos no crescimento de uma população apresentam como solução analítica uma família monoparamétrica de sigmóides freqüentemente referenciadas como curvas logísticas. O termo curva e função de crescimento também são muito utilizados para denominar modelos empíricos de crescimento plantas (Pessoa et al., 1997). A função de Richards é um exemplo bem difundido dessa aplicação (France \& Thornley, 1984).

Várias aplicações de curvas de crescimento são freqüentemente utilizadas em estudos de desenvolvimento fenológico de plantas, havendo uma série de exemplos de modelos matemáticos baseados em tais curvas (Pessoa et al., 1997). 


\section{MATERIAL E MÉTODOS}

\subsection{Local do experimento}

O experimento foi conduzido em Piracicaba-SP (22 $43^{\prime}$ latitude Sul, $47^{\circ} 38^{\prime}$ longitude Oeste, $580 \mathrm{~m}$ de altitude) na área experimental do Departamento de Produção Vegetal da Escola Superior de Agricultura "Luiz de Queiroz", Universidade de São Paulo, em solo classificado como NITOSSOLO VERMELHO Eutroférrico.

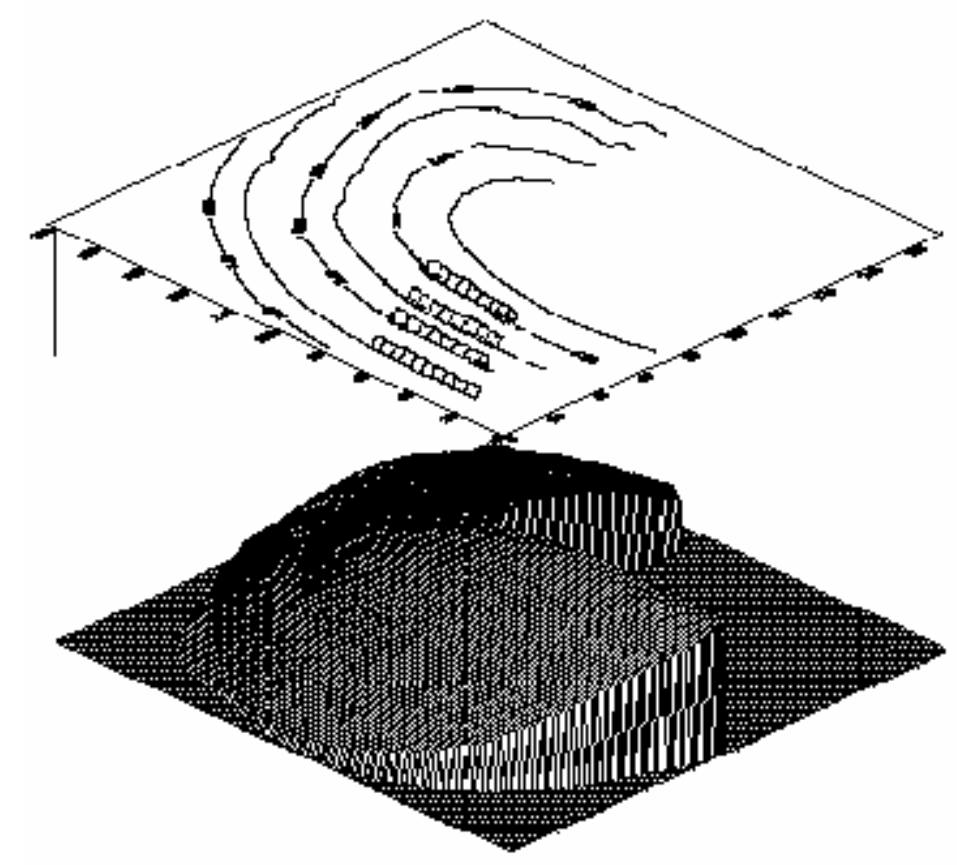

Figura 2 - Disposição do conjunto experimental sob pivô central da área do Departamento de Produção Vegetal da ESALQ, Universidade de São Paulo. Piracicaba, SP. 


\subsection{Clima}

Os valores diários de temperatura máxima, mínima e média e de chuva, desde a semeadura até a colheita, são apresentadas nas Tabelas 3 a 6 .

Tabela 3. Valores diários de temperatura máxima $\left(\operatorname{Tmax},{ }^{\circ} \mathrm{C}\right)$, mínima $\left(\operatorname{Tmin},{ }^{\circ} \mathrm{C}\right) \mathrm{e}$ média $\left(T m,{ }^{\circ} \mathrm{C}\right)$ e chuva $(C, \mathrm{~mm})$ de 1 a 30 de abril de 2002.

\begin{tabular}{ccccc}
\hline Data & Tmax & Tmin & Tm & C \\
\hline $01 / 04 / 02$ & 33,7 & 18,7 & 26,2 & 0,0 \\
$02 / 04 / 02$ & 33,2 & 18,9 & 26,1 & 0,0 \\
$03 / 04 / 02$ & 34,4 & 20,2 & 27,3 & 17,8 \\
$04 / 04 / 02$ & 31,3 & 18,4 & 24,9 & 0,0 \\
$05 / 04 / 02$ & 29,7 & 17,3 & 23,5 & 0,0 \\
$06 / 04 / 02$ & 30,0 & 17,7 & 23,9 & 5,3 \\
$07 / 04 / 02$ & 30,0 & 17,0 & 23,5 & 0,0 \\
$08 / 04 / 02$ & 30,2 & 16,4 & 23,3 & 0,0 \\
$09 / 04 / 02$ & 30,2 & 16,4 & 23,3 & 0,0 \\
$10 / 04 / 02$ & 31,0 & 16,4 & 23,7 & 0,0 \\
$11 / 04 / 02$ & 32,2 & 16,7 & 24,5 & 0,0 \\
$12 / 04 / 02$ & 32,8 & 17,2 & 25,0 & 0,0 \\
$13 / 04 / 02$ & 30,4 & 18,5 & 24,5 & 0,0 \\
$14 / 04 / 02$ & 30,6 & 18,3 & 24,5 & 0,0 \\
$15 / 04 / 02$ & 32,3 & 18,8 & 25,6 & 0,0 \\
$16 / 04 / 02$ & 33,0 & 18,0 & 25,5 & 0,0 \\
$17 / 04 / 02$ & 33,8 & 18,3 & 26,1 & 0,0 \\
$18 / 04 / 02$ & 34,0 & 18,4 & 26,2 & 0,0 \\
$19 / 04 / 02$ & 31,2 & 19,4 & 25,3 & 0,0 \\
$20 / 04 / 02$ & 31,9 & 16,9 & 24,4 & 0,0 \\
$21 / 04 / 02$ & 30,9 & 17,5 & 24,2 & 0,0 \\
$22 / 04 / 02$ & 31,7 & 19,3 & 25,5 & 0,0 \\
$23 / 04 / 02$ & 31,5 & 16,2 & 23,9 & 0,0 \\
$24 / 04 / 02$ & 32,4 & 16,4 & 24,4 & 0,0 \\
$25 / 04 / 02$ & 33,0 & 16,5 & 24,8 & 0,0 \\
$26 / 04 / 02$ & 32,1 & 15,5 & 23,8 & 0,0 \\
$27 / 04 / 02$ & 31,5 & 15,8 & 23,7 & 0,0 \\
$28 / 04 / 02$ & 30,8 & 17,0 & 23,9 & 4,1 \\
$29 / 04 / 02$ & 32,5 & 16,4 & 24,5 & \\
$30 / 04 / 02$ & 30,9 & 19,0 & & 0,0 \\
& & & 25,0 & \\
\hline
\end{tabular}


Tabela 4. Valores diários de temperatura máxima $\left(\operatorname{Tmax},{ }^{\circ} \mathrm{C}\right)$, mínima $\left(\operatorname{Tmin},{ }^{\circ} \mathrm{C}\right) \mathrm{e}$ média $\left(T m,{ }^{\circ} \mathrm{C}\right)$ e chuva $(C, \mathrm{~mm})$ de 1 a 31 de maio de 2002.

\begin{tabular}{ccccc}
\hline Data & Tmax & Tmin & Tm & C \\
\hline $01 / 05 / 02$ & 28,2 & 18,6 & 23,4 & 0,0 \\
$02 / 05 / 02$ & 31,1 & 14,6 & 22,9 & 3,6 \\
$03 / 05 / 02$ & 28,5 & 18,5 & 23,5 & 11,5 \\
$04 / 05 / 02$ & 26,4 & 17,9 & 22,2 & 1,1 \\
$05 / 05 / 02$ & 28,6 & 17,1 & 22,9 & 11,8 \\
$06 / 05 / 02$ & 29,1 & 18,0 & 23,6 & 0,3 \\
$07 / 05 / 02$ & 29,4 & 17,0 & 23,2 & 0,0 \\
$08 / 05 / 02$ & 28,8 & 16,8 & 22,8 & 0,0 \\
$09 / 05 / 02$ & 26,0 & 16,8 & 21,4 & 0,0 \\
$10 / 05 / 02$ & 27,8 & 14,9 & 21,4 & 0,0 \\
$11 / 05 / 02$ & 28,7 & 15,8 & 22,3 & 0,0 \\
$12 / 05 / 02$ & 29,5 & 16,5 & 23,0 & 0,0 \\
$13 / 05 / 02$ & 30,8 & 14,6 & 22,7 & 0,0 \\
$14 / 05 / 02$ & 30,7 & 14,2 & 22,5 & 0,0 \\
$15 / 05 / 02$ & 31,4 & 14,8 & 23,1 & 0,0 \\
$16 / 05 / 02$ & 26,0 & 14,4 & 20,2 & 1,4 \\
$17 / 05 / 02$ & 27,9 & 15,8 & 21,9 & 1,1 \\
$18 / 05 / 02$ & 29,9 & 15,9 & 22,9 & 0,5 \\
$19 / 05 / 02$ & 19,9 & 15,7 & 17,8 & 19,7 \\
$20 / 05 / 02$ & 28,8 & 15,7 & 22,3 & 20,7 \\
$21 / 05 / 02$ & 23,0 & 16,0 & 19,5 & 40,7 \\
$22 / 05 / 02$ & 21,4 & 15,9 & 18,7 & 0,0 \\
$23 / 05 / 02$ & 23,0 & 12,0 & 17,5 & 0,0 \\
$24 / 05 / 02$ & 22,0 & 12,5 & 17,3 & 0,0 \\
$25 / 05 / 02$ & 23,4 & 8,3 & 15,9 & 0,0 \\
$26 / 05 / 02$ & 24,5 & 8,3 & 16,4 & 0,0 \\
$27 / 05 / 02$ & 25,1 & 9,0 & 17,1 & 0,0 \\
$28 / 05 / 02$ & 25,9 & 8,3 & 17,1 & 0,0 \\
$29 / 05 / 02$ & 25,4 & 11,8 & 18,6 & 0,0 \\
$30 / 05 / 02$ & 26,5 & 11,2 & 18,9 & \\
$31 / 05 / 02$ & 24,3 & 12,7 & 18,5 & \\
\hline & & & & 0,0 \\
\hline
\end{tabular}


Tabela 5. Valores diários de temperatura máxima $\left(\operatorname{Tmax},{ }^{\circ} \mathrm{C}\right)$, mínima $\left(\operatorname{Tmin},{ }^{\circ} \mathrm{C}\right) \mathrm{e}$ média $\left(T m,{ }^{\circ} \mathrm{C}\right)$ e chuva $(C, \mathrm{~mm})$ de 1 a 30 de junho de 2002.

\begin{tabular}{|c|c|c|c|c|}
\hline Data & Tmax & Tmin & $\mathrm{Tm}$ & $\mathrm{C}$ \\
\hline $01 / 06 / 02$ & 27,1 & 14,1 & 20,6 & 0,0 \\
\hline 02/06/02 & 27,2 & 13,1 & 20,2 & 0,0 \\
\hline 03/06/02 & 28,2 & 12,2 & 20,2 & 0,0 \\
\hline 04/06/02 & 28,6 & 11,8 & 20,2 & 0,0 \\
\hline 05/06/02 & 30,0 & 11,6 & 20,8 & 0,0 \\
\hline 06/06/02 & 29,2 & 13,2 & 21,2 & 0,0 \\
\hline 07/06/02 & 28,7 & 12,2 & 20,5 & 0,0 \\
\hline 08/06/02 & 30,1 & 12,5 & 21,3 & 0,0 \\
\hline 09/06/02 & 29,0 & 12,9 & 21,0 & 0,0 \\
\hline $10 / 06 / 02$ & 30,2 & 16,3 & 23,3 & 0,0 \\
\hline $11 / 06 / 02$ & 29,2 & 15,0 & 22,1 & 0,0 \\
\hline $12 / 06 / 02$ & 30,0 & 14,8 & 22,4 & 0,0 \\
\hline $13 / 06 / 02$ & 29,5 & 14,8 & 22,2 & 0,0 \\
\hline $14 / 06 / 02$ & 30,3 & 13,6 & 22,0 & 0,0 \\
\hline $15 / 06 / 02$ & 25,6 & 14,5 & 20,1 & 0,0 \\
\hline $16 / 06 / 02$ & 26,6 & 12,2 & 19,4 & 0,0 \\
\hline $17 / 06 / 02$ & 30,2 & 12,9 & 21,6 & 0,0 \\
\hline $18 / 06 / 02$ & 28,6 & 12,0 & 20,3 & 0,0 \\
\hline $19 / 06 / 02$ & 29,8 & 12,2 & 21,0 & 0,0 \\
\hline $20 / 06 / 02$ & 28,3 & 12,7 & 20,5 & 0,0 \\
\hline $21 / 06 / 02$ & 27,2 & 11,2 & 19,2 & 0,0 \\
\hline $22 / 06 / 02$ & 24,7 & 12,3 & 18,5 & 0,0 \\
\hline $23 / 06 / 02$ & 23,8 & 12,4 & 18,1 & 0,0 \\
\hline $24 / 06 / 02$ & 26,5 & 10,7 & 18,6 & 0,0 \\
\hline 25/06/02 & 25,4 & 10,8 & 18,1 & 0,0 \\
\hline $26 / 06 / 02$ & 25,6 & 9,4 & 17,5 & 0,0 \\
\hline $27 / 06 / 02$ & 28,0 & 10,8 & 19,4 & 0,0 \\
\hline $28 / 06 / 02$ & 24,7 & 12,8 & 18,8 & 0,0 \\
\hline 29/06/02 & 26,8 & 11,2 & 19,0 & 0,0 \\
\hline $30 / 06 / 02$ & 28,5 & 12,7 & 20,6 & 0,0 \\
\hline
\end{tabular}


Tabela 6. Valores diários de temperatura máxima $\left(\operatorname{Tmax},{ }^{\circ} \mathrm{C}\right)$, mínima $\left(\operatorname{Tmin},{ }^{\circ} \mathrm{C}\right) \mathrm{e}$ média $\left(T m,{ }^{\circ} \mathrm{C}\right)$ e chuva $(C, \mathrm{~mm})$ de 1 a 19 de julho de 2002.

\begin{tabular}{ccccc}
\hline Data & Tmax & Tmin & Tm & C \\
\hline $01 / 07 / 02$ & 29,0 & 12,1 & 20,6 & 0,0 \\
$02 / 07 / 02$ & 26,4 & 12,0 & 19,2 & 0,0 \\
$03 / 07 / 02$ & 27,6 & 11,3 & 19,5 & 0,0 \\
$04 / 07 / 02$ & 28,5 & 12,1 & 20,3 & 0,0 \\
$05 / 07 / 02$ & 26,9 & 13,0 & 20,0 & 0,0 \\
$06 / 07 / 02$ & 26,2 & 12,8 & 19,5 & 0,0 \\
$07 / 07 / 02$ & 22,0 & 11,0 & 16,5 & 0,0 \\
$08 / 07 / 02$ & 19,1 & 6,2 & 12,7 & 0,0 \\
$09 / 07 / 02$ & 21,5 & 4,7 & 13,1 & 0,0 \\
$10 / 07 / 02$ & 23,4 & 6,0 & 14,7 & 0,0 \\
$11 / 07 / 02$ & 17,0 & 7,5 & 12,3 & 3,2 \\
$12 / 07 / 02$ & 18,9 & 11,8 & 15,4 & 0,4 \\
$13 / 07 / 02$ & 19,7 & 10,4 & 15,1 & 2,4 \\
$14 / 07 / 02$ & 21,7 & 7,6 & 14,7 & 0,0 \\
$15 / 07 / 02$ & 25,2 & 6,2 & 15,7 & 0,0 \\
$16 / 07 / 02$ & 25,4 & 5,9 & 15,7 & 0,0 \\
$17 / 07 / 02$ & 24,1 & 5,8 & 15,0 & 0,0 \\
$18 / 07 / 02$ & 23,5 & 8,3 & 15,9 & 0,0 \\
$19 / 07 / 02$ & 25,4 & 8,9 & 17,2 & 0,0 \\
\hline
\end{tabular}

\subsection{Genótipo}

Foi utilizada a variedade cultivada IAC-Carioca Tybatã-L933LM30630 14-6 (Gen 14-6), originária de plantas selecionadas no cruzamento de L933 × LM30630, para resistência ao vírus do mosaico-dourado e a outros patógenos como antracnose, ferrugem e mosaico-comum. Essa variedade apresenta plantas de crescimento indeterminado, hastes verdes, de guia curta a longa em função do ambiente, porte semiereto e flores de cor branca. As vagens do IAC-Carioca Tybatã apresentam cor amareloesverdeada em tonalidade clara no ponto de maturidade fisiológica, podendo ou não exibir, nesse estádio, estrias avermelhadas. Na colheita, as vagens são de cor palha ou creme-clara com ou sem estrias avermelhadas bem claras, quase imperceptíveis. As sementes são elípticas, semicheias, de coloração creme marmorizado com listras marrons e halo creme-claro. A massa média de cem sementes é de 23,22 g, com teor protéico médio de 24,11\%. As plantas apresentam ciclo médio, em torno de 86, 90 e 99 
dias da emergência à colheita para os semeaduras das águas, da seca e de inverno, respectivamente.

\subsection{Condução da cultura}

Realizourse o preparo do solo com aração e gradagem (sistema convencional). O feijão foi semeado manualmente em 1 de abril de 2002, onde foram utilizadas 20 sementes. $\mathrm{m}^{-1}$, o dobro da população desejada $\left(10\right.$ plantas. $\left.\mathrm{m}^{-1}\right)$.

Após a emergência foi efetuado o desbaste, no qual permaneceram 10 plantas. $\mathrm{m}^{-1}$, perfazendo uma população de 200.000 plantas.ha $^{-1}$.

A adubação de semeadura foi realizada com 80 kg.ha ${ }^{-1}$ de $\mathrm{P}_{2} \mathrm{O}_{5}$ (Fonte: Superfosfato Simples) e $50 \mathrm{~kg}^{-h a^{-1}}$ de $\mathrm{K}_{2} \mathrm{O}$ (Fonte: Cloreto de Potássio) para todos os tratamentos. Quanto à adubação nitogenada, foram aplicados 20,20 e $20 \mathrm{~kg} \cdot \mathrm{ha}^{-1}$ de N (Fontes: Sulfato de Amônio na semeadura e Uréia em cobertura) para as parcelas com dose de $60 \mathrm{~kg} \cdot \mathrm{ha}^{-1}$ de $\mathrm{N}$, por ocasião da semeadura, e em cobertura nos estádios $\mathrm{V}_{3}$ (1 trifólio) (19 de abril de 2002) e $\mathrm{V}_{4}$ (3 trifólios) (10 de maio de 2002), respectivamente; e 20, 50 e $50 \mathrm{~kg} \cdot \mathrm{ha}^{-1}$ para as parcelas com $120 \mathrm{~kg} \cdot \mathrm{ha}^{-1}$ de $\mathrm{N}$ utilizando as mesmas fontes e épocas utilizadas para a dose de $60 \mathrm{~kg} \cdot \mathrm{ha}^{-1}$ de N. Logo após a adubação, foi realizada a irrigação por aspersão via pivô central, com lâmina de $5 \mathrm{~mm}$, no intuito de incorporar o fertilizante.

Visando o controle de plantas daninhas, insetos e fungos na área, realizourse o acompanhamento diário da cultura, sendo necessária a aplicação de herbicida para folhas largas (Flex: 1,0 L.ha ${ }^{-1}$ ) quando as plantas de feijão apresentaram o primeiro trifólio completamente desenvolvido (estádio $\mathrm{V}_{3}$ ), inseticidas (Nuvacron: $750 \mathrm{~mL} \cdot \mathrm{ha}^{-1}$, Folidol: $500 \mathrm{mLha}^{-1}$ e Decis: $150 \mathrm{~mL} \cdot \mathrm{ha}^{-1}$ ) e fungicida (Cerconil: $2,0 \mathrm{~kg}^{-h a^{-1}}$ ). Tais operações foram realizadas com o auxílio de um pulverizador costal. Os inseticidas Nuvacron e Folidol foram aplicados no estádio R. O inseticida Decis foi aplicado duas vezes, no estádio $\mathrm{R}_{7}$ (primeiras vagens) e no estádio $\mathrm{R}_{8}$ (surgimento das primeiras vagens cheias). Já o fungicida foi aplicado apenas no $R_{8}$. 
Efetuou-se a capina dos corredores da área experimental (entre as parcelas) objetivando a manutenção de todas as parcelas sempre livre da presença de plantas daninhas.

\subsection{Delineamento experimental}

Foi adotado o delineamento experimental inteiramente casualizado, com 27 tratamentos 4 repetições. Os tratamentos se constituíam de combinações dos fatores doses de nitrogênio $\left(0,60\right.$ e $120 \mathrm{~kg} \cdot \mathrm{ha}^{-1}$ ) e épocas de avaliação (nove estádios fenológicos). A área total de cada parcela experimental foi $9 \mathrm{~m}^{2}$ (3 $\mathrm{m}$ de comprimento e 6 fileiras de plantas espaçadas de $0,5 \mathrm{~m}$ ), com área útil de $4,0 \mathrm{~m}^{2}$.

\subsection{Atributos avaliados}

\subsubsection{Fenologia}

Todos os estádios fenológicos $\left(\mathrm{V}_{0}, \mathrm{~V}_{1}, \mathrm{~V}_{2}, \mathrm{~V}_{3}, \mathrm{~V}_{4}, \mathrm{R}_{5}, \mathrm{R}_{6}, \mathrm{R}_{7}, \mathrm{R}_{8}\right.$ e $\left.\mathrm{R}_{9}\right)$ foram caracterizados conforme metodologia proposta por Gepts \& Fernández (1982), os quais foram correlacionados com o número de dias após a emergência $(D A E)$, graus-dia $(G D)$ e desenvolvimento relativo $(D r)$.

\subsubsection{Fitomassa seca}

As determinações referentes à fitomassa seca de hastes, folhas e órgãos reprodutivos foram realizadas em cada estádio, em 8 plantas retiradas por parcela (amostragem destrutiva), cada qual representando uma das linhas centrais, totalizando 32 plantas retiradas por tratamento. Já para as determinações referentes à fitomassa seca de raízes foram realizadas em cada estádio, coletando de 2 a 8 plantas por parcela (amostragem destrutiva).

Para a determinação da fitomassa seca de cada órgão, as plantas coletadas de cada uma das parcelas de cada estádio fenológico, foram ensacadas para secagem em estufa a $60^{\circ} \mathrm{C}$ durante 72 horas (tempo suficiente para obtenção de massa constante) e posterior pesagem. 


\subsubsection{Rendimento de grãos e seus componentes}

Para determinação do rendimento da cultura de feijão $\left(R, \mathrm{~kg}_{\mathrm{n}} \mathrm{ha}^{-1}\right)$ foram determinados o número médio de vagens por planta $(N V p)$, o número médios de grãos por vagem $(N G v)$ e a massa de 1.000 grãos corrigida para $13 \%$ de umidade $\left(M g_{13 \%}, \mathrm{~g}\right)$. O rendimento foi calculado pela equação abaixo, considerando-se uma população de

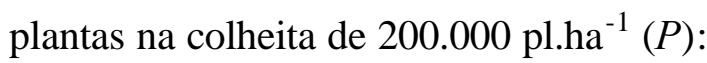

$$
R=\frac{P \cdot N V p \cdot N G v \cdot M g_{13 \%}}{1.000}
$$

O número de vagens por planta foi determinado utilizando dez plantas da área útil de cada parcela. Das vagens colhidas (de 10 plantas), foram retiradas dez vagens de cada planta para determinar o número de grãos por vagem e oito amostras de 100 grãos, por tratamento, para determinar a massa de 1.000 grãos. Posteriormente, determinou-se a umidade pelo método padrão de estufa para correção da massa de 1.000 grãos para $13 \%$ de umidade.

\subsection{Análise estatística}

Para descrever o padrão de variação da fitomassa seca de raízes, hastes, folhas, órgãos reprodutivos e fitomassa seca total, foram ajustados modelos não lineares, pelo método de quadrados mínimos, utilizando o procedimento NLIN (Non LINear regression) do SAS $^{\circledR}$ System (SAS 1998).

\subsubsection{Modelos propostos para descrever a variação de fitomassa seca em função do desenvolvimento relativo da cultura de feijão}

\subsubsection{Fistomassa seca de raízes, hastes e folhas}

Para descrição da variação temporal da fitomassa seca de raízes, folhas e hastes, foi utilizado o seguinte modelo (modelo 1):

$$
F S_{e j d p}=k \cdot \exp \left[a_{j d}+b_{j d} \frac{D r_{e}}{100}+c_{j d}\left(\frac{D r_{e}}{100}\right)^{0,5}\right]+\varepsilon_{e j d p} \quad\left(\text { se } 0 \leq D r_{e} \leq 100\right)
$$

em que $F S_{e j d p}$ se refere à fitomassa seca $\left(\mathrm{kg} \cdot \mathrm{ha}^{-1}\right)$ do $j$-ésimo órgão $(j=$ raízes, hastes, folhas) na e-ésima época ( $\left.e=\mathrm{V}_{0}, \mathrm{~V}_{1}, \mathrm{~V}_{2}, \mathrm{~V}_{3}, \mathrm{~V}_{4}, \mathrm{R}_{5}, \mathrm{R}_{6}, \mathrm{R}_{7}, \mathrm{R}_{8}, \mathrm{R}_{9}\right)$ correspondente à $d$ - 
ésima dose de nitrogênio $\left(d=0,60,120 \mathrm{~kg} \cdot \mathrm{ha}^{-1}\right)$ na $p$-ésima parcela $(p=1,2,3,4), k$ ao parâmetro empírico unitário $\left(\mathrm{kg} \cdot \mathrm{ha}^{-1}\right)$ para conferir consistência dimensional ao modelo, $D r_{e}$ ao desenvolvimento relativo $(\%)$ da cultura referente à $e$-ésima época de avaliação, $a_{j d}, b_{j d}$ e $c_{j d}$ aos parâmetros empíricos do modelo correspondente à $d$-ésima dose de nitrogênio na $p$-ésima parcela experimental.

A caracterização do modelo 1 é apresentada na Tabela 7 , na qual $\frac{d F S_{e j d p}}{d D r_{e}}$ e $\frac{d^{2} F S_{e j d p}}{d D r_{e}^{2}}$ são a primeira e a segunda derivadas, respectivamente, da função proposta para descrever a variação da fitomassa seca de raízes, hastes e folhas $\left(F S_{e j d p}\right)$ em função do desenvolvimento relativo $\left(D r_{e}\right)$, sendo $Z(\%)$ o ponto de inflexão.

$$
\begin{gathered}
\frac{d F S_{e j d p}}{d D r_{e}}=\frac{\frac{k}{100} \exp \left[a_{j d}+b_{j d} \frac{D r_{e}}{100}+c_{j d}\left(\frac{D r_{e}}{100}\right)^{0,5}\right]\left[b_{j d}+\frac{c_{j d}}{2}\left(\frac{D r_{e}}{100}\right)^{-0,5}\right]}{100} \\
\frac{d^{2} F S_{e j d p}}{d D r_{e}^{2}}=\frac{k \cdot \exp \left[a_{j d}+b_{j d} \frac{D r_{e}}{100}+c_{j d}\left(\frac{D r_{e}}{100}\right)^{0,5}\right]\left[k\left(b_{j d}+\frac{c_{j d}}{2}\left(\frac{D r_{e}}{100}\right)^{-0,5}\right)^{2}-\frac{c_{j d}\left(\frac{D r_{e}}{4}\right)^{-}}{100}\right)^{-}}{\frac{c_{j d}}{4 k}\left(\frac{100}{Z_{n}}\right)^{3 / 2}-\frac{c_{j d}^{2}}{4 k}\left(\frac{100}{Z_{n}}\right)-c_{j d}\left(\frac{100}{Z_{n}}\right)^{1 / 2}-b^{2}} \\
\left.Z_{n+1}=Z n-\frac{c_{j d}}{200}\left[\left(\frac{100}{Z_{n}}\right)^{3 / 2}-\frac{3}{4 k}\left(\frac{100}{Z_{n}}\right)^{5 / 2}+\frac{c_{j d}}{2}\right]^{2}\right]
\end{gathered}
$$

em que $n$ se refere ao número de ordem da interação correspondente ao procedimento proposto por Newton - Raphson. 
Tabela 7. Caracterização geral do modelo referente à fitomassa seca de raízes, folhas e hastes (modelo 1).

\begin{tabular}{|c|c|c|}
\hline Condição & Descrição & Conseqüência \\
\hline 1 & $D r_{e}=0$ & $F S_{e j d p}=K \cdot \exp \left(a_{j d}\right)$ \\
\hline 2 & $D r_{e}=D r_{m} *$ & $\frac{d F S_{e j d p}}{d D r_{e}}=0$ \\
\hline 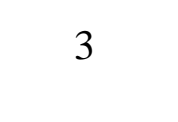 & $D r_{e}=D r_{m}=25\left(\frac{c_{j d}}{b_{j d}}\right.$ & $F S_{e j d p}=F S_{\max }$ \\
\hline 4 & $D r_{e}=Z$ & $\frac{d^{2} F S_{e j d p}}{d D r_{e}^{2}}=0$ \\
\hline 5 & $0<D r_{e}<Z$ & $\frac{d^{2} F S_{e j d p}}{d D r_{e}^{2}}>0$ \\
\hline 6 & $Z<D r_{e}<100$ & $\frac{d^{2} F S_{e j d p}}{d D r_{e}^{2}}<0$ \\
\hline 7 & $D r_{e}=100$ & $F S_{\text {ejdp }} \leq F S_{\max }$ \\
\hline 8 & $0<D r_{e} D r_{m}$ & $\frac{d F S_{e j d p}}{d D r_{e}}>0$ \\
\hline 9 & $D r_{m}<D r_{e}<100$ & $\frac{d F S_{e j d p}}{d D r_{e}}<0$ \\
\hline
\end{tabular}

* $D r_{m}$ : Desenvolvimento relativo da cultura de feijão referente a máxima fitomassa seca $\left(F S_{\max }\right)$ de raízas, hastes ou folhas.

\subsubsection{Fitomassa seca de órgãos reprodutivos}

Para descrição da variação temporal dos órgãos reprodutivos, foi utilizado o seguinte modelo (modelo 2): 


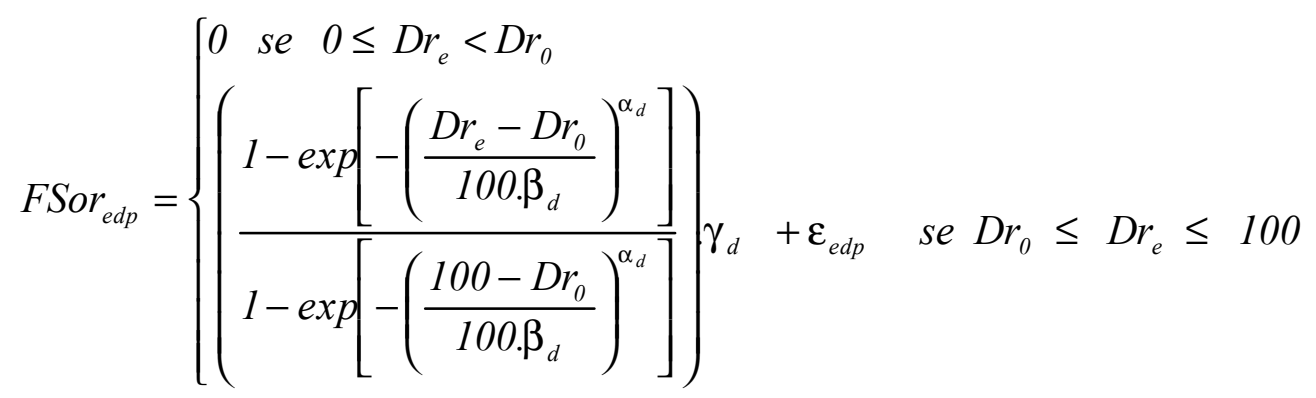

em que $F_{\text {Sor }}$ edp se refere à fitomassa seca $\left(\mathrm{kg} \cdot \mathrm{ha}^{-1}\right)$ dos órgãos reprodutivos na $e$-ésima época correspondente à $d$-ésima dose de nitrogênio na $p$-ésima parcela, $D r_{e}$ desenvolvimento relativo $(\%)$ da cultura de feijão correspondente à $e$-ésima época de avaliação, $D r_{0}$ desenvolvimento relativo da cultura de feijão correspondente ao início do acúmulo de fitomassa seca dos órgãos reprodutivos e $\alpha_{d}, \beta_{d}$ e $\gamma_{d}$ aos parâmetros empíricos do modelo, sendo $\gamma_{d}$ a estimativa da fitomassa seca $\left(\mathrm{kg} . \mathrm{ha}^{-1}\right)$ máxima dos órgãos reprodutivos referente à $d$-ésima dose.

A caracterização do modelo 2 é apresentada na Tabela 8, na qual $\frac{d F S o r_{e d p}}{d D r_{e}}$ e $\frac{d^{2} F S o r_{e d p}}{d D r_{e}^{2}}$ são a primeira e segunda derivadas, respectivamente, da função proposta para descrever a variação da fitomassa seca de órgãos reprodutivos $\left(F\right.$ Sor $\left._{e d p}\right)$ em função do desenvolvimento relativo $\left(D r_{e}\right)$, sendo $Z(\%)$ o ponto de inflexão (se $\left.D r_{0} \leq D r_{e} \leq 100\right)$.

$$
\begin{gathered}
\frac{d F \operatorname{Sor}_{e d p}}{d D r_{e}}=\gamma_{d} \cdot\left(\frac{\alpha_{d}}{\left\{1-\exp \left[-\left(\frac{100-D r_{0}}{100 \beta_{d}}\right)^{\alpha_{d}}\right]\right\} 100 \beta_{d}}\right)\left(\frac{D r_{e}-D r_{0}}{100 \beta_{d}}\right)^{\alpha_{d}-1} \exp \left[-\left(\frac{D r_{e}-D r_{0}}{100 \beta_{d}}\right)^{\alpha_{d}}\right] \\
\frac{d^{2} F S o r_{d p}}{d D r_{e}^{2}}=\gamma_{d}\left\{\frac{\alpha_{d} \cdot \exp \left[-\left(\frac{D r_{e}-D r_{0}}{100 \beta_{d}}\right)^{\alpha_{d}}\right]\left(\frac{D r_{e}-D r_{0}}{100 \beta_{d}}\right)^{\alpha_{d}-2}}{\left\{1-\exp \left[-\left(\frac{100-D r_{0}}{100 \beta_{d}}\right)^{\alpha_{d}}\right]\right\} 100 \beta_{d}}\right\}\left\{\left(\alpha_{d}-1\right)-\frac{\alpha_{d}}{100 \beta_{d}}\left(\frac{D r_{e}-D r_{0}}{100 \beta_{d}}\right)^{\alpha_{d}}\right\} \\
Z=100 \beta_{d}\left[\left(\frac{\alpha_{d}-1}{\alpha_{d}}\right) 100 \beta_{d}\right]^{1 / \alpha_{d}}+D r_{0}
\end{gathered}
$$


Tabela 8. Caracterização geral do modelo referente à fitomassa seca dos órgãos reprodutivos (modelo 2 ).

\begin{tabular}{ccc}
\hline Condição & Descrição & Conseqüência \\
\hline 1 & $0 \leq D r_{e} \leq D r_{0}$ & $F S o r_{e d p}=0$ \\
2 & $0 \leq D r_{e}<D r_{0}$ & $\frac{d F S o r_{e d p}}{d D r_{e}}=0$ \\
3 & $D r_{e}=100$ & $F \operatorname{Sor}_{e d p}=\gamma_{d}$ \\
4 & $D r_{0}<D r_{e} \leq 100$ & $\frac{d F S o r_{e d p}}{d D r_{e}}>0$ \\
5 & $D r_{e}=Z\left(D r_{0}<Z<100\right)$ & $\frac{d^{2} F \operatorname{Sor}_{e d p}}{d D r_{e}^{2}}=0$ \\
7 & $D r_{0}<D r_{e}<Z$ & $\frac{d^{2} F S o r_{e d p}}{d D r_{e}^{2}}>0$ \\
& $Z<D r_{e} \leq 100$ & $\frac{d^{2} F S o r_{e d p}}{d D r_{e}^{2}}<0$ \\
\hline
\end{tabular}

\subsubsection{Fitomassa seca total}

Para descrição da variação temporal da fitomassa seca total (modelo 3), foi utilizado um modelo semelhante ao modelo 2, porém com $D r_{0}=0$, pois o acúmulo de fitomassa seca total inicia logo após a emergência:

$$
F S T_{e d p}=\gamma_{d} \cdot\left(\frac{1-\exp \left[-\left(\frac{D r_{e}}{100 \beta_{d}}\right)^{\alpha_{d}}\right]}{1-\exp \left[-\left(\frac{1}{\beta_{d}}\right)^{\alpha_{d}}\right]}\right)+\varepsilon_{e d p} \text { se } 0 \leq D r_{e} \leq 100
$$

em que $F S T_{e d p}$ se refere à fitomassa seca total $\left(\mathrm{kg} \cdot \mathrm{ha}^{-1}\right)$ na $e$-ésima época correspondente à $d$-ésima dose de nitrogênio na $p$-ésima parcela, $D r_{e}$ desenvolvimento relativo $(\%)$ da cultura de feijão correspondente à e-ésima época de avaliação, $\alpha_{d}, \beta_{d}$ e $\gamma_{d}$ aos 
parâmetros empíricos do modelo, sendo $\gamma_{d}$ a estimativa da fitomassa seca $\left(\mathrm{kg} \mathrm{ha}^{-1}\right)$ máxima total.

A caracterização da função proposta para descrever a variação da fitomassa seca total $(F S T)$ em função do desenvolvimento relativo $(D r)$ é detalhada na Tabela 9, em que $\frac{d F S T_{e d p}}{d D r_{e}}$ e $\frac{d^{2} F S T_{e d p}}{d D r_{e}^{2}}$ são a primeira e segunda derivadas da função $F S T=f\left(D r_{e}\right)$, respectivamente, e $Z$, o ponto de inflexão.

$$
\begin{aligned}
& \frac{d F S T_{e d p}}{d D r_{e}}=\gamma_{d} \cdot\left(\frac{\alpha_{d}}{\left\{1-\exp \left[-\left(\frac{1}{\beta_{d}}\right)^{\alpha_{d}}\right]\right\} 100 \cdot \beta_{d}}\right)\left(\frac{D r_{e}}{100 \cdot \beta_{d}}\right)^{\alpha_{d}-1} \exp \left[-\left(\frac{D r_{e}}{100 \cdot \beta_{d}}\right)^{\alpha_{d}}\right. \\
& \left.\frac{d^{2} F S T_{e d p}}{d D r_{e}^{2}}=\gamma_{d}\left\{\frac{\alpha_{d} \cdot \exp \left[-\left(\frac{D r_{e}}{100 \beta_{d}}\right)^{\alpha_{d}}\right]\left(\frac{D r_{e}}{100 \beta_{d}}\right)^{\alpha_{d}-2}}{\left\{1-\exp \left[-\left(\frac{1}{100 \beta_{d}}\right)^{\alpha_{d}}\right]\right\} 100 \beta_{\mathrm{d}}}\right\}\left(\alpha_{d}-1\right)-\frac{\alpha_{d}}{100 \beta_{d}}\left(\frac{D r_{e}}{100 \beta_{d}}\right)^{\alpha_{d}}\right\} \\
& Z=100 \beta_{d}\left[\left(\frac{\alpha_{d}-1}{\alpha_{d}}\right) 100 \beta_{d}\right]^{1 / \alpha_{d}}
\end{aligned}
$$


Tabela 9. Caracterização geral do modelo referente à fitomassa seca total (modelo 3).

\begin{tabular}{ccc}
\hline Condição & Descrição & Conseqüêencia \\
\hline 1 & $D r_{e}=0$ & $F S T_{e d p}=0$ \\
2 & $D r_{e}=0$ & $\frac{d F S T_{e d p}}{d D r_{e}}=0$ \\
3 & $D r_{e}=100$ & $F S T_{e d p}=\gamma_{d}$ \\
4 & $0<D r_{e}<100$ & $\frac{d F S T_{e d p}}{d D r_{e}}>0$ \\
5 & $D r_{e}=Z(0<Z<100)$ & $\frac{d^{2} F S T_{e d p}}{d D r_{e}^{2}}=0$ \\
6 & $0<D r_{e}<Z$ & $\frac{d^{2} F S T_{e d p}}{d D r_{e}^{2}}>0$ \\
7 & $Z<D r_{e}<100$ & $\frac{d^{2} F S T_{e d p}}{d D r_{e}^{2}}<0$ \\
\hline
\end{tabular}

\subsubsection{Modelo quadrático para descrever o efeito de nitrogênio sobre fitomassa seca, rendimento de grãos e seus componentes}

Foi avaliado o efeito da dose de nitrogênio sobre a fitomassa seca de raízes $(F S r)$, haste $(F S h)$ e folhas $(F S f)$ no estádio $\mathrm{R}_{6}$, e o efeito sobre o rendimento de grãos $(R$, kg.ha ${ }^{-1}$ ) na colheita, utilizando o seguinte modelo quadrático (modelo 4):

$$
Y_{e j d p}=\mu_{e j d}+L_{e j d} \cdot N_{d}+Q_{e j d} \cdot N_{d}^{2}+\varepsilon_{e j d p}
$$

em que $Y_{e j d p}$ ao valor observado $\left(\mathrm{kg}_{\text {.ha }}{ }^{-1}\right)$ da $j$-ésima variável resposta $(j=F S r, F S h, F S f$, $R$ ) na $e$-ésima época ( $e=\mathrm{R}_{6}$, colheita) correspondente à $d$-ésima dose de nitrogênio na $p$ ésima parcela, $N_{d}$ à $d$-ésima dose de nitrogênio $\left(0,60\right.$ e $\left.120 \mathrm{~kg} \mathrm{ha}^{-1}\right), \mu_{e j d}$ ao valor médio da fitomassa seca $\left(\mathrm{kg} \cdot \mathrm{ha}^{-1}\right)$ da $j$-ésima variável resposta correspondente à dose zero $\left(N_{d}\right.$ $=0 \mathrm{~kg} \cdot \mathrm{ha}^{-1}$ de $\mathrm{N}$ ) na $e$-ésima época na $p$-ésima parcela; $L_{e j d}$ ao efeito linear (adimensional) da $d$-ésima dose correspondente à $j$-ésima variável resposta na $e$-ésima 
época, $Q_{e j d}$ ao efeito quadrático $\left(\mathrm{kg}_{\text {.ha }}{ }^{-1}\right)$ da dose na $j$-ésima variável resposta da $e$-ésima

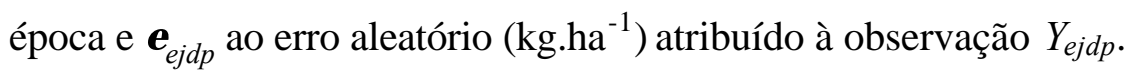

O esquema da análise da variância referente ao modelo 4 está descrito na Tabela 10. Os parâmetros foram estimados pelo método dos quadrados mínimos utilizando o procedimento GLM (General Linear Models) do SAS ${ }^{\circledR}$ System (SAS 1998). Para avaliar a significância dos parâmetros dos modelos quadráticos foram utilizados testes $t$ unilaterais para contrastes (Montgomery, 2000).

Tabela 10. Esquema da análise de variância referente ao modelo quadrático (estádio $\mathrm{R}_{6} \mathrm{e}$ colheita).

\begin{tabular}{cccc}
\hline Causa da variação & Graus de liberdade $^{1}$ & Quadrado Médio & $\mathrm{F}$ \\
\hline Regressão & $n_{\text {par }} 1=3-1=2$ & $\mathrm{~V}_{1}$ & $\mathrm{~V}_{1} / \mathrm{V}_{2}$ \\
Erro & $n_{\text {parc }}-n_{\text {par }}=12-3=9$ & $\mathrm{~V}_{2}$ & \\
Total & $n_{\text {parc }}-1=12-1=11$ & & \\
${ }^{1} n_{\text {parc }}$ : número de parcelas: $12 ; n_{\text {par }}$ : número de parâmetros: 3. & &
\end{tabular}




\section{RESULTADOS E DISCUSSÃO}

\subsection{Fenologia}

Foi utilizada a soma calórica a partir da semeadura devido a diferença em termos de desenvolvimento relativo ser desprezível (Tabela 11). Esse procedimento permite na prática estimar a época de florescimento e a duração do ciclo a partir da semeadura. A germinação, período entre a semeadura e a emergência, foi de cinco dias. Cabe ressaltar que a duração desse processo também está altamente correlacionada com temperatura.

Já o desenvolvimento relativo unitário se dá quando a cultura atinge o ponto de maturidade fisiológica. No caso específico do experimento, a colheita foi efetuada 15 dias após ter sido atingido o último estádio fenológico $\left(\mathrm{R}_{9}\right.$ - ponto de maturidade fisiológica) (Tabela 13).

Para efeito de estimativa da soma calórica, foi utilizada a temperatura base (inferior) de $10^{\circ} \mathrm{C}$ (Tabela 11 , Tabela 12 e Tabela 13).

As observações de fenologia foram apresentadas conjuntamente com número de dias após a semeadura e graus-dia. O número de dias após a semeadura é útil por se tratar de uma referência prática, onde normalmente é utilizada para estimar a taxa de crescimento (em termos de acúmulo de fitomassa seca) e absorção de nutrientes. A soma calórica (ou graus-dia) é utilizada como referência de planejamento. A fenologia é utilizada como referência de manejo (Tabela 11).

O desenvolvimento relativo foi utilizado como variável independente no intuito de possibilitar a extrapolação e comparação do resultado, nortear a intervenção no sistema agrícola (ações de manejo) e verificar se o padrão de desempenho é similar nas diferentes condições de ambiente. 
Tabela 11. Número de dias após a semeadura $(D A S)$, data, fenologia, diferença diária entre a temperatura média $\left(T m,{ }^{\circ} \mathrm{C}\right)$ e a temperatura base inferior $(T b=$ $\left.10^{\circ} \mathrm{C}\right)$, graus-dia acumulados $\left(\mathrm{GDac},{ }^{\circ} \mathrm{C} . \mathrm{dia}\right)$ e desenvolvimento relativo (Dr) da cultura no período de 1 a 30 de abril de 2002.

\begin{tabular}{|c|c|c|c|c|c|}
\hline DAS & Data & Fenologia & $\mathrm{Tm}-\mathrm{Tb}$ & GDac & Dr \\
\hline 1 & $01 / 04 / 02$ & Semeadura & 26,2 & 16,2 & 0,01 \\
\hline 2 & $02 / 04 / 02$ & & 16,1 & 32,3 & 0,03 \\
\hline 3 & $03 / 04 / 02$ & & 17,3 & 49,6 & 0,04 \\
\hline 4 & $04 / 04 / 02$ & & 14,9 & 64,4 & 0,06 \\
\hline 5 & $05 / 04 / 02$ & Emergência & 13,5 & 77,9 & 0,07 \\
\hline 6 & $06 / 04 / 02$ & & 13,9 & 91,8 & 0,08 \\
\hline 7 & $07 / 04 / 02$ & $\mathrm{~V}_{1}$ & 13,5 & 105,3 & 0,09 \\
\hline 8 & $08 / 04 / 02$ & & 13,3 & 118,6 & 0,11 \\
\hline 9 & $09 / 04 / 02$ & & 13,3 & 131,9 & 0,12 \\
\hline 10 & $10 / 04 / 02$ & & 13,7 & 145,6 & 0,13 \\
\hline 11 & $11 / 04 / 02$ & $\mathrm{~V}_{2}$ & 14,5 & 160,0 & 0,14 \\
\hline 12 & $12 / 04 / 02$ & & 15,0 & 175,0 & 0,16 \\
\hline 13 & $13 / 04 / 02$ & & 14,5 & 189,5 & 0,17 \\
\hline 14 & $14 / 04 / 02$ & & 14,5 & 203,9 & 0,18 \\
\hline 15 & $15 / 04 / 02$ & & 15,6 & 219,5 & 0,19 \\
\hline 16 & $16 / 04 / 02$ & & 15,5 & 235,0 & 0,21 \\
\hline 17 & $17 / 04 / 02$ & $\mathrm{~V}_{3}$ & 16,1 & 251,0 & 0,22 \\
\hline 18 & $18 / 04 / 02$ & & 16,2 & 267,2 & 0,24 \\
\hline 19 & $19 / 04 / 02$ & & 15,3 & 282,5 & 0,25 \\
\hline 20 & $20 / 04 / 02$ & & 14,4 & 296,9 & 0,26 \\
\hline 21 & $21 / 04 / 02$ & & 14,2 & 311,1 & 0,28 \\
\hline 22 & $22 / 04 / 02$ & & 15,5 & 326,6 & 0,29 \\
\hline 23 & $23 / 04 / 02$ & & 13,9 & 340,5 & 0,30 \\
\hline 24 & $24 / 04 / 02$ & & 14,4 & 354,9 & 0,31 \\
\hline 25 & $25 / 04 / 02$ & & 14,8 & 369,6 & 0,33 \\
\hline 26 & $26 / 04 / 02$ & $\mathrm{~V}_{4}$ & 13,8 & 383,4 & 0,34 \\
\hline 27 & $27 / 04 / 02$ & & 13,7 & 397,1 & 0,35 \\
\hline 28 & $28 / 04 / 02$ & & 13,9 & 411,0 & 0,36 \\
\hline 29 & $29 / 04 / 02$ & & 14,5 & 425,4 & 0,38 \\
\hline 30 & $30 / 04 / 02$ & & 15,0 & 440,4 & 0,39 \\
\hline
\end{tabular}


Tabela 12. Número de dias após a semeadura $(D A S)$, data, fenologia, diferença diária entre a temperatura média $\left(\mathrm{Tm},{ }^{\circ} \mathrm{C}\right)$ e a temperatura base inferior $(\mathrm{Tb}=$ $\left.10^{\circ} \mathrm{C}\right)$, graus-dia acumulados $\left(G D a c,{ }^{\circ} \mathrm{C}\right.$. dia $)$ e desenvolvimento relativo (Dr) da cultura no período de 1 a 31 de maio de 2002.

\begin{tabular}{|c|c|c|c|c|c|}
\hline DAS & Data & Fenologia & $\mathrm{Tm}-\mathrm{Tb}$ & GDac & Dr \\
\hline 31 & $01 / 05 / 02$ & & 13,4 & 453,8 & 0,40 \\
\hline 32 & $02 / 05 / 02$ & & 12,9 & 466,6 & 0,41 \\
\hline 33 & 03/05/02 & & 13,5 & 480,1 & 0,43 \\
\hline 34 & $04 / 05 / 02$ & & 12,2 & 492,3 & 0,44 \\
\hline 35 & $05 / 05 / 02$ & & 12,9 & 505,1 & 0,45 \\
\hline 36 & $06 / 05 / 02$ & & 13,6 & 518,7 & 0,46 \\
\hline 37 & $07 / 05 / 02$ & & 13,2 & 531,9 & 0,47 \\
\hline 38 & $08 / 05 / 02$ & & 12,8 & 544,7 & 0,48 \\
\hline 39 & $09 / 05 / 02$ & & 11,4 & 556,1 & 0,49 \\
\hline 40 & $10 / 05 / 02$ & & 11,4 & 567,4 & 0,50 \\
\hline 41 & $11 / 05 / 02$ & & 12,3 & 579,7 & 0,51 \\
\hline 42 & $12 / 05 / 02$ & & 13,0 & 592,7 & 0,53 \\
\hline 43 & $13 / 05 / 02$ & & 12,7 & 605,4 & 0,54 \\
\hline 44 & $14 / 05 / 02$ & & 12,5 & 617,8 & 0,55 \\
\hline 45 & $15 / 05 / 02$ & $\mathrm{R}_{5}$ & 13,1 & 630,9 & 0,56 \\
\hline 46 & $16 / 05 / 02$ & & 10,2 & 641,1 & 0,57 \\
\hline 47 & $17 / 05 / 02$ & & 11,9 & 653,0 & 0,58 \\
\hline 48 & $18 / 05 / 02$ & $\mathrm{R}_{6}$ & 12,9 & 665,9 & 0,59 \\
\hline 49 & $19 / 05 / 02$ & & 7,8 & 673,7 & 0,60 \\
\hline 50 & $20 / 05 / 02$ & & 12,3 & 685,9 & 0,61 \\
\hline 51 & $21 / 05 / 02$ & & 9,5 & 695,4 & 0,62 \\
\hline 52 & $22 / 05 / 02$ & & 8,7 & 704,1 & 0,62 \\
\hline 53 & $23 / 05 / 02$ & $\mathrm{R}_{7}$ & 7,5 & 711,6 & 0,63 \\
\hline 54 & $24 / 05 / 02$ & & 7,3 & 718,8 & 0,64 \\
\hline 55 & $25 / 05 / 02$ & & 5,9 & 724,7 & 0,64 \\
\hline 56 & $26 / 05 / 02$ & & 6,4 & 731,1 & 0,65 \\
\hline 57 & $27 / 05 / 02$ & & 7,1 & 738,1 & 0,65 \\
\hline 58 & $28 / 05 / 02$ & & 7,1 & 745,2 & 0,66 \\
\hline 59 & $29 / 05 / 02$ & & 8,6 & 753,8 & 0,67 \\
\hline 60 & $30 / 05 / 02$ & & 8,9 & 762,7 & 0,68 \\
\hline 61 & $31 / 05 / 02$ & & 8,5 & 771,2 & 0,68 \\
\hline
\end{tabular}


Tabela 13. Número de dias após a semeadura $(D A S)$, data, fenologia, diferença diária entre a temperatura média $\left(T m,{ }^{\circ} \mathrm{C}\right)$ e a temperatura base inferior $(T b=$ $\left.10^{\circ} \mathrm{C}\right)$, graus-dia acumulados $\left(G D a c,{ }^{\circ} \mathrm{C}\right.$.dia) e desenvolvimento relativo da cultura (Dr) no período de 1 de junho a 19 de julho de 2002.

\begin{tabular}{|c|c|c|c|c|c|}
\hline DAS & Data & Fenologia & $\mathrm{Tm}-\mathrm{Tb}$ & GDac & Dr \\
\hline 62 & $01 / 06 / 02$ & & 10,6 & 781,8 & 0,69 \\
\hline 63 & $02 / 06 / 02$ & & 10,2 & 791,9 & 0,70 \\
\hline 64 & $03 / 06 / 02$ & & 10,2 & 802,1 & 0,71 \\
\hline 65 & $04 / 06 / 02$ & & 10,2 & 812,3 & 0,72 \\
\hline 66 & $05 / 06 / 02$ & & 10,8 & 823,1 & 0,73 \\
\hline 67 & $06 / 06 / 02$ & & 11,2 & 834,3 & 0,74 \\
\hline 68 & $07 / 06 / 02$ & $\mathrm{R}_{8}$ & 10,5 & 844,8 & 0,75 \\
\hline 69 & $08 / 06 / 02$ & & 11,3 & 856,1 & 0,76 \\
\hline 70 & $09 / 06 / 02$ & & 11,0 & 867,0 & 0,77 \\
\hline 71 & $10 / 06 / 02$ & & 13,3 & 880,3 & 0,78 \\
\hline 72 & $11 / 06 / 02$ & & 12,1 & 892,4 & 0,79 \\
\hline 73 & $12 / 06 / 02$ & & 12,4 & 904,8 & 0,80 \\
\hline 74 & $13 / 06 / 02$ & & 12,2 & 916,9 & 0,81 \\
\hline 75 & $14 / 06 / 02$ & & 12,0 & 928,9 & 0,82 \\
\hline 76 & $15 / 06 / 02$ & & 10,1 & 938,9 & 0,83 \\
\hline 77 & $16 / 06 / 02$ & & 9,4 & 948,3 & 0,84 \\
\hline 78 & $17 / 06 / 02$ & & 11,6 & 959,9 & 0,85 \\
\hline 79 & $18 / 06 / 02$ & & 10,3 & 970,2 & 0,86 \\
\hline 80 & $19 / 06 / 02$ & & 11,0 & 981,2 & 0,87 \\
\hline 81 & $20 / 06 / 02$ & & 10,5 & 991,7 & 0,88 \\
\hline 82 & $21 / 06 / 02$ & & 9,2 & 1000,9 & 0,89 \\
\hline 83 & $22 / 06 / 02$ & & 8,5 & 1009,4 & 0,89 \\
\hline 84 & $23 / 06 / 02$ & & 8,1 & 1017,5 & 0,90 \\
\hline 85 & $24 / 06 / 02$ & & 8,6 & 1026,1 & 0,91 \\
\hline 86 & $25 / 06 / 02$ & & 8,1 & 1034,2 & 0,92 \\
\hline 87 & $26 / 06 / 02$ & & 7,5 & 1041,7 & 0,92 \\
\hline 88 & $27 / 06 / 02$ & & 9,4 & 1051,1 & 0,93 \\
\hline 89 & $28 / 06 / 02$ & & 8,8 & 1059,8 & 0,94 \\
\hline 90 & $29 / 06 / 02$ & & 9,0 & 1068,8 & 0,95 \\
\hline 91 & $30 / 06 / 02$ & & 10,6 & 1079,4 & 0,96 \\
\hline 92 & 01/07/02 & & 10,6 & 1090,0 & 0,97 \\
\hline 93 & $02 / 07 / 02$ & & 9,2 & 1099,2 & 0,97 \\
\hline 94 & 03/07/02 & & 9,5 & 1108,6 & 0,98 \\
\hline 95 & $04 / 07 / 02$ & & 10,3 & 1118,9 & 0,99 \\
\hline 96 & $05 / 07 / 02$ & $\mathrm{R}_{9}$ & 10,0 & 1128,9 & 1,00 \\
\hline 110 & $19 / 07 / 02$ & Colheita & - & - & - \\
\hline
\end{tabular}




\subsection{Modelos ajustados para descrever a variação de fitomassa seca em função de desenvolvimento relativo}

Para cada órgão foi ajustado um modelo que melhor descreve a variação da fitomassa seca em função do desenvolvimento relativo da cultura de feijão em função do conhecimento do padrão da curva de crescimento.

Para cada caso, foram estimados os valores dos parâmetros empíricos dos modelos descritos, onde foram colocados os limites inferior e superior correspondentes ao intervalo de confiança de $95 \%$.

Para cada órgão, procedeu-se a confecção da curva padrão reduzida obtida pela relação entre os valores observados em cada época divididos pelos valores máximos para cada caso. Sendo assim, a fitomassa seca relativa passou a varira de 0 a 1 , o que permitiu verificar se as diferentes doses de nitrogênio, apesar de propiciar diferentes valores absolutos de fitomassa seca, em termos relativos, apresentava a vantagem de verificar se as variações apresentavam o mesmo padrão (permite verificar se o mesmo modelo é utilizável), bem como se os valores relativos são coincidentes (permite verificar a validade da extrapolação).

\subsubsection{Fitomassa seca de raízes}

A produção de massa de raiz é imprescindível para definir o desempenho da cultura de feijão no campo. Quanto maior for o volume de solo explorado por unidade de planta, menor deverá ser o teor crítico dos diferentes nutrientes no solo. Porém, maior fitomassa produzida de raiz pode não ser desejável, pois a maior produção requer maior dispêndio de carboidrato alocado ao sistema radicular em termos relativos. Sendo assim, o desenvolvimento e crescimento da parte aérea (especialmente haste e folhas) pode ficar prejudicada.

Por outro lado, um sistema radicular muito reduzido também não é desejável devido ao maior risco de perda de produtividade da cultura de feijão, em função de estresse biótico (pragas, doenças e plantas daninhas) e abiótico (água e temperatura, principalmente) do ambiente. 
Sendo assim, o manejo cultural e do ambiente deve propiciar um sistema radicular que haja um perfeito equilíbrio entre raiz e parte aérea. Dentre as diferentes formas de intervenção, destaca-se a adubação nitrogenada, a qual possibilita um desenvolvimento e crescimento inicial maior devido ao reduzido volume de solo explorado pelo sistema radicular, em termos absolutos. A importância dessa prática e minimizar a exposição da plântula a patógenos do solo (pragas e doenças) e tornar a cultura mais competitiva por água, nutrientes e luz no início do ciclo vital da cultura.

Devido à dificuldade de mensuração do sistema radicular a medida que o tempo passa, o número de repetições variou de estádio para estádio. Isso ocorreu devido ao aumento da quantidade de massa de raízes associado ao alto teor de argila do solo. Porém, para efeito de estimativa, procurou-se determinar a fitomassa seca de raízes por unidade de planta com maior exatidão. Posteriormente, procedeu-se a estimativa por unidade de área em função da população de plantas após o desbaste.

A fitomassa seca de raízes foi medida em cada estádio fenológico, e o modelo 1 foi ajustado aos dados observados. A Tabela 14 apresenta os valores estimados dos parâmetros empíricos $(a, b$ e $c$ ) para as três doses de nitrogênio: 0 (Figura 3A), 60 (Figura 3B) e 120 (Figura 3C) kg.ha ${ }^{-1}$.

Todas as curvas apresentaram o mesmo padrão de crescimento (Figura 4). Para efeito prático de extrapolação do resultado, é importante essa constatação. O valor relativo foi calculado dividido a fitomassa seca de raiz de cada época pela fitomassa seca máxima de raiz. Esse procedimento permite estimar a ordem de grandeza da produção de massa de raiz, que por sua vez é dependente da adubação nitrogenada. 


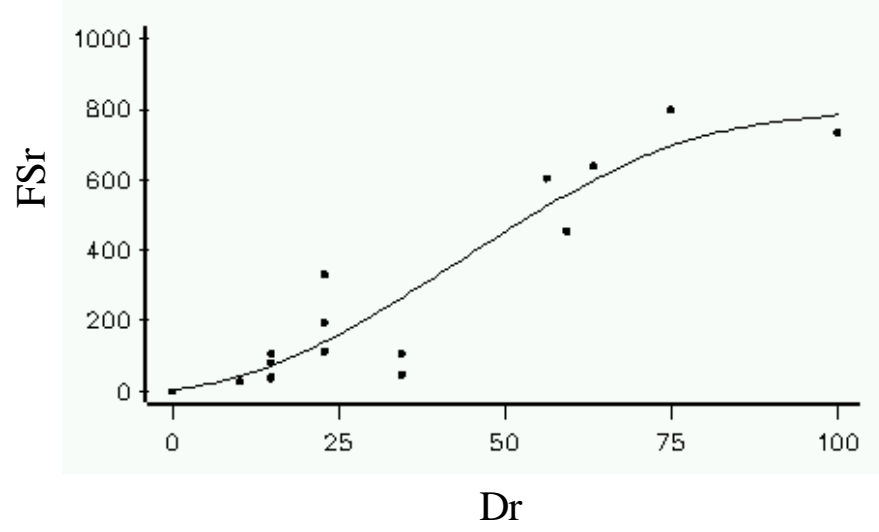

(A)

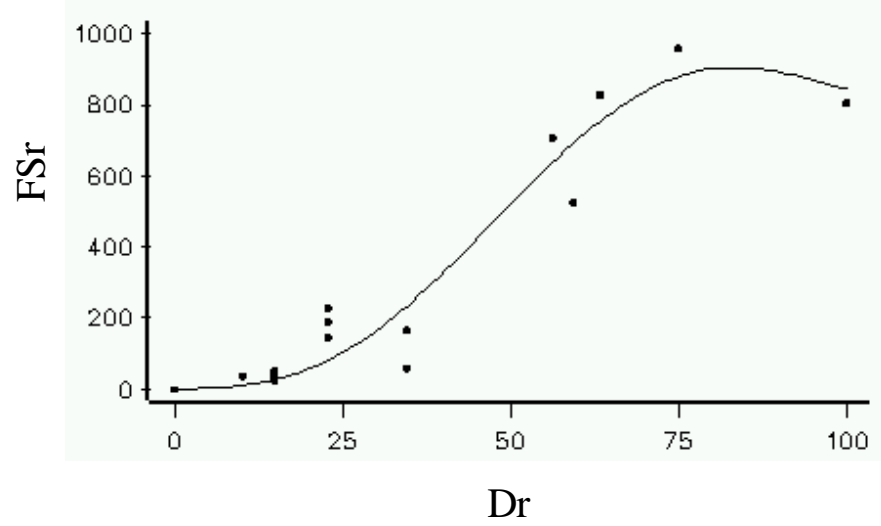

(B)

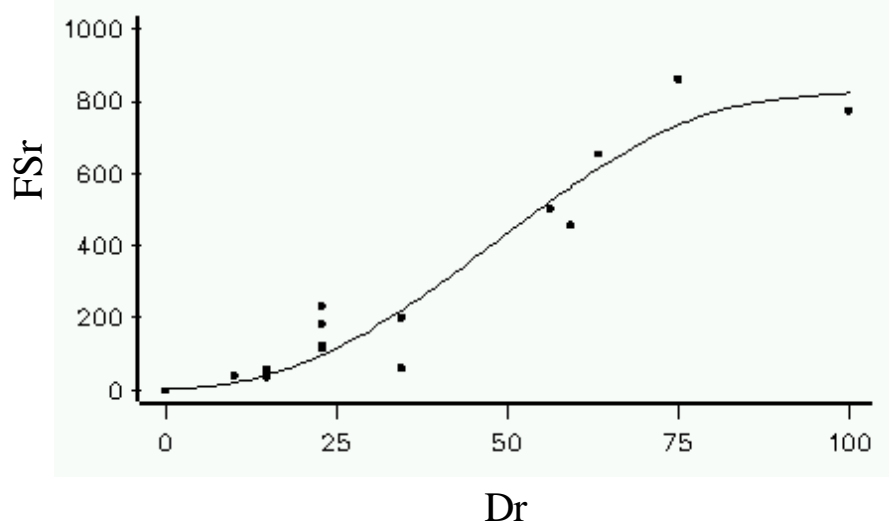

(C)

Figura 3 - Variação da fitomassa seca de raízes $\left(F S r, \mathrm{~kg}_{\text {.ha }}{ }^{-1}\right)$ em função do desenvolvimento relativo $(\mathrm{Dr}, \%)$ da cultura de feijão para diferentes doses de nitrogênio: (A) 0 kg.ha ${ }^{-1}$, (B) $60 \mathrm{~kg} \cdot \mathrm{ha}^{-1}$ e (C) $120 \mathrm{~kg} \cdot \mathrm{ha}^{-1}$. 
Tabela 14. Estimativas dos parâmetros dos modelos que descrevem a variação temporal da fitomassa seca acumulada de raízes da cultura de feijão para as doses 0 , 60 e $120 \mathrm{~kg} \cdot \mathrm{ha}^{-1}$ de nitrogênio.

\begin{tabular}{|c|c|c|c|c|c|}
\hline \multirow{2}{*}{ Parâmetros } & \multirow{2}{*}{$\begin{array}{l}\text { Dose } \\
\text { de N }\end{array}$} & \multirow{2}{*}{ Estimativa } & \multirow{2}{*}{$\begin{array}{l}\text { Erro Padrão } \\
\text { Assintótico }\end{array}$} & \multicolumn{2}{|c|}{ Intervalo de Confiança Assintótico de 95\% } \\
\hline & & & & Limite Inferior & Limite Superior \\
\hline \multirow{3}{*}{ a } & 0 & 0,349 & 1,497 & $-2,809$ & 3,508 \\
\hline & 60 & $-3,662$ & 1,785 & $-7,427$ & 0,103 \\
\hline & 120 & $-1,426$ & 1,362 & $-4,300$ & 1,449 \\
\hline \multirow{3}{*}{$\mathrm{b}$} & 0 & $-6,279$ & 2,462 & $-11,473$ & $-1,085$ \\
\hline & 60 & $-12,374$ & 2,589 & $-17,836$ & $-6,912$ \\
\hline & 120 & $-8,432$ & 2,049 & $-12,756$ & $-4,108$ \\
\hline \multirow{3}{*}{ c } & 0 & 12,594 & 3,864 & 4,442 & 20,747 \\
\hline & 60 & 22,775 & 4,311 & 13,680 & 31,869 \\
\hline & 120 & 16,570 & 3,355 & 9,492 & 23,649 \\
\hline
\end{tabular}

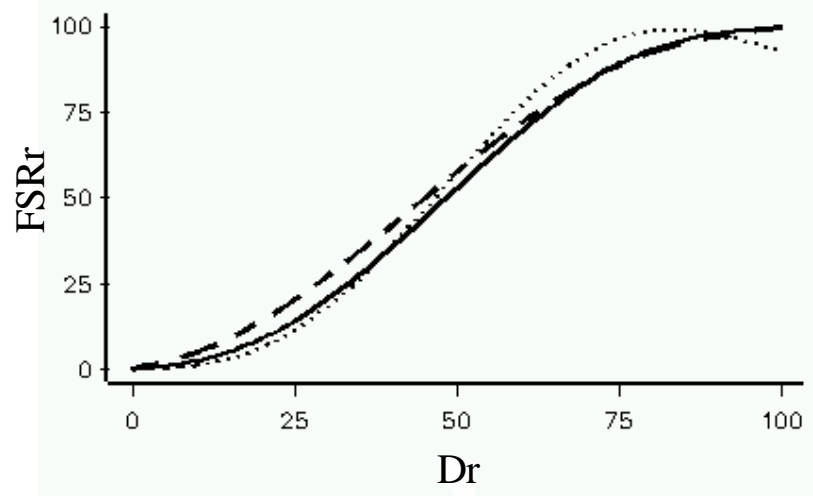

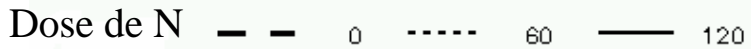

Figura 4 - Variação da fitomassa seca relativa de raízes (FSRr, \%) em função do desenvolvimento relativo $(\mathrm{Dr}, \%)$ da cultura de feijão para diferentes doses de nitrogênio $\left(0,60\right.$ e $\left.120 \mathrm{~kg} \cdot \mathrm{ha}^{-1}\right)$. 


\subsubsection{Fitomassa seca de hastes}

A variação temporal de fitomassa seca de hastes apresenta um padrão sigmoidal, onde inicialmente a taxa de crescimento é baixa porém crescente até atingir o ponto de . máxima taxa, correspondente ao ponto de inflexão da curva referente à variação da $F S r$ em função do $D r$. Posteriormente, a cultura apresenta uma taxa de crescimento decrescente, inicialmente positiva e depois negativa.

Esse padrão de crescimento é conseqüência da metodologia utilizada. A taxa de crescimento pode apresentar valores negativos devido à senescência e quando a referência é a fitomassa seca observável. No procedimento referente à análise de crescimento, não se observa o que foi produzido até o momento da observação, e sim a observação do que a cultura apresenta naquele momento.

Por outro lado, poder-se-ia entender que a caracterização do padrão de acúmulo de fitomassa seca é a descrição indireta da alocação relativa de fotoassimilados oriundos da fotossíntese líquida aos diferentes órgãos da planta. A produção de hastes é fundamental para garantir uma melhor distribuição das folhas para maior interceptação de radiação solar.

A Tabela 15 apresenta a estimativa dos parâmetros empíricos referentes ao modelo 1, o qual foi ajustado aos valores observados, minimizando a soma dos quadrados dos resíduos, utilizando como variáveis dependente e independente a fitomassa seca de hastes ( $\left.F S h, \mathrm{~kg} \cdot \mathrm{ha}^{-1}\right)$ e o desenvolvimento relativo da cultura $(D r)$, respectivamente.

A Figura 5 apresenta a variação temporal da fitomassa seca de hastes FSh, kg.ha ${ }^{-1}$ ) da cultura de feijão para diferentes doses de nitrogênio: 0 (Figura 5A), 60 (Figura 5B) e $120 \mathrm{~kg}^{-h^{-1}}$ (Figura 5C).

Como apresentado para raiz, a variação da fitomassa seca relativa de haste em função do desenvolvimento relativo da cultura apresenta padrão de crescimento similar para as três doses $\left(0,60\right.$ e $\left.120 \mathrm{~kg} \cdot \mathrm{ha}^{-1}\right)$ de nitrogênio utilizadas (Figura 6). 


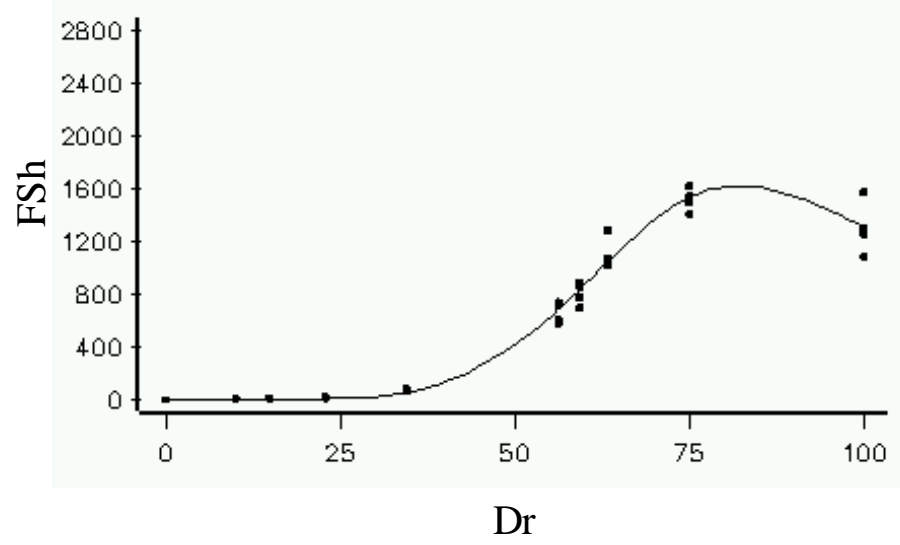

(A)
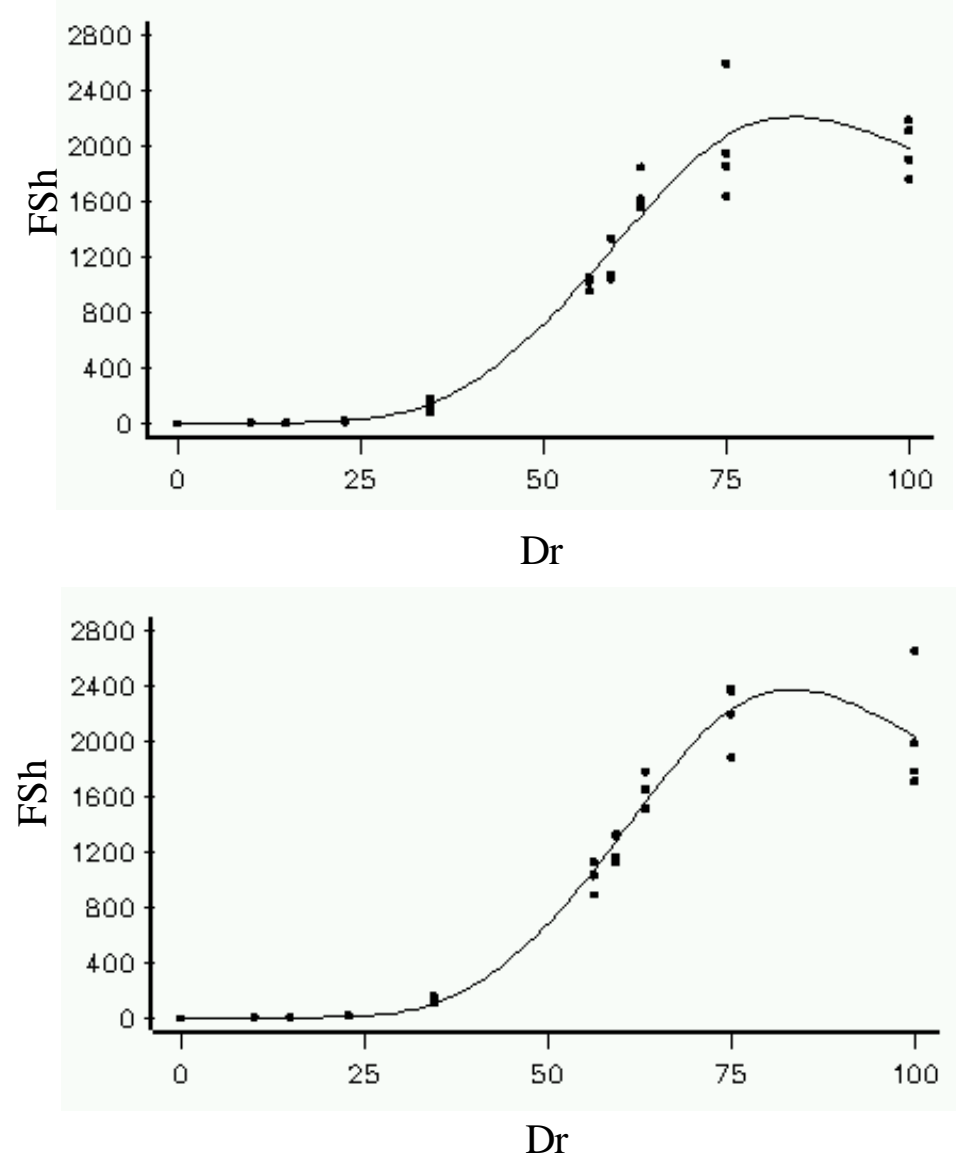

(C)

Figura 5 - Variação da fitomassa seca de hastes ( $F S h, \mathrm{~kg} . \mathrm{ha}^{-1}$ ) em função do desenvolvimento relativo $(\mathrm{Dr}, \%)$ da cultura de feijão para diferentes doses de nitrogênio: (A) 0 kg.ha ${ }^{-1}$, (B) $60 \mathrm{~kg} \cdot \mathrm{ha}^{-1} \mathrm{e}$ (C) $120 \mathrm{~kg} \cdot \mathrm{ha}^{-1}$. 
Tabela 15. Estimativas dos parâmetros dos modelos que descrevem a variação temporal da fitomassa seca acumulada de hastes da cultura de feijão para as doses 0 , 60 e $120 \mathrm{~kg} \cdot \mathrm{ha}^{-1}$ de nitrogênio.

\begin{tabular}{|c|c|c|c|c|c|}
\hline \multirow{2}{*}{ Parâmetros } & \multirow{2}{*}{$\begin{array}{l}\text { Dose } \\
\text { de N }\end{array}$} & \multirow{2}{*}{ Estimativa } & \multirow{2}{*}{$\begin{array}{l}\text { Erro Padrão } \\
\text { Assintótico }\end{array}$} & \multicolumn{2}{|c|}{ Intervalo de Confiança Assintótico de 95\% } \\
\hline & & & & Limite Inferior & Limite Superior \\
\hline & & & & $\mathrm{ha}^{-1}-\mathrm{-}$ & \\
\hline \multirow{3}{*}{ a } & 0 & $-19,963$ & 2,012 & $-24,040$ & $-15,887$ \\
\hline & 60 & $-13,152$ & 2,388 & $-17,989$ & $-8,314$ \\
\hline & 120 & $-16,280$ & 2,375 & $-21,092$ & $-11,467$ \\
\hline \multirow{3}{*}{$\mathrm{b}$} & 0 & $-32,723$ & 2,572 & $-37,933$ & $-27,512$ \\
\hline & 60 & $-24,339$ & 3,067 & $-30,553$ & $-18,124$ \\
\hline & 120 & $-28,398$ & 3,040 & $-34,557$ & $-22,238$ \\
\hline \multirow{3}{*}{ c } & 0 & 59,862 & 4,568 & 50,605 & 69,118 \\
\hline & 60 & 45,084 & 5,437 & 34,067 & 56,102 \\
\hline & 120 & 52,297 & 5,398 & 41,360 & 63,234 \\
\hline
\end{tabular}

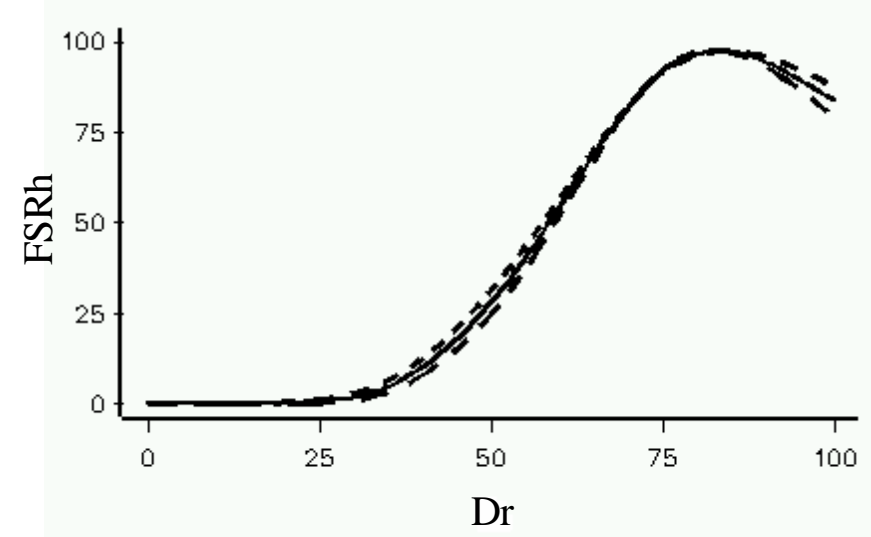

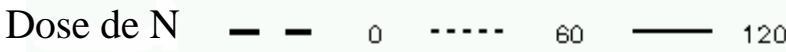

Figura 6 - Variação da fitomassa seca relativa de hastes (FSRh, \%) em função do desenvolvimento relativo $(\mathrm{Dr}, \%)$ da cultura de feijão para diferentes doses de nitrogênio $\left(0,60\right.$ e $\left.120 \mathrm{~kg} \cdot \mathrm{ha}^{-1}\right)$. 


\subsubsection{Fitomassa seca de folhas}

A variação temporal de massa de matéria seca de folhas observável apresenta um padrão de crescimento descrito pelo modelo 1 .

A produção de folhas apresenta importância prática devido a correlação com alguns processos importantes, bem como permite verificar alguns critérios de aferição de manejo.

Em termos de processos correlacionados, destaca-se a evaporação e a transpiração. Esses processos, devido à dificuldade de mensuração, normalmente são tratados conjuntamente em termos de evapotranspiração. Quanto maior a fitomassa seca de folhas, maior será a área foliar (ou o índice de área foliar - área foliar por unidade de área de solo explorado pela cultura), maior a transpiração e maior a evapotranspiração. Portanto, verifica-se que a máxima evapotranspiração ocorre entre os estádios $R_{5}$ e $R_{6}$.

Sendo assim, a definição da época de semeadura deve propiciar a coincidência de máxima probabilidade de chover a evapotranspiração no florescimento (época em que ocorre máximo índice de área foliar).

Em termos de critério de aferição de manejo, acredita-se que o melhor desempenho fitotécnico da cultura de feijão ocorre quando a planta floresce com dezesseis a vinte folhas e quando ocorre fechamento das ruas no $R_{6}$. Sendo assim, devese definir a correta população e distribuição de plantas (espaçamento entre fileiras) para que isso ocorra, levando em consideração a adubação nitrogenada e outros fatores, tais como fertilidade do solo, temperatura e chuva, principalmente.

A produção de folha apresentou padrão similar a raiz e a haste, exceto para a dose de $60 \mathrm{~kg} \cdot \mathrm{ha}^{-1}$ (Figura 8). Houve uma defasagem referente ao ponto de máximo acúmulo de fitomassa seca de folha. Esse fato pode explicar o porquê da obenção de máxima produtividade referente à dose de $60 \mathrm{~kg} \cdot \mathrm{ha}^{-1}$ de nitrogênio. Em genótipos de crescimento indeterminado, o sentido do florescimento é ascendente. Portanto, quanto maior a quantidade de folhas no final do ciclo, maior o pegamento de flores no terço superior da planta e, conseqüentemente, maior a produtividade. Na prática, é usual manejar a cultura no intuito de maximizar a duração foliar no final do ciclo, como por exemplo a recomendação de adubação nitrogenada no $\mathrm{R}_{7}$ por alguns autores. 


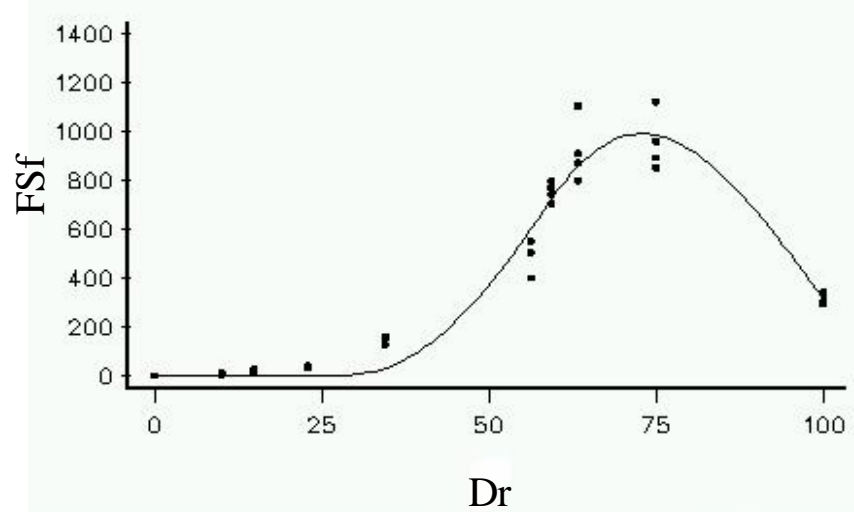

(A)

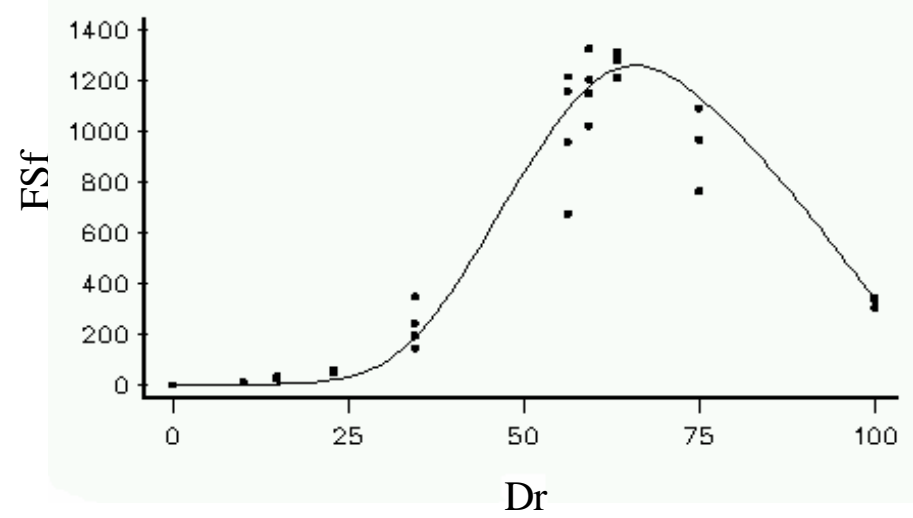

(B)

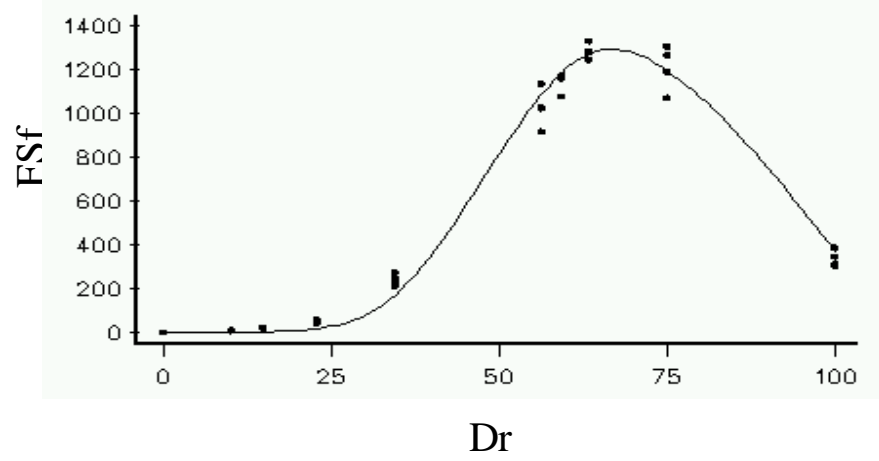

(C)

Figura 7 - Variação da fitomassa seca de folhas (FSf, kg.ha $\left.{ }^{-1}\right)$ em função do desenvolvimento relativo $(\mathrm{Dr}, \%)$ da cultura de feijão para diferentes doses de nitrogênio: (A) $0 \mathrm{~kg} \cdot \mathrm{ha}^{-1}$, (B) $60 \mathrm{~kg} \cdot \mathrm{ha}^{-1} \mathrm{e}$ (C) $120 \mathrm{~kg} \cdot \mathrm{ha}^{-1}$. 
Tabela 16. Estimativas dos parâmetros dos modelos que descrevem a variação temporal da fitomassa seca acumulada de folhas da cultura de feijão para as doses 0 , 60 e $120 \mathrm{~kg} \cdot \mathrm{ha}^{-1}$ de nitrogênio.

\begin{tabular}{|c|c|c|c|c|c|}
\hline \multirow{2}{*}{ Parâmetros } & \multirow{2}{*}{$\begin{array}{l}\text { Dose } \\
\text { de N }\end{array}$} & \multirow{2}{*}{ Estimativa } & \multirow{2}{*}{$\begin{array}{l}\text { Erro Padrão } \\
\text { Assintótico }\end{array}$} & \multicolumn{2}{|c|}{ Intervalo de Confiança Assintótico de 95\% } \\
\hline & & & & Limite Inferior & Limite Superior \\
\hline & & & & $\mathrm{ha}^{-1}$ & ---------------- \\
\hline \multirow{3}{*}{ a } & 0 & $-30,113$ & 3,554 & $-37,313$ & $-22,912$ \\
\hline & 60 & $-17,904$ & 3,516 & $-25,028$ & $-10,780$ \\
\hline & 120 & $-18,516$ & 1,633 & $-21,825$ & $-15,207$ \\
\hline \multirow{3}{*}{$\mathrm{b}$} & 0 & $-51,272$ & 4,951 & $-61,304$ & $-41,239$ \\
\hline & 60 & $-37,902$ & 5,156 & $-48,350$ & $-27,455$ \\
\hline & 120 & $-38,272$ & 2,364 & $-43,062$ & $-33,482$ \\
\hline \multirow{3}{*}{$\mathrm{c}$} & 0 & 87,132 & 8,404 & 70,104 & 104,159 \\
\hline & 60 & 61,621 & 8,520 & 44,359 & 78,883 \\
\hline & 120 & 62,707 & 3,933 & 54,738 & 70,676 \\
\hline
\end{tabular}

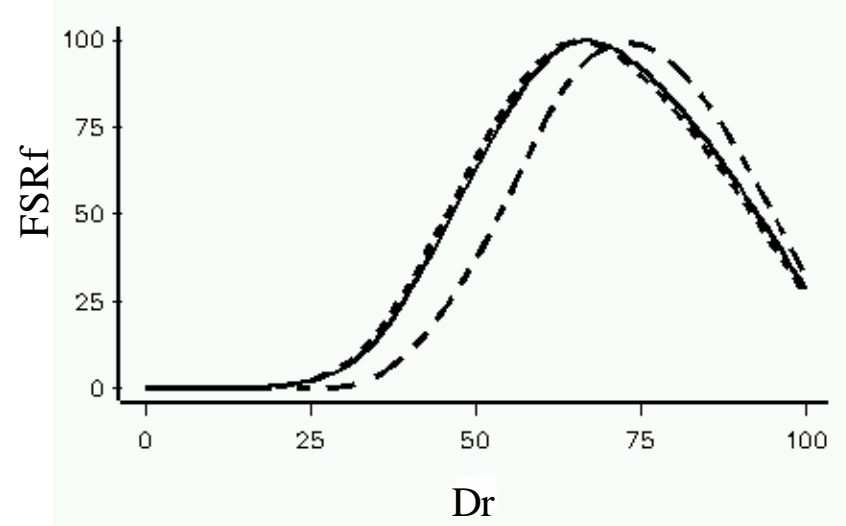

Dose de N - - $\quad 0 \quad \cdots+. .6060$

Figura 8 - Variação da fitomassa seca relativa de folhas (FSRf, \%) em função do desenvolvimento relativo $(D r, \%)$ da cultura de feijão para diferentes doses de nitrogênio $\left(0,60\right.$ e $\left.120 \mathrm{~kg} \cdot \mathrm{ha}^{-1}\right)$. 
A Tabela 16 apresenta os valores das estimativas dos parâmetros referentes aos modelos que descrevem a variação da fitomassa seca observável acumulada de folha, em função do desenvolvimento relativo da cultura de feijão, para as três doses utilizadas de nitrogênio $\left(0,60\right.$ e $\left.120 \mathrm{~kg}^{\circ} \mathrm{ha}^{-1}\right)$.

A Figura 7 apresenta variação temporal da fitomassa seca de folhas da cultura de feijão para diferentes doses de nitrogênio: 0 kg.ha ${ }^{-1}$ (Figura 7A), 60 kg.ha ${ }^{-1}$ (Figura 7B) e $120 \mathrm{~kg} \cdot \mathrm{ha}^{-1}$ (Figura 7C).

\subsubsection{Fitomassa seca de órgãos reprodutivos}

Os órgãos reprodutivos se apresentam como dreno fisiologicamente forte após o florescimento. Durante a fase vegetativa, a fitomassa seca de órgãos reprodutivos é considerada nula. Após o florescimento, foi utilizado o modelo 2 para ser ajustado aos dados experimentais.

A Tabela 17 apresenta os valores estimados dos parâmetros do modelo que descreve a variação da fitomassa seca observável acumulada de órgãos reprodutivos, em função do desenvolvimento relativo da cultura de feijão, para as três doses utilizadas de nitrogênio $\left(0,60\right.$ e $\left.120 \mathrm{~kg}^{\circ} \mathrm{ha}^{-1}\right)$.

A Figura 10 apresenta a variação temporal da fitomassa seca relativa de órgãos reprodutivos da cultura de feijão para as diferentes doses de nitrogênio $\left(0 \mathrm{~kg} \cdot \mathrm{ha}^{-1}, 60\right.$

kg.ha ${ }^{-1}$ e $120 \mathrm{~kg} \cdot \mathrm{ha}^{-1}$ ), onde fica evidenciado que, em termos relativos (relação entre o valor da fitomassa seca observada em cada época e o valor máximo observado de fitomassa seca), a fitomassa seca de órgãos reprodutivos apresenta o mesmo padrão.

A Figura 9 apresenta a variação temporal da fitomassa seca de órgãos reprodutivos da cultura de feijão para as três diferentes doses de nitrogênio: 0 (Figura 9A), 60 (Figura 9B) e 120 kg.ha ${ }^{-1}$ (Figura 9C).

O padrão de crescimento durante a fase reprodutiva é uma sigmóide estritamente crescente, em que o valor máximo ocorre no ponto de maturidade fisiológica $\left(\mathrm{R}_{9}\right)$ (Figura 10 e Figura 9).

Observa-se que, apesar do padrão de crescimento de fitomassa seca de órgãos reprodutivos ser uma sigmóide estritamente crescente, a cultura apresenta uma taxa de 
acúmulo praticamente constante, o que pode acarretar, num modelo mais simplificado, como numa aproximação linear, onde o coeficiente angular equivalente à taxa média de acúmulo de fitomassa seca de órgãos eprodutivos.

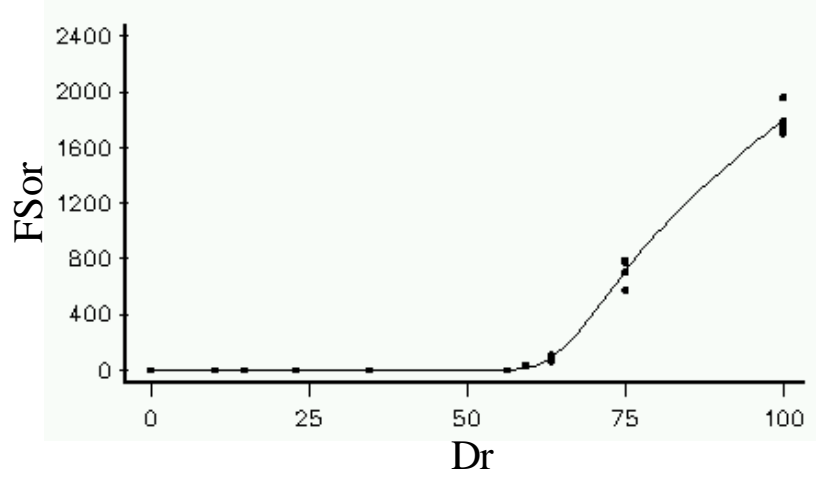

(A)

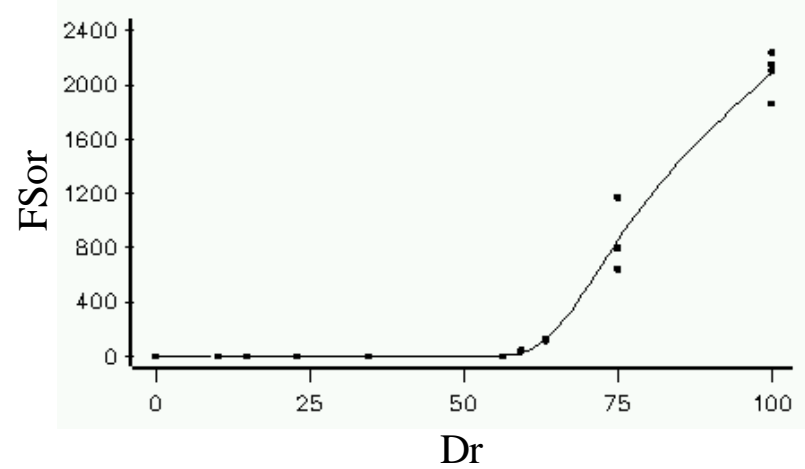

(B)

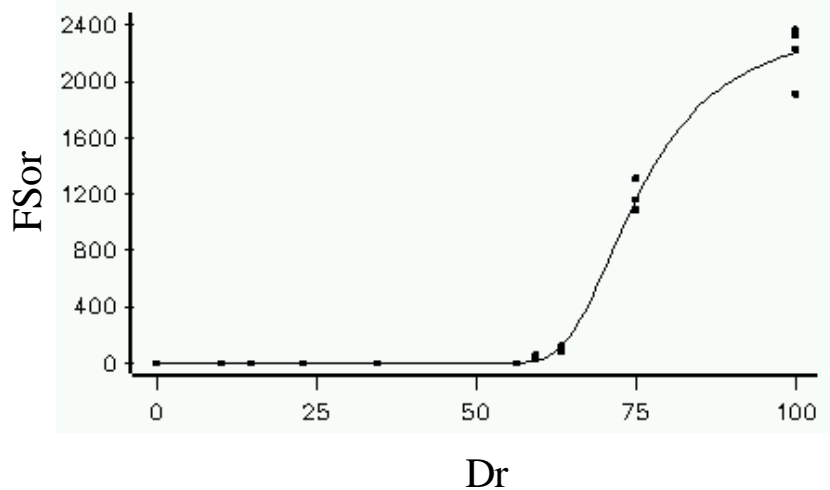

(C)

Figura 9 - Variação da fitomassa seca de órgãos reprodutivos $\left(F S o r, \mathrm{~kg} \cdot \mathrm{ha}^{-1}\right)$ em função do desenvolvimento relativo $(D r, \%)$ da cultura de feijão para diferentes doses de nitrogênio: (A) 0 kg.ha ${ }^{-1}$, (B) $60 \mathrm{~kg} \cdot \mathrm{ha}^{-1}$ e (C) $120 \mathrm{~kg} \mathrm{ha}^{-1}$. 
Tabela 17. Estimativas dos parâmetros dos modelos que descrevem a variação temporal da fitomassa seca acumulada de órgãos reprodutivos da cultura de feijão para as doses 0,60 e $120 \mathrm{~kg} \mathrm{ha}^{-1}$ de nitrogênio.

\begin{tabular}{|c|c|c|c|c|c|}
\hline \multirow{2}{*}{ Parâmetros } & \multirow{2}{*}{$\begin{array}{l}\text { Dose } \\
\text { de N }\end{array}$} & \multirow{2}{*}{ Estimativa } & \multirow{2}{*}{$\begin{array}{l}\text { Erro Padrão } \\
\text { Assintótico }\end{array}$} & \multicolumn{2}{|c|}{ Intervalo de Confiança Assintótico de 95\% } \\
\hline & & & & Limite Inferior & Limite Superior \\
\hline \multirow{4}{*}{$\alpha$} & & - & - & $h \mathrm{~h}^{-1}------------$ & ------------------ \\
\hline & 0 & 2,309 & 0,371 & 1,526 & 3,093 \\
\hline & 60 & 2,175 & 0,495 & 1,130 & 3,220 \\
\hline & 120 & 2,723 & 0,457 & 1,759 & 3,686 \\
\hline \multirow{3}{*}{$\beta$} & 0 & 0,258 & 0,022 & 0,211 & 0,305 \\
\hline & 60 & 0,260 & 0,036 & 0,184 & 0,336 \\
\hline & 120 & 0,209 & 0,007 & 0,194 & 0,224 \\
\hline \multirow{3}{*}{$\gamma$} & 0 & 1801,223 & 32,158 & 1733,375 & 1869,071 \\
\hline & 60 & 2092,925 & 58,466 & 1969,573 & 2216,277 \\
\hline & 120 & 2211,194 & 49,470 & 2106,823 & 2315,565 \\
\hline
\end{tabular}

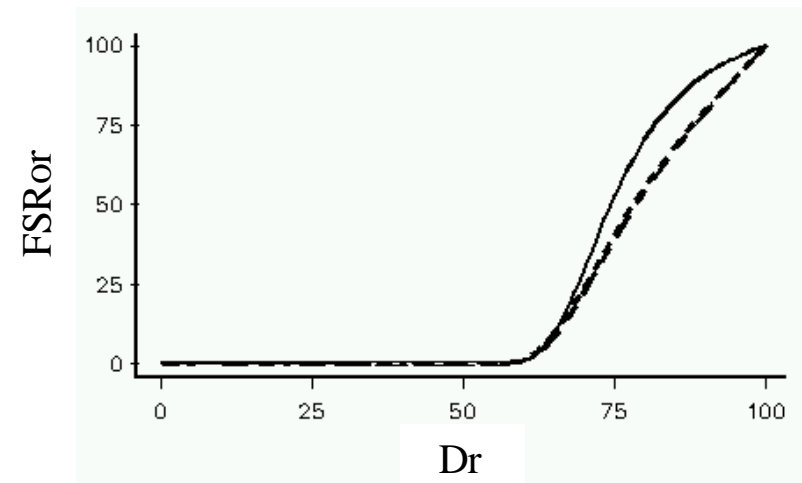

Dose de $\mathrm{N} \quad-\quad-\quad 0 \quad \cdots . .6060$

Figura 10 - Variação da fitomassa seca relativa de órgãos reprodutivos $(F S R o r, \%)$ em função do desenvolvimento relativo $(D r, \%)$ da cultura de feijão para diferentes doses de nitrogênio $\left(0,60\right.$ e $\left.120 \mathrm{~kg} \cdot \mathrm{ha}^{-1}\right)$. 


\subsubsection{Fitomassa seca total}

No intuito de minimizar o erro acumulado, utilizou-se o modelo 3 para descrever a variação temporal da fitomassa seca total, onde os parâmetros $\alpha, \beta$ e $\gamma$ foram determinados, ou seja, procedeu-se a análise de regressão com os valores observados de fitomassa seca total invés de somar os valores de fitomassa seca de raízes, hastes, folhas e órgãos reprodutivos.

A Tabela 18 apresenta os valores estimados dos parâmetros do modelo que descreve a variação da fitomassa seca total acumulada observável, em função do desenvolvimento relativo da cultura de feijão, para as três doses de nitrogênio $(0,60$ e $\left.120 \mathrm{~kg} \cdot \mathrm{ha}^{-1}\right)$.

A Figura 12 apresenta a variação temporal da fitomassa seca relativa total da cultura de feijão para diferentes doses de nitrogênio $\left(0,60\right.$ e $\left.120 \mathrm{~kg}^{\mathrm{h}} \mathrm{ha}^{-1}\right)$.

A Figura 11 apresenta a variação temporal da fitomassa seca total da cultura de feijão para três diferentes doses de nitrogênio: 0 (Figura 11A), 60 (Figura 11B) e 120 kg.ha ${ }^{-1}$ (Figura 11C).

O padrão da curva de crescimento da fitomassa seca total é sigmoidal, podendo ser estritamente crescente ou não. Quando a variação temporal apresenta padrão estritamente crescente, isso significa que a produção de órgãos reprodutivos, durante a fase reprodutiva, é superior à senescência de raízes, hastes e folhas. A menor senescência dos órgãos, em geral, é desejável ocorrer para obtenção de maiores rendimentos.

A relação funcional entre produtividade, duração do ciclo e atributos do clima, como temperatura, chuva e radiação solar, é amplamente conhecida na literatura. Sendo assim, optou-se apenas citar os trabalhos que estão diretamente relacionados ou influenciaram na elaboração desta Dissertação. 


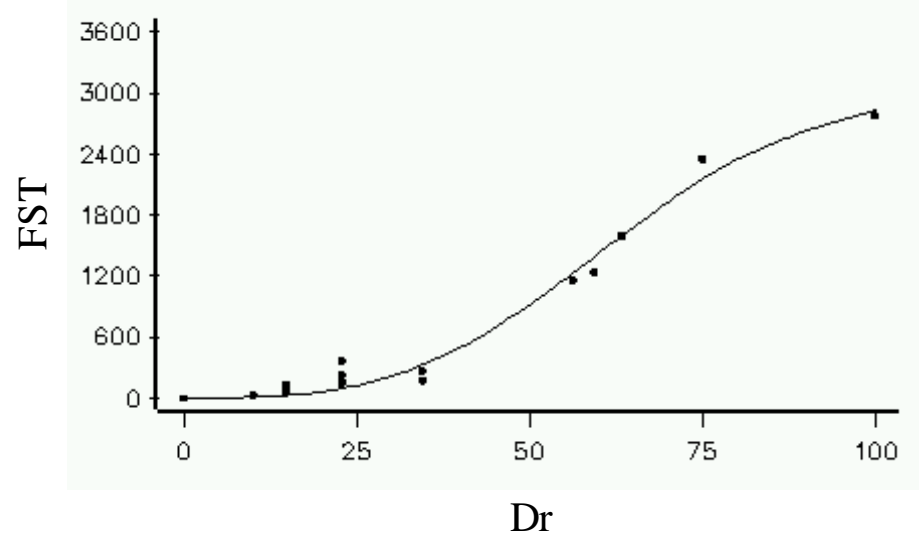

(A)

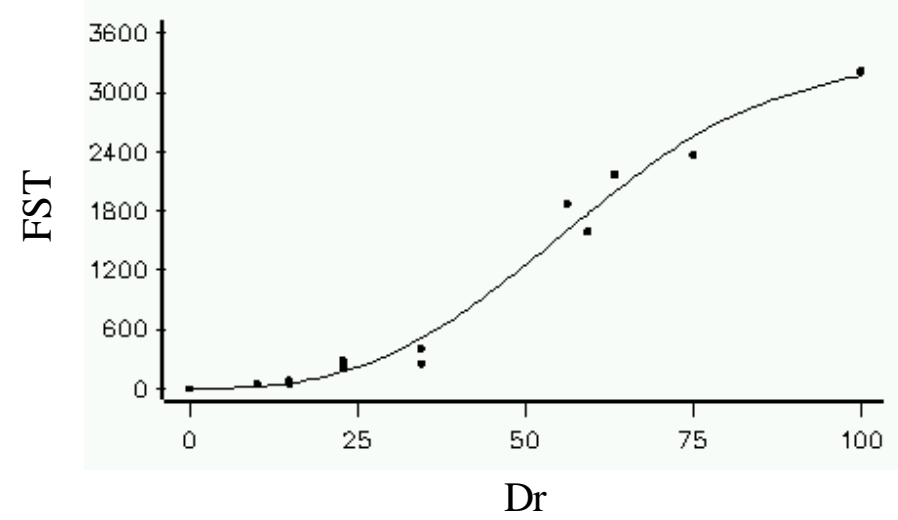

(B)

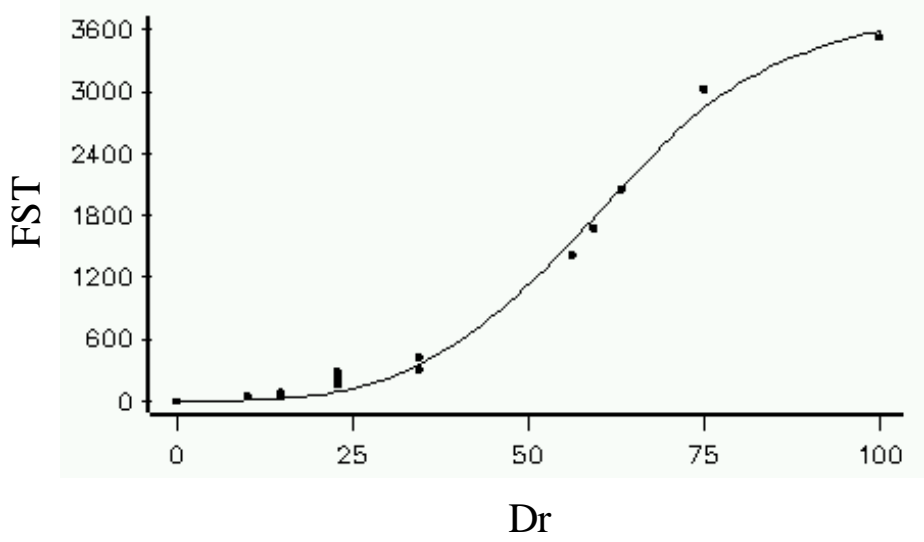

(C)

Figura 11 - Variação da fitomassa seca total $\left(F S T, \mathrm{~kg}^{-h^{-1}}{ }^{-1}\right.$ em função do desenvolvimento relativo $(D r, \%)$ da cultura de feijão para diferentes doses de nitrogênio: (A) 0 kg.ha ${ }^{-1}$, (B) 60 kg.ha ${ }^{-1}$ e (C) 120 kg.ha ${ }^{-1}$. 
Tabela 18. Estimativas dos parâmetros dos modelos que descrevem a variação temporal da fitomassa seca total acumulada da cultura de feijão para as doses 0,60 e $120 \mathrm{~kg} \cdot \mathrm{ha}^{-1}$ de nitrogênio.

\begin{tabular}{|c|c|c|c|c|c|}
\hline \multirow{2}{*}{ Parâmetros } & \multirow{2}{*}{$\begin{array}{l}\text { Dose } \\
\text { de N }\end{array}$} & \multirow{2}{*}{ Estimativa } & \multirow{2}{*}{$\begin{array}{l}\text { Erro Padrão } \\
\text { Assintótico }\end{array}$} & \multicolumn{2}{|c|}{ Intervalo de Confiança Assintótico de 95\% } \\
\hline & & & & Limite Inferior & Limite Superior \\
\hline \multirow{4}{*}{$\alpha$} & & & ------- & $\mathrm{ha}^{-1}---------------$ & - \\
\hline & 0 & 3,118 & 0,433 & 2,183 & 4,053 \\
\hline & 60 & 2,834 & 0,294 & 2,199 & 3,468 \\
\hline & 120 & 3,482 & 0,289 & 2,858 & 4,106 \\
\hline \multirow{3}{*}{$\beta$} & 0 & 0,688 & 0,041 & 0,599 & 0,777 \\
\hline & 60 & 0,649 & 0,033 & 0,576 & 0,721 \\
\hline & 120 & 0,667 & 0,018 & 0,630 & 0,705 \\
\hline \multirow{3}{*}{$\gamma$} & 0 & 2837,997 & 145,173 & 2524,369 & 3151,625 \\
\hline & 60 & 3174,267 & 141,132 & 2869,371 & 3479,164 \\
\hline & 120 & 3592,914 & 108,391 & 3358,750 & 3827,078 \\
\hline
\end{tabular}

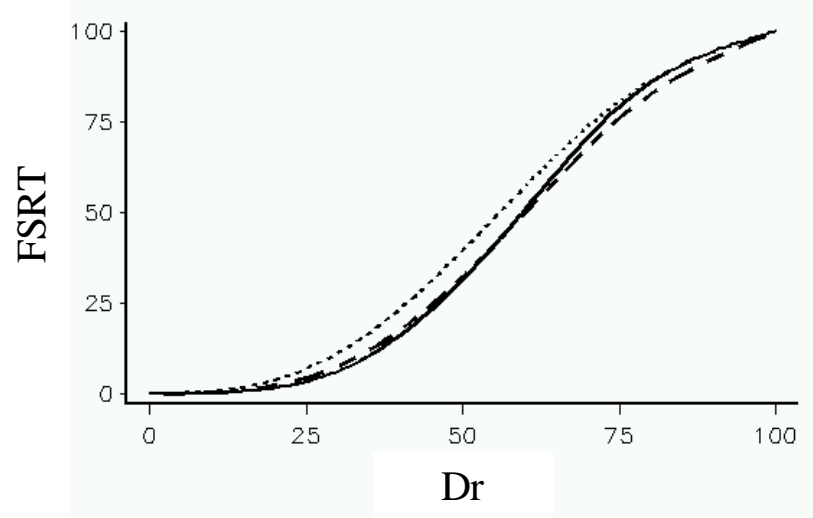

Dose de N - - $\quad 0 \quad \cdots \quad$ - $\quad 60-120$

Figura 12 - Variação da fitomassa seca relativa total (FSRT, \%) em função do desenvolvimento relativo $(\mathrm{Dr}, \%)$ da cultura de feijão para diferentes doses de nitrogênio $\left(0,60\right.$ e $\left.120 \mathrm{~kg} \cdot \mathrm{ha}^{-1}\right)$. 


\subsection{Análise do efeito da adubação nitrogenada na produção de fitomassa seca}

Em geral, a adubação nitrogenada apresentou efeito quadrático sobre a fitomassa seca de raízes, folhas, hastes (Figura 13) e fitomassa seca total (Figura 14B). O efeito das doses sobre órgãos reprodutivos foi linear (Figura 14A) (Tabela 19 - valor $P=$ 0,4042).

As estimativas dos erros padrão e valores $p$ associados ao teste $t$ unilateral para contrastes referentes a fitomassa seca de raízes, hastes, folhas, órgãos reprodutivos e total no florescimento, estão apresentadas na Tabela 19.

A análise do efeito da adubação nitrogenada na produção de fitomassa seca permite determinar qual a dose de nitrogênio que propicia maior rendimento de grãos.

Em função do conhecimento prévio (resultados de pesquisa) e da observação dos resultados obtidos, adotou-se o modelo quadrático para descrever a relação funcional entre a produção de fitomassa seca de raízes (Figura 13A), hastes (Figura 13B) e folhas (Figura 13C) e doses de nitrogênio.

Sendo assim, verifica-se que a dose recomendável está em torno de $60 \mathrm{~kg} \cdot \mathrm{ha}^{-1}$ de nitrogênio. Doses inferiores a esse valor limitam a produtividade devido a cultura de feijão demandam nitrogênio numa taxa superior à ofertada pelo solo, o qual depende do sistema agrícola. Doses mais elevadas propiciam uma redução da produção de fitomassa seca dos diferentes órgãos devido à maior ocorrência de doença, conseqüência do acúmulo de nitrogênio na folha, na forma de nitrato, devido a absorção do mesmo ter ocorrido numa magnitude superior à capacidade metabólica da espécie de incorporar o nitrogênio a compostos orgânicos.

Os valores estimados dos parâmetros referentes ao modelo quadrático que descreve o efeito da adubação nitrogenada na fitomassa seca de raízes $\left(F S r, \mathrm{~kg} \mathrm{ha}^{-1}\right)$,

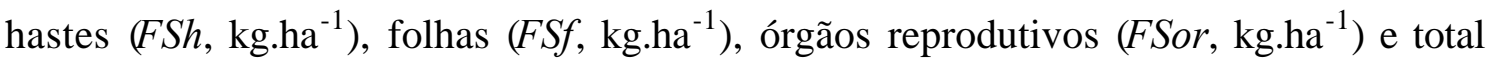
$\left(F S T, \mathrm{~kg} \mathrm{ha}^{-1}\right)$ no florescimento estão apresentados na Tabela 19. 


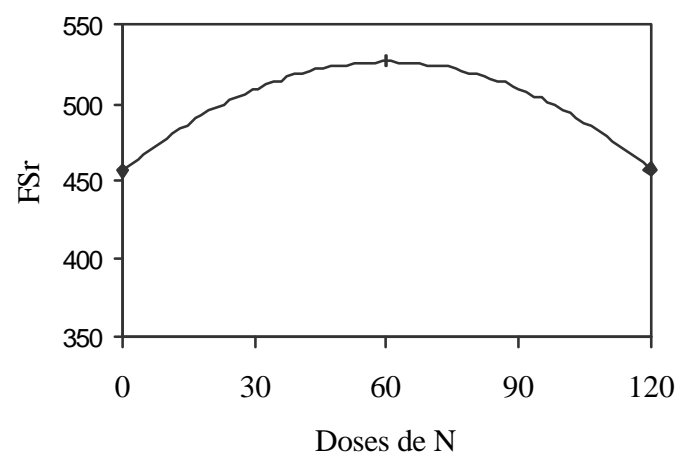

(A)

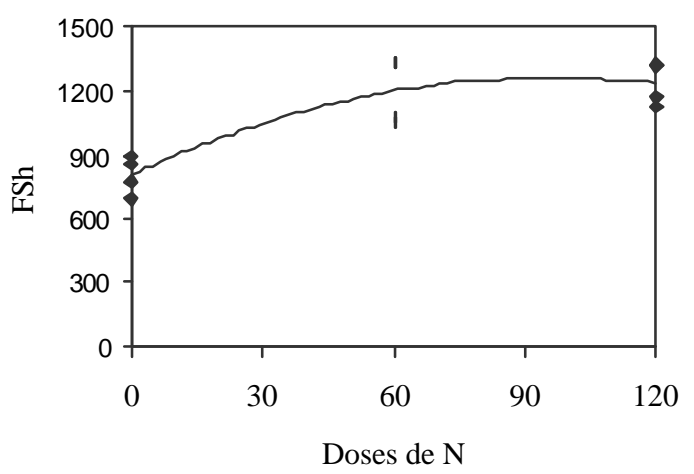

(B)

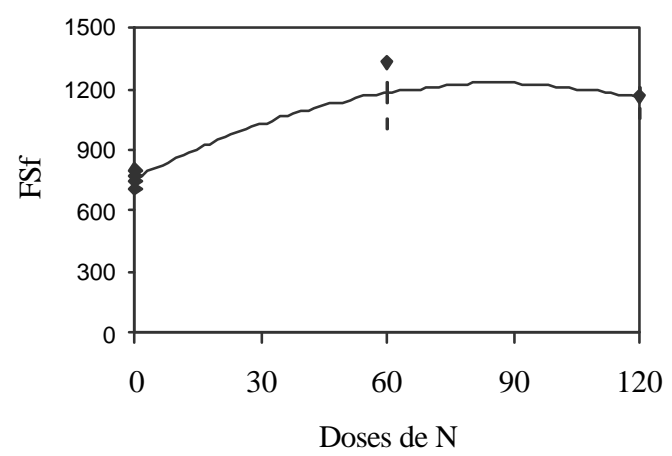

(C)

Figura 13 - Produção de fitomassa seca de raízes $\left(F S r, \mathrm{~kg} . h a^{-1}\right)(\mathrm{A})$, hastes $\left(F S h, \mathrm{~kg}^{-h^{-1}}\right)^{-1}$ (B) e folhas $\left(F S f, \mathrm{~kg} \mathrm{ha}^{-1}\right)(\mathrm{C})$ no florescimento em função de três doses de nitrogênio $\left(0,60\right.$ e $\left.120 \mathrm{~kg} \cdot \mathrm{ha}^{-1}\right)$. 


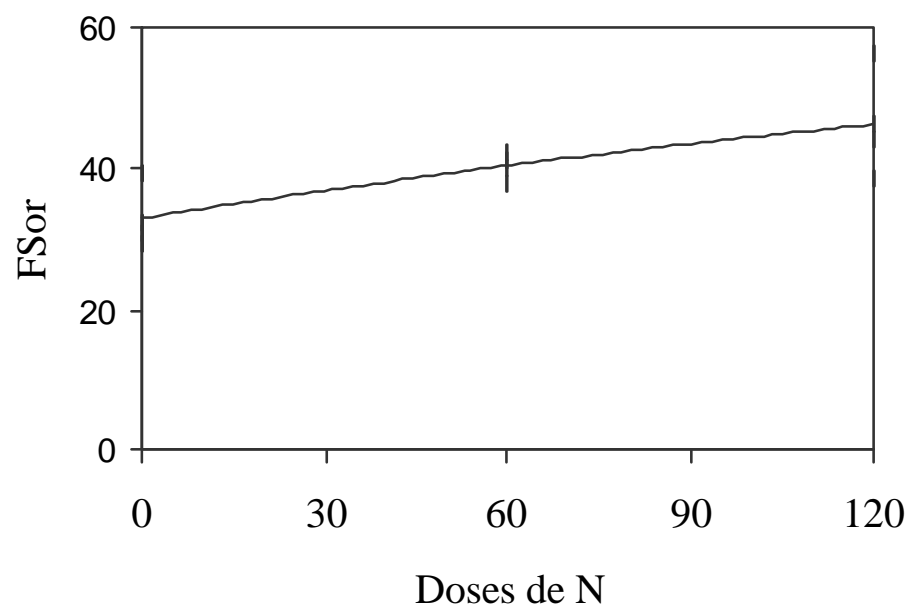

(A)

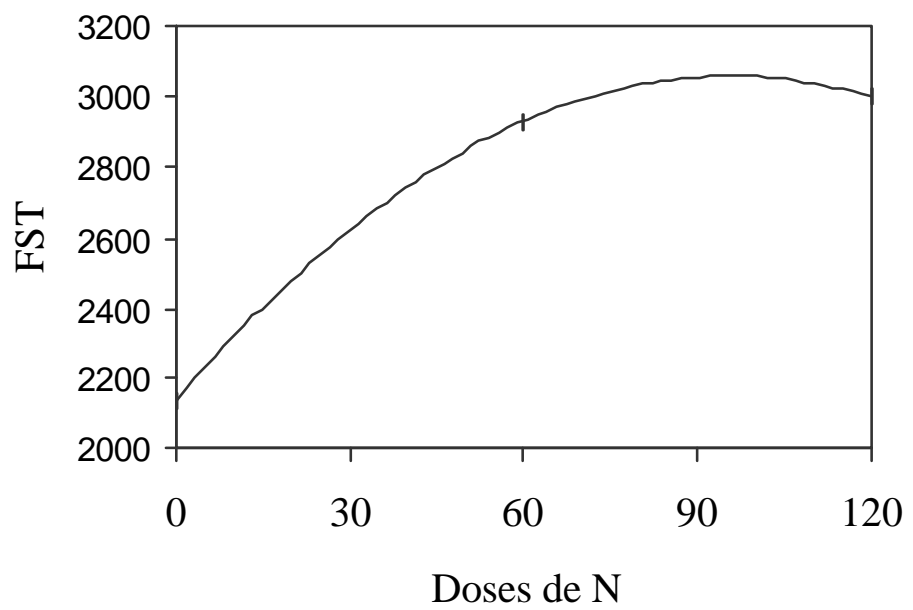

(B)

Figura 14 - Produção de fitomassa seca de órgãos reprodutivos (FSor, kg.ha $\left.{ }^{-1}\right)(\mathrm{A}) \mathrm{e}$ fitomassa seca total $\left(F S T, \mathrm{~kg} \cdot \mathrm{ha}^{-1}\right)(\mathrm{B})$ no florescimento em função de três doses de nitrogênio $\left(0,60\right.$ e $\left.120 \mathrm{~kg} \cdot \mathrm{ha}^{-1}\right)$. 
Tabela 19. Estimativas dos parâmetros referentes ao modelo quadrático que descreve o efeito da adubação nitrogenada na fitomassa seca de raízes $\left(F S r, \mathrm{~kg}_{\text {.ha }}{ }^{-1}\right)$, hastes $\left(F S h,{\mathrm{~kg} . h a^{-1}}^{-1}\right.$, folhas (FSf, kg.ha $\left.{ }^{-1}\right)$, órgãos reprodutivos $\left(F S o r, \mathrm{~kg}^{\circ} \mathrm{ha}^{-1}\right)$ e total $\left(F S T, \mathrm{~kg} \cdot \mathrm{ha}^{-1}\right)$ no florescimento.

\begin{tabular}{|c|c|c|c|c|}
\hline Variável & Parâmetro & Estimativa & Erro Padrão & Valor P \\
\hline \multirow{3}{*}{$\mathrm{FSr}$} & $\mu$ & 456,0000 & - & - \\
\hline & $\mathrm{L}$ & 2,3167 & - & - \\
\hline & $\mathrm{Q}$ & $-0,0192$ & - & - \\
\hline \multirow{3}{*}{ FSh } & $\mu$ & 807,1875 & 60,3885 & $<0,0001$ \\
\hline & $\mathrm{L}$ & 9,5177 & 2,5660 & 0,0024 \\
\hline & $\mathrm{Q}$ & $-0,0495$ & 0,0205 & 0,0197 \\
\hline \multirow{3}{*}{ FSf } & $\mu$ & 754,9375 & 40,4098 & $<0,0001$ \\
\hline & $\mathrm{L}$ & 10,8323 & 1,7171 & $<0,0001$ \\
\hline & Q & $-0,0629$ & 0,0137 & 0,015 \\
\hline \multirow{3}{*}{ FSor } & $\mu$ & 33,0625 & 2,5541 & $<0,0001$ \\
\hline & $\mathrm{L}$ & 0,1359 & 0,1085 & 0,1209 \\
\hline & $\mathrm{Q}$ & $-0,0002$ & 0,0009 & $0,4042 *$ \\
\hline \multirow{3}{*}{ FST } & $\mu$ & 1595,1875 & 71,4370 & $<0,0001$ \\
\hline & $\mathrm{L}$ & 20,4859 & 3,0355 & $<0,0001$ \\
\hline & $Q$ & $-0,1126$ & 0,0243 & 0,0006 \\
\hline
\end{tabular}

* Efeito quadrático não significativo.

4.4 Análise do efeito da adubação nitrogenada no rendimento de grãos e seus componentes

O efeito da adubação nitrogenada sobre o rendimento de grãos e seus componentes (Figura 15) também apresentou padrão quadrático. Na Tabela 20 são 
apresentadas as estimativas dos parâmetos dos modelos ajustados e os resultados dos testes de significância.

Tabela 20. Estimativas dos parâmetros referentes ao modelo quadrático que descreve o efeito da adubação nitrogenada na fitomassa seca de grãos $\left(F S g, \mathrm{~kg} \mathrm{ha}^{-1}\right)$, número de vagens por planta $\left(N V p l\right.$, vagens.planta $\left.{ }^{-1}\right)$ e número de grãos por vagem (grãos.vagem ${ }^{-1}$ ).

\begin{tabular}{ccccc}
\hline Variável & Parâmetro & Estimativa & Erro Padrão & Valor P \\
\hline \multirow{2}{*}{ FSg } & $\mu$ & 2140,6875 & 293,2428 & $<0,0001$ \\
& $\mathrm{~L}$ & 21,7161 & 12,4604 & 0,0765 \\
& $\mathrm{Q}$ & $-0,1357$ & 0,0998 & 0,1034 \\
& $\mu$ & & 0,4876 & $<0,0001$ \\
$\mathrm{NVpl}$ & $\mathrm{L}$ & 9,0000 & 0,0207 & 0,0079 \\
& $\mathrm{Q}$ & 0,0614 & 0,0002 & 0,0255 \\
& $-0,0004$ & & $<0,0001$ \\
& $\mu$ & & 0,3620 & 0,0305 \\
& $\mathrm{~L}$ & 5,7500 & 0,0154 & 0,0437 \\
\hline
\end{tabular}

Em função da variabilidade espacial existente nos campos experimentais, optout se por utilizar nível de significância em torno de $10 \%$ para verificar o efeito linear e quadrático da adubação nitrogenada. 


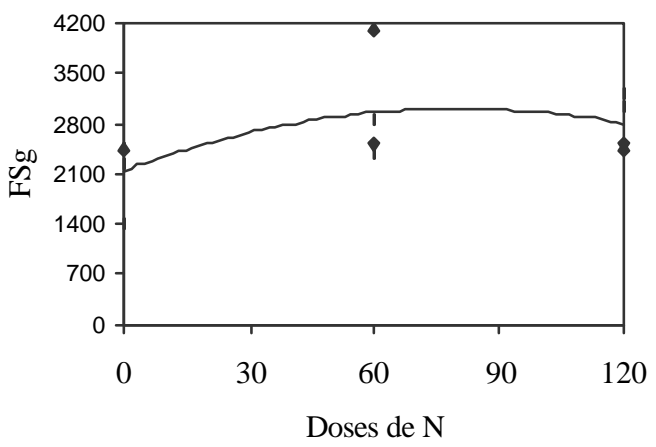

(A)

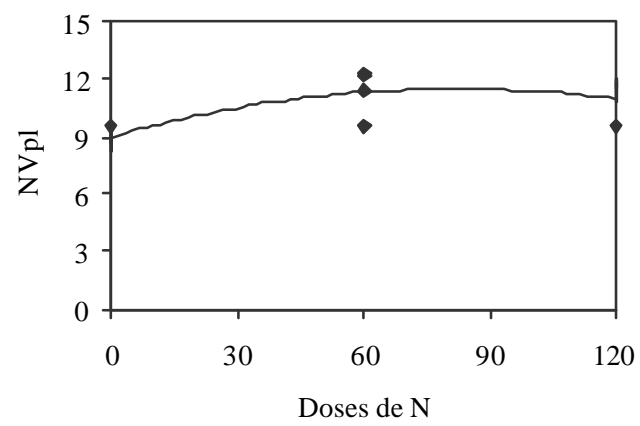

(B)

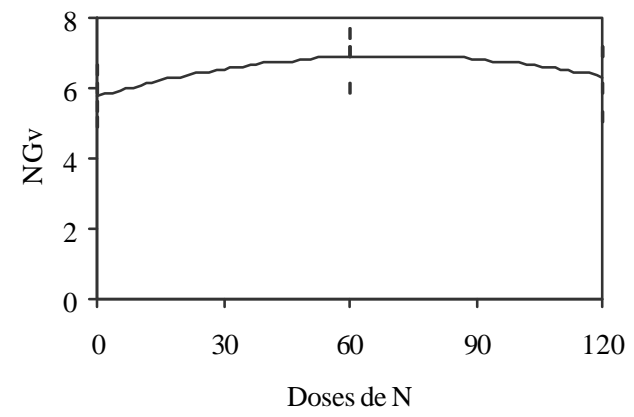

(C)

Figura 15 - Produção de fitomassa seca de grão $\left(F S g, \mathrm{~kg}_{\text {.ha }}{ }^{-1}\right)(\mathrm{A})$, número de vagens por planta $\left(N V p l\right.$, vagens.planta $\left.{ }^{-1}\right)(\mathrm{B})$ e número de grãos por vagem $(N G v$, grãos.vagem ${ }^{-1}$ ) (C) em função de três doses de nitrogênio $(0,60$ e 120 kg.ha-1). 


\section{CONCLUSÕES}

De acordo com os resultados obtidos, e com o que foi discutido, pode-se concluir que: (i) os modelos propostos são adequados para caracterizar a variação de fitomassa seca de raízes, hastes, folhas, órgãos reprodutivos e total durante o ciclo da cultura de feijão (Phaseolus vulgaris L.), (ii) de maneira geral, no florescimento e na colheita, a fitomassa seca dos diferentes órgãos da cultura de feijão e o rendimento de grãos, respectivamente, variam com a adubação nitrogenada segundo uma função quadrática, (iii) o máximo rendimento de grãos é obtido com a dose em torno de $60 \mathrm{~kg} \mathrm{ha}^{-1}$ de nitrogênio, e (iv) a variação da fitomassa seca relativa em função do desenvolvimento relativo da cultura de feijão apresenta o mesmo padrão de desempenho independentemente da dose de nitrogênio, o que permite extrapolar e comparar resultados de experimentos conduzidos em diferentes locais e épocas. 


\section{REFERÊNCIAS BIBLIOGRÁFICAS}

ALMEIDA, L. D.; BULISANI, E. A. Técnicas para aumentar a rentabilidade do feijoeiro. Correio Agrícola, v.1. p.236-243, 1980.

ARNOLD, C. Y. The determination and significance of the base temperature in a linear heat unit system. Proceedings of the American Society for Horticultural Science, v.74, p.430-445, 1959.

BLEIHOLDER, H.; HANSKARL, K.; LANGELÜDDEKE, P.; STAUSS, R. Codificação unificada dos estádios fenológicos de culturas e ervas daninhas. Pesquisa Agropecuária Brasileira, v.26, n.9, p.1423-1429, 1991.

BRANDES, D.; VIEIRA, C.; MAESTRI, M.; GOMES, F. R. Efeitos da população de plantas e da época de semeadura no crescimento do feijoeiro (Phaseolus vulgaris L.). II. Análise de crescimento. Experientiae, v.15, p.3-21, 1971.

BRANDES, D.; VIEIRA, C.; MAESTRI, M.; GOMES, F. R. Efeitos da população de plantas e da época de semeadura no crescimento do feijoeiro (Phaseolus vulgaris L.). III. Interceptação de luz e eficiência de conversão da energia solar. Experientiae, v.15, n.1, p.23-30, 1973.

CABALLERO, S. V.; LIBARDI, P. L.; REICHARDT, K.; MATSUI, E.; VICTORIA, R. L. Utilização do fertilizante nitrogenado aplicado a uma cultura de feijão. Pesquisa Agropecuária Brasileira, v.20, n.9, p.1031-1040, 1985. 
CALVACHE, M.; REICHARDT, K.; SILVA, J. C. A.; PORTEZAN FILHO, O. Adubação nitrogenada no feijão sob estresse de água. In: CONGRESSO BRASILEIRO DE CIÊNCIA DO SOLO, 25., Viçosa, 1995. Resumos expandidos. Viçosa: Sociedade Brasileira de Ciência do Solo, 1995. v.2, p.649-651.

\section{CENTRO INTEGRADO DE INFORMAÇÕES AGROMETEOROLÓGICAS -} CIIAGRO. Temperatura das culturas. http://www.iac.br/ciiagro/temperaturasculturas.htm (15 Out. 2002)

COBRA NETTO, A. Absorção e deficiências dos macronutrientes pelo feijoeiro (Phaseolus vulgaris L. var. Roxinho). Piracicaba, 1967. 69p. Tese (Doutorado) Escola Superior de Agricultura "Luiz de Queiroz”, Universidade de São Paulo.

CROOKSTON, R. K.; TREHARNE, K. J.; LUDFOR, P.; OZBUN, J. L. Response of beans of shading. Crop Science, v.15, p.412-416, 1975.

DAVIS, J. F. The effects of some environmental factors on the set of pods and yield of white cowpea beans. Journal of Ag ricultural Research, v.70, n.7, p.237-249, 1945.

De WIT, C. T. Simulation for assimilation, respiration, and transpiration of crops . Wageningen: A Halsted Press Book; John Wiley, 1978. 140p.

DINIZ, A. R.; ANDRADE, M. J. B.; BUENO, L. C. S.; CARVALHO, J. G. Resposta da cultura do feijão à aplicação de nitrogênio (semeadura e cobertura) e de molibdênio foliar. In: CONGRESSO BRASILEIRO DE CIÊNCIA DO SOLO, 25., Viçosa, 1995. Resumos expandidos. Viçosa: Sociedade Brasileira de Ciência do Solo, 1995. v.3, p.1225-1227.

DOURADO NETO, D.; FANCELli, A. L. Produção de feijão. Guaíba: Agropecuária, 2000a. cap.1, p.23-48: Ecofisiologia e fenologia.

DOURADO NETO, D.; FANCELLI, A. L. Produção de feijão. Guaíba: Agropecuária, 2000b. cap.2, p.49-85: Nutrição, adubação e cala gem. 
DOURADO NETO, D.; TERUEL, D. A.; REICHARDT, K.; NIELSEN, D. R.; FRIZZONE, J. A.; BACCHI, O. O. Principles of crop modeling and simulation. I. Uses of mathematical models in agricultural science. Scientia Agricola, v.55, n. esp., p.46-50, 1998.

DUBETZ, S.; MAHALE, R. S. Effect of soil water stress on busch beans (Phaseolus vulgaris L.) at three stages of growth. Journal of the American Society for Horticultural Science, v.94, p.479-481, 1969.

EMPRESA BRASILEIRA DE PESQUISA AGROPECUÁRIA. Recomendações técnicas para o cultivo do feijão: zonas $67,70,72,75,76,87,90$ e 92. Brasília, 1993. p.33-38: Adubação química.

ENGEL, A. B. Introdução à biomatemática determinista dos sistemas ecológicos . Campinas: Editora da UNICAMP, 1984. 173p. (CNMAC. Minicurso, 6).

FANCELli, A. L. Valor Nutritivo. In: FANCELLI, A. L. Cultura do feijão. Piracicaba: ESALQ, 1987a. cap.2, p.3-4.

FANCELli, A. L. Clima e solo. In: FANCELLI, A. L. Cultura do feijão. Piracicaba: ESALQ, 1987b. cap.6, p.18-43.

FANCELli, A. L. A cultura do feijão irrigado. Piracicaba: FEALQ; ESALQ, Departamento de Agricultura, 1990a. p.1-24: Aspectos básicos de fisiologia do feijoeiro.

FANCELLI, A. L. Feijão irrigado. Piracicaba: FEALQ; ESALQ, Departamento de Agricultura, 1990b. p.7-24: Fenologia e exigências climáticas do feijoeiro.

FANCELLI, A. L. Feijão irrigado. Piracicaba: FEALQ; ESALQ, Departamento de Agricultura, 1992. p.5-22: Fenologia e exigências climáticas do feijoeiro.

FANCELLI, A. L. Tecnologia para a produção do feijoeiro. Piracicaba: SEBRAE, 1994. 154p. 
FNP CONSULTORIA \& COMÉRCIO. AGRIANUAL 2002: anuário da agricultura brasileira. São Paulo, 2001. p. 348-352: Feijão.

FRANCE, J.; THORNLEY, J. H. M. Mathematical models in agriculture : a quantitative approach to problems in agriculture and related sciences. London: Butterworth, 1984. 335p.

FRANCO. A. A. Nutrição nitrogenada na cultura do feijoeiro. Informações Agronômicas, n.70, p.4-5, dez. 1995.

GEPTS, P.; FERNÁNDEZ, F. Etapas de desarrollo de la planta de frijol comum (Phaseolus vulgaris L.). Cali: CIAT, 1982. 10p. (Mimeografado)

HAAG, H. P.; MALAVOLTA, E.; GARGANTINI, H.; BLANCO, H. G. Absorção de nutrientes pela cultura do feijoeiro. Bragantia, v.26, n.30, p. 380-391, 1967.

HOSTALÁCIO, S.; VÁLIO, I. F. M. Desenvolvimento de plantas de feijão cv. Goiano Precoce, em diferentes regimes de irrigação. Pesquisa Agropecuária Brasileira, v.19, n.1, p.53-57, 1984.

HUNGRIA, M.; NEVES, M. C. P.; VICTORIA, R. L. Assimilação do nitrogênio pelo feijoeiro. II. Absorção e translocação do $\mathrm{N}$ mineral e do $\mathrm{N}_{2}$ fixado. Revista Brasileira de Ciência do Solo, v.9, n.3, p.201-209, 1985.

JONES, J. W.; MISHOE, J. W.; BOOTE, K. J. Introduction to simulation and modeling. Taiwan: Food and Fertilizer Technology Center, 1987. 18p. (Technical Bulletin, 100).

JONES, L. H. Adaptative responses to temperature in dwarf french beans, Phaseolus vulgaris L. Annals of Botany, v. 35, p.581-596, 1971.

LAING, D. R.; JONES, P. G.; DAVIS, H. G. Common Bean (Phaseolus vulgaris L.). In: GOLDSWORTH, P. R.; FISHER, N. M. The physiology of tropical feld crops. New York: John Willey, 1984. p.305-351. 
LAING, D. R.; KRETCHMER, P. J.; ZULUAGA, S.; JONES, P. G. Field bean. In: INTERNATIONAL RICE RESEARCH INSTITUTE. Potential productivity of field crops under different environments. Los Baños, 1983. p.227-248.

LANA, E. P.; HABER, E. S. Seasonal variability as indicated by cumulative degreehours with sweet corn. Proceedings of the American Society for Horticultural Science, v.59, p.389-392, 1952.

LINDSEY, A. A.; NEWMAN, J. E. Use of official weather data in spring timetemperature analysis of an Indiana phenological record. Ecology, v.37, p.812-823, 1956.

MAFRA, R. C.; VIEIRA, C.; BRAGA, J. M.; SIQUEIRA, C.; BRANDES, D. Efeitos da população de plantas e da época de semeadura na crescimento do feijoeiro (Phaseolus vulgaris L.). IV. Absorção de nutrientes. Experientiae, v.17, n.9, p.217-239, 1974.

MAGALHÃES, A. A.; CARELLI, M. L. Germinação de sementes de feijão (Phaseolus vulgaris L.) sob condições variadas de pressão osmótica. Bragantia, v.31, n.5, p.1926, 1972.

MAGAlHÃES, A. A.; MILlAR, A. A.; CHOUDHURY, E. N. Efeito do déficit fenológico de água sobre a produção de feijão. Turrialba, v.29, n.4, p.269-273, 1979.

MARSCHNER, H. Mineral nutrition of higher plants London: Academic Press, 1986. cap.1, p.3-5: Nutricional physiology.

MEIRELLES, N. M. F.; LIBARDI, P. L.; REICHARDT, K. Absorção e lixiviação de nitrogênio em cultura de feijão (Phaseolus vulgaris L.). Revista Brasileira de Ciência do Solo, v.4, n.2, p.83-88, 1980.

MENEZES, J. R. de. Manejo da cultura de feijão: enfoque sistêmico. In: SIMPÓSIO DA CUltura DE FEIJÃO IRRIGADO, 4., Piracicaba, 2001. Anais. Piracicaba: ESALQ, Departamento de Produção Vegetal, 2001.p.35-42. 
MIYASAKA, S.; FREIRE, E. S.; MASCARENHAS, H. A. A. Modo e época de aplicação de nitrogênio na cultura do feijoeiro. Bragantia, v.22, n.2, p.511-519, 1963.

MONTGOMERY, D.C. Design and analysis of experiments. 5. ed. New York: John Wiley, 2000. 696p.

MORAES, J. F. V. Calagem e adubação. In: ZIMMERMANN, M. J. O.; ROCHA, M.; YAMADA, T. Cultura do feijoeiro: fatores que afetam a produtividade. Piracicaba: POTAFOS, 1988. p.261-301.

MUZILli, O; GODOY, O. P. Acidez do solo e desenvolvimento do feijoeiro. II. Ação de diferentes níveis de acidez do solo na absorção de $\mathrm{N}, \mathrm{P}, \mathrm{K}, \mathrm{Ca}$ e $\mathrm{Mg}$ pelo feijoeiro (Phaseolus vulgaris L.), cultivar Goiano precoce em solo latosol roxo distrófico. Londrina: IAPAR, 1977. 36p. (IAPAR. Boletim, 8)

NAYLOR, T. H.; BALINTFY, J. L.; BURDICK, D. S.; KONG, C. Técnicas de simulação em computadores. São Paulo: Vozes, 1977. 402p.

OLIKER, M.; POLJAKOFF-MAYBER, A.; MAYER, A. M. Changes in weight nitrogen accumulation respiration and photosynthesis during growth and development of seed and pods of Phaseolus vulgaris. American Journal of Botany, v.65, n.3, p.366-371, 1978.

OLIVEIRA, I. P. de; THUNG, M. D. T. Nutrição mineral. In: ZIMMERMANN, M. J. O.; ROCHA, M.; YAMADA, T. Cultura do feijoeiro: fatores que afetam a produtividade. Piracicaba: POTAFOS, 1988. p.175-212.

PERES, J. R. R.; SUHET, A. R.; MENDES, I. C.; VARGAS, M. A. T. Efeito de inoculação com rizóbio e da adubação nitrogenada em sete cultivares de feijão em solo de Cerrado. Revista Brasileira de Ciência do Solo, v.18, n.3, p.415-520, 1994. 
PESSOA, M. C. P. Y. Simulação e inteligência artificial aplicadas ao estudo da dinâmica populacional do bicudo do algodoeiro na região de Campinas/SP. Campinas, 1994. 320p. Tese (Doutorado) - Faculdade de Engenharia Elétrica, Universidade Estadual de Campinas.

PESSOA, M. C. P. Y.; LUCHIARI, A. J.; FERNANDES, E. N.; LIMA, M. A. Principais modelos matemáticos e simuladores utilizados para análise de impactos ambientais das atividades agrícolas. Jaguariúna: Embrapa, CNPMA, 1997. 83p. (Embrapa. CNPMA. Documento, 8)

PORTES, T. A. Ecofisiologia. In: ARAUJO, R. S.; RAVA, C. A.; STONE, L. F.; ZIMMERMANN, M. J. O. (Coord.) Cultura do feijoeiro comum no Brasil. Piracicaba: POTAFOS, 1996. p.101-137.

PORTES, T. A.; CARVALHO, J. R. P. de. Área foliar, radiação solar, temperatura do ar e rendimentos em consorciação e em monocultivo de diferentes cultivares de milho e feijão. Pesquisa Agropecuária Brasileira, v.18, n.7, p.755-762, 1983.

PROSSER, J. I. Mathematical modelling of genetically engineered microorganisms in the environment. In: EDWARDS, C. (Ed.) Monitoring genetically manipulated microorganisms in the environment. Chichester: John Wiley, 1993. p.171-193.

ROSOLEM, C. A. Nutrição e adubação do feijoeiro. Piracicaba: POTAFOS, 1987. 93p.

ROSOLEM, C. A. Calagem e adubação mineral. In: ARAUJO, R. S.; RAVA, C. A.; STONE, L. F.; ZIMMERMANN, M. J. O. (Coord.) Cultura do feijoeiro comum no Brasil. Piracicaba: POTAFOS, 1996. p.353-390.

ROSOLEM, C. A; MARUBAYASHI, O. M. Seja o doutor do seu feijoeiro. Piracicaba: POTAFOS, 1994. 4p.(Informações Agronômicas, 68). 
SAAD, A. M.; LIBARDI, P. L. Feijão (Phaseolus vulgaris L.) irrigado por pivô central. In: SEMINÁRIO DE QUIMIGACÃO, Barreiras, 1997. Anais. São Paulo: DowElanco, 1997. p.25-34.

SAS INSTITUTE. User's guide : 7. Cary, 1998. 1028p.

TANAKA, A.; FUJITA, K. Growth, photosynthesis and yield components in relation to grain yield of the field bean. Journal of the Faculty of Agriculture of the Hokkaido University, v.59, n.2, p.145-238, 1979.

THOM, H. C. S.The rational relationship between heating degree days and temperature. Monthly Weather Review, v. 82, p.1-6, 1954.

THORNLEY, J. H. M. Mathematical models in plant physiology. New York: Academic Press, 1976. 318p.

VALE, L. S. R. Doses de calcário, desenvolvimento da planta, componentes de produção, produtividade de grãos e absorção de nutrientes de dois cultivares de feijão. Botucatu, 1994. 71p. Dissertação (Mestrado) - Faculdade de Ciências Agronômicas, Universidade Estadual Paulista “Júlio de Mesquita Filho”.

VIEIRA, C. Cultura do feijão. 2.ed. Viçosa: Imprensa Universitária da UFV, 1983. p.39-54: Adubação mineral.

WANG, J. Y. A critique of the heat unit approach to plant response studies. Ecology, v.41, p.785-790, 1960.

WU, H.; CHILDRESS, W. M.; LI, Y.; SPENCE, R. D.; REN, J. Na integrated simulation model for semi-arid agroecosystem in the Loess Planteau of Northwestern China. Agricultural Systems, v.52, p.83-111, 1996.

ZADOKS, J. C.; CHANG, T. T.; KONZAK, C. F. A decimal code for the growth stages of cereals. Weed Research, v.14, p.415-421, 1974. 